DANILO DE MOURA

CONDIÇÕES DO ESCOAMENTO E DE CONFORTO

TÉRMICO EM CABINE DE AERONAVE

São Paulo

2009 


\section{CONDIÇÕES DO ESCOAMENTO E DE CONFORTO TÉRMICO EM CABINE DE AERONAVE}

Dissertação apresentada à Escola

Politécnica da Universidade de São

Paulo para obtenção do título de

Mestre em Engenharia

Área de Concentração:

Engenharia Mecânica

Orientador:

Arlindo Tribess

São Paulo

2009 
Este exemplar foi revisado e alterado em relação à versão original, sob responsabilidade única do autor e com a anuência de seu orientador.

São Paulo, 20 de março de 2009

Assinatura do Autor

Assinatura do Orientador

\section{FICHA CATALOGRÁFICA}

Moura, Danilo de

Condições do escoamento e de conforto térmico em cabine de aeronave/ Danilo de Moura. - ed. rev.- São Paulo, 2009.

$74 \mathrm{p}$.

Dissertação (Mestrado) - Escola Politécnica da Universidade de São Paulo. Departamento de Engenharia Mecânica

1. Conforto térmico. 2. Escoamento. 3. Aeronave. 4. Cabine

I. Universidade de São Paulo. Escola Politécnica. Departamento de Engenharia Mecânica II. t 
Aos meus pais, João Batista de Moura e Rosimar Martins de Moura, por todos os esforços realizados ao longo de suas histórias diante das adversidades.

À minha amada esposa, Daiana Tino de Moura, que com toda sua ternura, alegria $e$ amor, completa minha vida. 


\section{AGRADECIMENTOS}

Ao meu orientador, Prof. Dr. Arlindo Tribess, por todo seu esforço e paciência, que ao longo desses anos muito me ensinou, contribuindo para meu crescimento intelectual, profissional e pessoal.

Aos Engenheiros Marcelo Luis Pereira e Victor Barbosa Felix pela ajuda prestada nos ensaios experimentais e no desenvolvimento da dissertação.

Aos Profs. Drs. Edson Luiz Zaparoli e Guenther Carlos Krieger Filho pela contribuição para o aprimoramento deste trabalho.

À Fundação de Amparo à Pesquisa do Estado de São Paulo pela bolsa concedida. 


\section{SUMÁRIO}

\section{LISTA DE TABELAS \\ LISTA DE FIGURAS \\ LISTA DE SÍMBOLOS \\ RESUMO}

1 INTRODUÇÃ

1.1 Estudos do escoamento e de conforto térmico em cabines de aeronave...................3

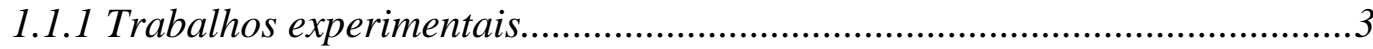

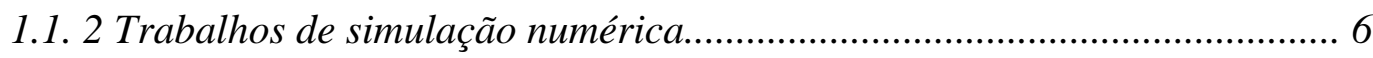

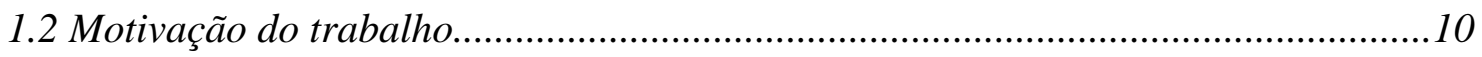

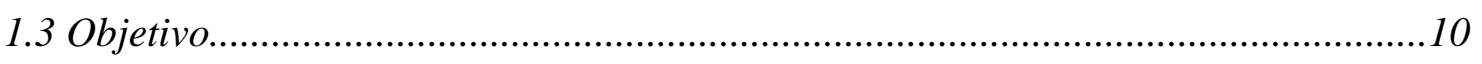

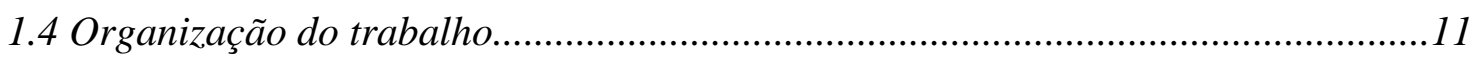

2 CONFORTO TÉRMICO....................................................................................12

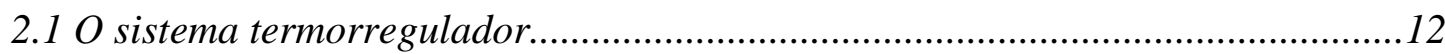

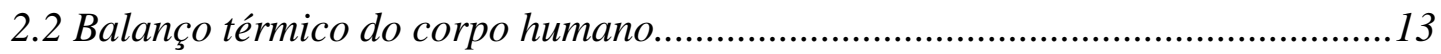

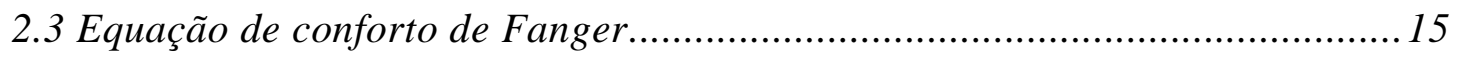

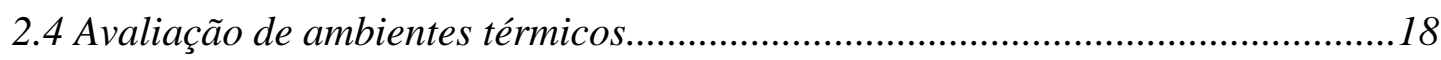

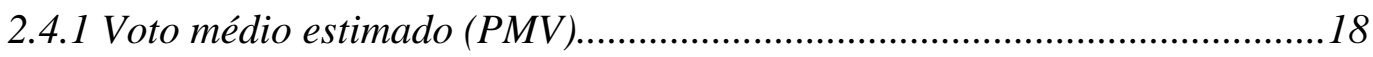

2.4.2 Percentagem de pessoas insatisfeitas (PPD).......................................... 21

2.4.3 Desconforto térmico local......................................................................22

3 AVALIAÇÃO DE CONFORTO TÉRMICO EM VEÍCULOS............................ 23 AUTOMOTIVOS

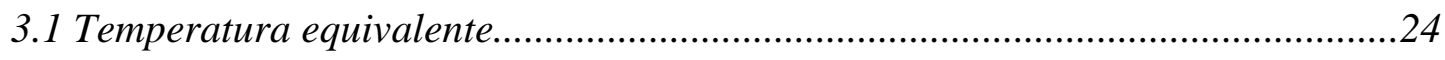

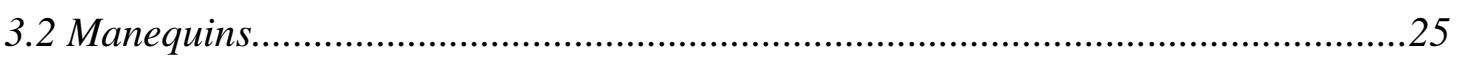

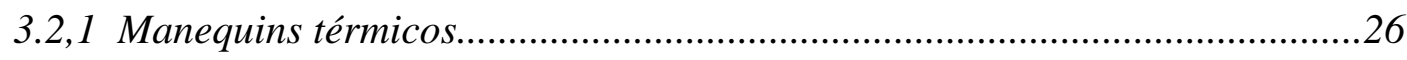

3.2,2 Manequins com sensores aquecidos.........................................................2.

3.3 Avaliação de conforto térmico utilizando temperaturas equivalentes.....................27

33.1 Equacionamento das trocas de calor...........................................................27

3.3.2 Procedimento de calibração do manequim.....................................................28

3.3.3 Diagramas de sensação térmica..........................................................22

4 O LABORATÓRIO E DETALHES DO MOCK-UP........................................32

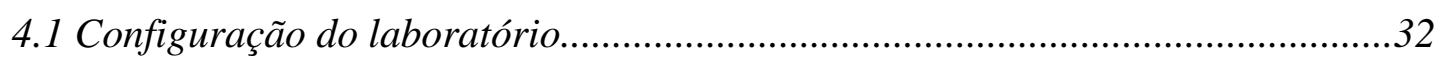


4.2 Ambiente de testes .33

4.3 Projeto e configuração do mock-up....... 35

5 AVALIAÇÃO EXPERIMENTAL DO ESCOAMENTO E DE CONFORTO 42 CONFORTO TÉRMICO EM CABINE DE AERONAVE

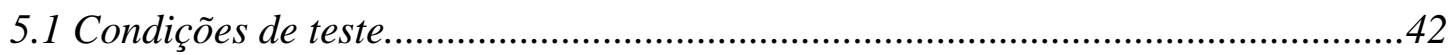

5.2 Levantamento de variáveis do escoamento............................................................42

5.2.1 Instrumentos de medição..............................................................................43

5.2.2 Especificações e características dos manequins aquecidos...........................44

5.3 Medições com manequim térmico instrumentado..................................................45

5.3.1 Especificações e características do manequim instrumentado.......................45

5.3.2 Calibração do manequim...........................................................................4

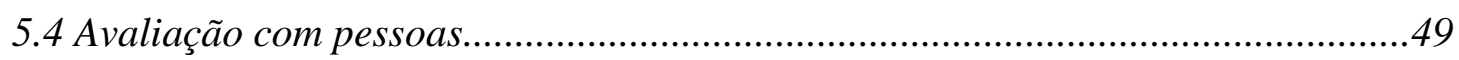

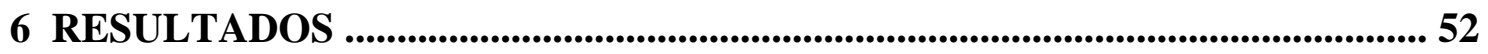

6.1 Medições de velocidades de ar e cálculo das vazões nos difusores ........................52

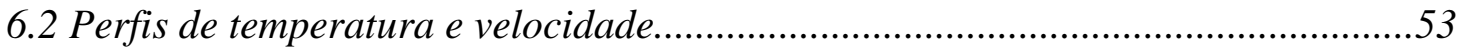

6.3 Temperaturas equivalentes obtidas com manequim térmico instrumentado...........59

6.4 Resultados da avaliação subjetiva......................................................................62

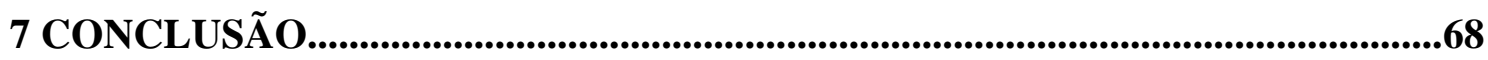

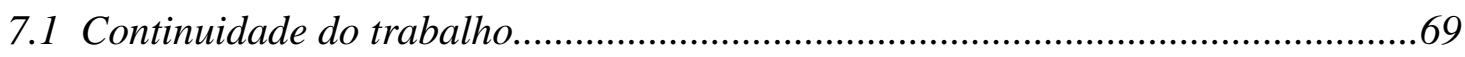

8 REFERÊNCIAS BIBLIOGRÁFICAS....................................................................71

APÊNDICE A 


\section{LISTA DE TABELAS}

$\begin{array}{lll}\text { Tabela 2.1 } & \text { Metabolismos para diferentes atividades } & 17\end{array}$

$\begin{array}{lll}\text { Tabela 2.2 Escala de sensação térmica da ASHRAE } & 18\end{array}$

Tabela 2.3 Determinação do voto médio estimado - PMV (ISO 7730:1994). 19 Atividade sedentária $($ met $=1.0)$ e umidade relativa do ar de $50 \%$

Tabela 5.1 Características dos instrumentos de medição 44

Tabela 5.2 Localização das regiões de análise (segmentos) 46

Tabela 5.3 Características dos equipamentos de medição do manequim 43

Tabela 5.5 Resultados da calibração do manequim 49

Tabela 5.6 Escala de sensação térmica da ISO 14505-3 (2006) 50

Tabela 5.7 Escala de desconforto local da ISO 14505-3 (2006) 50

Tabela 6.1 Valores de velocidade nos difusores 53

Tabela 6.2 Temperaturas equivalentes, temperaturas superficiais, coeficiente $\quad 62$ de troca e calor combinado e fluxo de calor do manequim para temperatura de cabine de $19^{\circ} \mathrm{C}$

Tabela 6.3 Temperaturas equivalentes, temperaturas superficiais, coeficiente de 62 troca e calor combinado e fluxo de calor do manequim para temperatura de cabine de $24^{\circ} \mathrm{C}$

Tabela 6.4 Votos dados pelas pessoas e VTM calculado para cada parte do corpo. 65 Temperatura de cabine de $24^{\circ} \mathrm{C}$

Tabela 6.5 Votos dados pelas pessoas e VTM calculado para cada parte do corpo. 65 Temperatura de cabine de $19^{\circ} \mathrm{C}$

Tabela 6.6 Votos dados pelas pessoas e VCM calculado para cada parte do corpo. 68 Temperatura de cabine de $24^{\circ} \mathrm{C}$

Tabela 6.7 Votos dados pelas pessoas e VCM calculado para cada parte do corpo. 68 Temperatura de cabine de $19^{\circ} \mathrm{C}$ 


\section{LISTA DE FIGURAS}

Figura 1.1 Sistema de distribuição com mistura de ar na cabine 2 (Zhang e Chen, 2007)

Figura 1.2 Detalhe do mock-up mostrando os manequins e cilindros aquecidos 4 (Strøm-Tejsen et al., 2007).

Figura 1.3 Detalhes da cabine do mock-up (Zhang et al., 2007) 5

Figura 1.4 Cabine de Airbus 380 e detalhe de região de análise 5 (Pennecot et al., 2004)

Figura $\quad 1.5$ Testes realizados em mock-up simples e em aparato experimental 6 em sala de laboratório (Jacobs e Gids, 2005).

Figura 1.6 Manequim com 18 segmentos, geometria do mock-up e malha 7 gerada (Stancato et al., 2006).

Figura 1.7 Temperaturas equivalentes e diagrama de sensação térmica 8 (Stancato et al., 2006).

Figura 1.8 Geometria utilizada para simulação e configuração dos manequins 8 (Gao e Niu, 2007).

Figura 1.9 Vetores velocidade no interior da cabine (Gao e Niu, 2007)

Figura 1.10 Linhas de corrente da simulação do sistema de insuflamento pelo 9 piso (Zhang e Chen, 2007)

Figura 1.11 Linhas de corrente da simulação do sistema com insuflamento convencional (lado esquerdo) e do sistema com insuflamento pelo piso e distribuição personalizada de ar (Zhang e Chen, 2007).

Figura 2.1 Modelo cilíndrico da interação térmica: corpo humano - meio envolvente (ASHRAE, 2001)

Figura 2.2 Zonas de conforto da ASHRAE para atividade sedentária

(ASHRAE 55, 2004)

Figura 2.3 Relação entre PMV e PPD

$\begin{array}{lll}\text { Figura 3.3 Manequim com } 16 \text { segmentos } & 30\end{array}$

Figura 3.4 Diagrama para avaliação de $\mathrm{T}_{\mathrm{eq}}$ em função da sensação térmica 30 condição de verão, resfriamento (ISO 14505-2,2004).

Figura 3.5 Diagrama para avaliação de $\mathrm{T}_{\text {eq }}$ em função da sensação térmica condição 31 de inverno, aquecimento (ISO 14505-2, 2004).

Figura 4.1 Tela do sistema de controle, mostrando o chiller, a sala do fan-coil e 33 o ambiente de testes (Leite, 2003). 
Figura 4.2. Ambiente de testes antes da instalação do mock-up 33 (Leite e Tribess, 2001)

$\begin{array}{lll}\text { Figura } 4.3 & \text { Fluxograma de ar da cabine } & 34\end{array}$

Figura 4.4 Planta baixa do laboratório após modificações 35

Figura 4.5 Configuração do mock-up 36

Figura 4.6 Vista esquemática exterior do mock-up mostrando a entrada 36

$\begin{array}{lll}\text { Figura } 4.7 & \text { Vista esquemática do interior do mock-up } & 37\end{array}$

Figura 4.8 Detalhe da estrutura metálica do mock-up 38

Figura 4.6 Detalhes do bin e de difusores de ar do mock-up 36

Figura 4.7 Detalhes do retorno de ar 36

Figura 4.8 Vistas internas do mock-up instalado, mostrando as poltronas, o bin 37 e um manequim instrumentado.

Figura 4.9 Detalhe da estrutura metálica do mock-up e do banco 38

Figura 4.10 Detalhe da estrutura metálica parcialmente chapeada 38

Figura 4.11 Detalhe da parte externa do mock-up e dutos de alimentação de ar 39

Figura 4.12 Detalhe da parte externa do o mock-up e dutos de alimentação de ar 39

Figura 4.13 Detalhes do bin e de difusores de ar do mock-up 40

Figura 4.14 Detalhes do retorno de ar 40

Figura 4.15 Vistas internas do mock-up instalado, mostrando as poltronas $\quad 41$ o bin e um manequim instrumentado

Figura 4.16 Vista do mock-up com manequins aquecidos 41

Figura 5.1 Posicionamento dos manequins aquecidos e de um dos pedestais no 43 mock-up.

Figura 5.2 Sensores de temperatura e de velocidade do ar 43

$\begin{array}{lll}\text { Figura 5.3 Vista esquematizada do manequim aquecidos } & 44\end{array}$

Figura 5.4 Detalhes do manequim instrumentado 46

$\begin{array}{lll}\text { Figura 5.5 Visualização dos valores medidos } & 47\end{array}$

Figura 5.6 Posicionamento do manequim na câmara de calibração 48

Figura 5.7 Voluntários posicionados na cabine para testes 51

Figura 6.1 Numeração dos difusores para medição de velocidade 52

Figura 6.2 Orientação de lados, direito esquerdo, na cabine 53

Figura 6.3 Perfis de temperatura: lado direito do mock-up com temperatura de 54 cabine de $24^{\circ} \mathrm{C}$ 
Figura 6.4 Perfis de temperatura: lado esquerdo do mock-up com temperatura de cabine de $24^{\circ} \mathrm{C}$

Figura 6.5 Perfis de temperatura: corredor do mock-up com temperatura de cabine de $24^{\circ} \mathrm{C}$

Figura 6.6 Perfis de temperatura: lado direito do mock-up com temperatura de cabine de $19^{\circ} \mathrm{C}$

Figura 6.7 Perfis de temperatura: lado esquerdo do mock-up com temperatura de cabine de $19^{\circ} \mathrm{C}$

Figura 6.8 Perfis de temperatura: corredor do mock-up com temperatura de cabine de $19^{\circ} \mathrm{C}$

Figura 6.9 Perfis de velocidade: lado direito do mock-up com temperatura de 58 cabine de $24^{\circ} \mathrm{C}$

Figura 6.10 Perfis de velocidade: lado esquerdo do mock-up com temperatura de cabine de $24^{\circ} \mathrm{C}$

Figura 6.11 Perfis de velocidade: corredor do mock-up com temperatura de cabine de $24^{\circ} \mathrm{C}$

Figura 6.12 Perfis de velocidade: lado direito do mock-up com temperatura de cabine de $19^{\circ} \mathrm{C}$

Figura 6.13 Perfis de velocidade: lado esquerdo do mock-up com temperatura de cabine de $19^{\circ} \mathrm{C}$

Figura 6.14 Perfis de velocidade: corredor do mock-up com temperatura de cabine de $19^{\circ} \mathrm{C}$

Figura 6.15 Posicionamento do manequim térmico instrumentado na cabine

Figura 6.16 Temperaturas equivalentes em diagrama de sensação térmica segundo norma 14505-2 (2004)

Figura 6.17 Escala utilizada na obtenção do voto térmico médio (VTM) 64

Figura 6.18 Voto térmico médio (VTM) 66

Figura 6.19 Escala utilizada na obtenção do voto de conforto médio (VTM) 67

Figura 6.20 Voto de conforto médio (VCM) 


\section{LISTA DE SÍMBOLOS}

C Calor perdido pela pele por convecção por unidade de tempo e área $\left(\mathrm{W} / \mathrm{m}^{2}\right)$

$\mathrm{C}_{\mathrm{R}} \quad$ Calor convectivo perdido pela respiração por unidade de tempo e área $\left(\mathrm{W} / \mathrm{m}^{2}\right)$

$\mathrm{E}_{\mathrm{dif}} \quad$ Calor perdido pela pele por difusão de vapor de vapor d'água por unidade de tempo e área $\left(\mathrm{W} / \mathrm{m}^{2}\right)$

$\mathrm{E}_{\mathrm{es}} \quad$ Calor perdido pela pele por evaporação de suor por unidade de tempo e área $\left(\mathrm{W} / \mathrm{m}^{2}\right)$

$E_{R} \quad$ Calor evaporativo perdido pela respiração por unidade de tempo e área $\left(\mathrm{W} / \mathrm{m}^{2}\right)$

$\mathrm{I}_{\mathrm{R}} \quad$ Índice de isolamento da roupa $\left({ }^{\circ} \mathrm{C} \mathrm{m} / \mathrm{W}\right)$

M Metabolismo $\left(\mathrm{W} / \mathrm{m}^{2}\right)$

$\mathrm{p}_{\mathrm{var}} \quad$ Pressão parcial do vapor d'água no ambiente $(\mathrm{Pa})$

$\mathrm{Q}_{\text {pele }} \quad$ Calor total perdido pela pele por unidade de tempo e área $\left(\mathrm{W} / \mathrm{m}^{2}\right)$

Q $\quad$ respiração $\quad$ Calor total perdido pela respiração por unidade de tempo e área $\left(\mathrm{W} / \mathrm{m}^{2}\right)$

$\mathrm{R}$

Calor perdido pela pele por radiação por unidade de tempo e área $\left(\mathrm{W} / \mathrm{m}^{2}\right)$

$\mathrm{T}_{\mathrm{ar}} \quad$ Temperatura do ar $\left({ }^{\circ} \mathrm{C}\right)$

$\mathrm{T}_{\mathrm{g}} \quad$ Temperatura de globo $\left({ }^{\circ} \mathrm{C}\right)$

$\begin{array}{ll}\mathrm{T}_{\mathrm{p}} & \text { Temperatura da pele }\left({ }^{\circ} \mathrm{C}\right)\end{array}$

$\bar{T}_{r} \quad$ Temperatura radiante média $\left({ }^{\circ} \mathrm{C}\right)$

$\mathrm{T}_{\mathrm{s}} \quad$ Temperatura superficial $\left({ }^{\circ} \mathrm{C}\right)$

$\mathrm{T}_{\mathrm{eq}} \quad$ Temperatura equivalente $\left({ }^{\circ} \mathrm{C}\right)$

$\dot{\mathrm{U}} \quad$ Taxa de variação de energia interna $\left(\mathrm{W} / \mathrm{m}^{2}\right)$

$\mathrm{V}_{\mathrm{ar}} \quad$ Velocidade média do ar $(\mathrm{m} / \mathrm{s})$

\section{LISTA DE SÍMBOLOS GREGOS}
$\phi$
Umidade relativa $(\%)$
$\rho$
Massa específica $\left(\mathrm{kg} / \mathrm{m}^{3}\right)$ 


\section{RESUMO}

A aviação comercial vem experimentando expressivo crescimento com elevado grau de competitividade. Produzir aeronaves com nível de conforto diferenciado transformou-se em importante ferramenta de marketing e de venda. Esta, porém, não é tarefa fácil.

Cabines de aeronave apresentam condições de escoamento e de trocas térmicas que tornam bastante difícil prover e avaliar condições de conforto térmico. Para tentar resolver o problema, estudos estão sendo realizados em centros de pesquisa, em colaboração com a indústria aeronáutica. $\mathrm{O}$ presente trabalho se insere neste contexto.

Neste trabalho foi realizado estudo do escoamento em cabine de aeronave, por meio de medição de variáveis ambientais de cabine, e de conforto térmico utilizando manequim térmico instrumentado e avaliação com pessoas. Para a realização dos ensaios foi projetado e construído mock-up de seção de cabine com 12 lugares. Foram analisadas condições do escoamento e de conforto térmico para duas condições de cabine, 19 e $24{ }^{\circ} \mathrm{C}$. Nos ensaios com pessoas participaram 11 voluntários.

Temperaturas equivalentes foram determinadas utilizando-se manequim térmico instrumentado e apresentadas em diagrama de sensação térmica previsto para este fim em norma técnica de veículos. Posteriormente, avaliações subjetivas, com resultados apresentados em diagramas de voto térmico médio (VTM) e de voto de conforto médio (VCM), foram realizadas.

Verificou-se que, apesar das condições complexas do escoamento, não ocorreram diferenças significativas de velocidade do ar na região de ocupação e nem de temperatura na direção vertical, que são fatores que poderiam ocasionar grande desconforto.

Verificou-se também a ocorrência de uma boa aproximação entre as avaliações de conforto térmico feitas por meio das temperaturas equivalentes e os resultados das análises subjetivas realizadas por meio de questionários. Nas avaliações subjetivas ocorreu um pequeno deslocamento dos resultados para o lado direito no diagrama de VTM. Finalmente, verificou-se que as pessoas preferiram as condições de cabine na temperatura de $19{ }^{\circ} \mathrm{C}$, com votos de conforto médio (VCM) de indiferentes a ligeiramente confortáveis, enquanto na temperatura de cabine de $24^{\circ} \mathrm{C}$ as condições foram consideradas ligeiramente desconfortáveis. 


\begin{abstract}
The commercial aviation has experienced an expressive growth with a high degree of competitiveness. The production of aircrafts with a higher comfort level has become an important tool for marketing and trading. However, this is not an easy task.

Aircraft cabins present airflow and thermal transfer conditions that make quite difficult to provide and to evaluate thermal comfort conditions. In order to try to solve this problem, studies are being performed in research centers, in collaboration with the aeronautical industry. This project is inserted in this context.

In this project a study of aircraft cabin airflow, through the measurement of the cabin environmental variables, and the thermal comfort using thermal mannequin and evaluation with people, was accomplished. For the accomplishment of the tests a mock-up of a cabin section with 12 places was projected and built. Conditions of airflow and thermal comfort within two cabin conditions, 19 and $24{ }^{\circ} \mathrm{C}$, were analyzed. The tests with people were performed by 11 volunteers.

Equivalent temperatures were obtained by using a thermal mannequin and were presented in a thermal sensation diagram, which had been seen to this purpose in vehicles technical norm. Later on, subjective evaluations, whose results were presented by an mean thermal vote (MTV) diagram and by an mean comfort vote (MCV) diagram, were accomplished.

It was verified that, in spite of the complex airflow conditions, significant differences neither of the air velocity in the occupation area nor of the temperature in the vertical direction happened, which are factors that could cause a great discomfort.

It was also verified a strong relation between thermal comfort evaluations accomplished through the equivalent temperatures and the results of the subjective analyses accomplished through questionnaires. In the subjective evaluations, a small displacement of the results to the right side in the MTV diagram occurred. Finally, it was verified that the volunteers preferred $19{ }^{\circ} \mathrm{C}$ temperature cabin condition, with mean comfort votes $(\mathrm{MCV})$ indicating from indifferent to lightly comfortable conditions, while in the $24^{\circ} \mathrm{C}$ cabin the conditions were considered lightly uncomfortable.
\end{abstract}




\section{Capítulo 1}

\section{INTRODUÇÃO}

A aviação comercial vem experimentando expressivo crescimento com elevado grau de competitividade. Produzir aeronaves com nível de conforto diferenciado transformou-se em importante ferramenta de marketing e de venda. Sabe-se que o conforto, e também a saúde de passageiros e tripulação de aeronaves, podem ser afetados por uma série de fatores ambientais, como qualidade do ar, pressão, temperatura, umidade relativa, ruído, vibração, iluminação, entre outros. Ao mesmo tempo, cabines de aeronaves podem representar um risco à transmissão de doenças, devido ao elevado número de pessoas em um habitáculo de volume reduzido, com menor espaço de circulação de ar comparado a ambientes de edificações, e prolongado tempo de exposição (Gao e Niu, 2007).

Esses fatores tornam o ambiente de cabine extremamente complexo e dificultam a obtenção e avaliação de condições de conforto. Função disso, estudos estão sendo realizados em centros de pesquisa, em colaboração com a indústria aeronáutica, para melhorar as condições de conforto térmico e de qualidade do ar de cabine. Novas tecnologias de distribuição de ar e de dispositivos de ventilação personalizada estão sendo testadas. Ambientes que reproduzem cabines de aeronaves, os mock-ups, estão sendo construídos e condições de conforto e de qualidade do ar de cabine avaliadas (Irgens e Melikov, 2004; Jacobs e Gids, 2005, Strøm-Tejsen et al., 2005; Strøm-Tejsen et al., 2007; Zhang e Chen, 2007; Zhang et al., 2007; Gao e Niu, 2007).

Neste contexto, o sistema de distribuição de ar é um dos mais importantes componentes do sistema de controle ambiental na correta distribuição do ar tratado para prover condições de saúde e conforto em cabines. Atualmente, o sistema de distribuição de ar comumente utilizado em cabines de aeronaves consiste no insuflamento de ar na parte superior e retorno na parte inferior com mistura do ar na cabine (Fig. 1.1). Este sistema, contudo, tem apresentado problemas de conforto térmico e pode, devido à sua característica de mistura, espalhar rapidamente doenças infecciosas pelo ar na cabine (Zhang et al., 2007). 


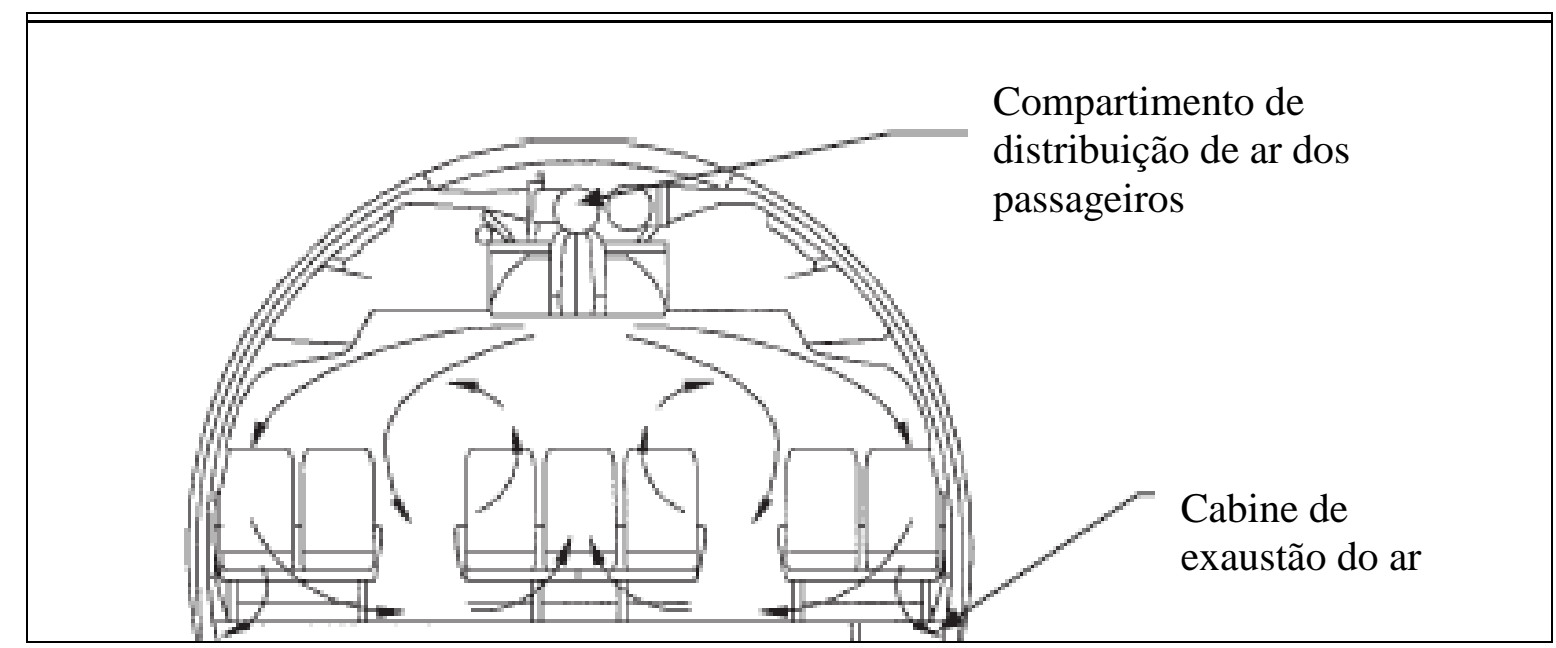

Figura 1.1. Sistema de distribuição com mistura de ar na cabine (Zhang e Chen, 2007)

O conforto térmico percebido por passageiros em cabine de aeronaves está diretamente relacionado com as variáveis ambientais, como temperatura, velocidade e umidade do ar. Parâmetros do ambiente de cabine, como temperatura radiante média, assimetria de radiação, layout e densidade de ocupação, também são fatores que influenciam diretamente no conforto térmico dos passageiros.

O escoamento do ar na cabine é bastante complexo e é dificultado pela alta densidade de ocupação, com pequeno espaço de circulação de ar, e layout, que muitas vezes proporcionam regiões de estagnação, ocasionando desconforto. Por outro lado, podem ocorrer regiões com gradientes de velocidade elevados, o que também pode ocasionar desconforto aos passageiros e tripulação.

Do acima apresentado, verifica-se que o estudo do escoamento e da distribuição de ar na cabine é de fundamental importância na obtenção de conforto térmico em cabines de aeronaves. Para o estudo do escoamento de ar em cabine de aeronave, além de avaliação experimental, diversos autores vêm utilizando técnicas de mecânica dos fluidos computacional - CFD (Aboosaidi et al., 1991 apud Zhang e Chen, 2007; Mizuno e Warfield, 1992; Pennecot et al. 2004; Stancato et al., 2006; Gao e Niu , 2007)

Quanto à avaliação de conforto térmico, um modelo de conforto térmico completo deve incluir (Guan et al., 2003b):

a) Um modelo físico de troca de calor e um modelo de vestimenta

b) Um modelo de termorregulação fisiológica do corpo humano.

c) Um modelo de sensação térmica psicológica para prever a resposta do ser humano ao ambiente baseado nas informações dos modelos anteriores. 
No desenvolvimento de todos esses modelos há a necessidade do levantamento de valores experimentais de variáveis ambientais e de sensação de conforto térmico. E a melhor forma de se fazer isso em aeronaves é por meio do levantamento de variáveis em condições controladas em mock-ups instrumentados (Zhang et al., 2007).

Em veículos automotivos e em aeronaves, em particular, onde diferentes partes do corpo experimentam diferentes condições térmicas, a forma mais indicada para avaliação do conforto térmico é o da determinação de temperaturas equivalentes $\left(\mathrm{T}_{\mathrm{eq}}\right)^{1}$ em diferentes partes (segmentos) de um manequim térmico (Madsen et al., 1986; Gameiro da Silva, 2002; Nilsson, 2004, Strøm-Tejsen et al., 2007). Segundo StrømTejsen et al. (2007) a correlação entre medições em manequins e avaliações subjetivas indica que a sensação local de conforto térmico pode ser estimada de forma segura a partir de medições em manequins.

$\mathrm{Na}$ avaliação de conforto térmico atenção especial deve ser dada à avaliação com pessoas. Por ser subjetivo, o conforto experimentado por passageiros em cabines de veículos pode variar de pessoa a pessoa. As respostas desses indivíduos, porém, são baseadas em variáveis percebidas, que caracterizam o ambiente a sua volta, e que interagem com condições psicológicas e fisiológicas individuais, como nível de stress, idade e condições de saúde dos passageiros (Gameiro da Silva, 2002; Hinninghofen e Enck, 2006).

\subsection{Estudos do escoamento e de conforto térmico em cabines de aeronave}

Neste item são apresentados trabalhos realizados, experimentalmente e por meio de simulação numérica (CFD), sobre a avaliação de conforto térmico e qualidade do ar em cabines de aeronaves.

\subsubsection{Trabalhos experimentais}

Estudos experimentais em cabines de aeronaves, na obtenção do campo de velocidades e verificação de condições de conforto térmico, são em número reduzido e a maior parte está sendo realizada em mock-ups construídos ou adaptados para esse fim. Isso se dá devido ao alto custo de se realizar experimentos em vôo (Zhang e Chen, 2007).

\footnotetext{
1 Temperatura equivalente $\left(\mathrm{T}_{\mathrm{eq}}\right)$ : temperatura de um invólucro imaginário com a temperatura radiante média igual à temperatura do ar e ar parado, no qual a pessoa troca a mesma quantidade de calor por radiação e convecção que nas condições reais (ASHRAE 62, 1989).
} 
No International Centre for Indoor Environment and Energy, da Dinamarca, pesquisadores têm realizado estudos em um mock-up com 21 assentos (três fileiras de sete assentos), instalado em uma câmara climática com temperatura controlada de forma a obter superfícies das paredes internas com temperaturas "realisticamente" baixas. Nos ensaios estão sendo utilizados 14 cilindros aquecidos e dois manequins térmicos (Fig. 1.2) para simular a carga térmica, os efeitos de convecção natural e de obstrução do fluxo de ar (Irgens e Melikov, 2004; Strøm-Tejsen et al., 2005; Strøm-Tejsen et al., 2007).

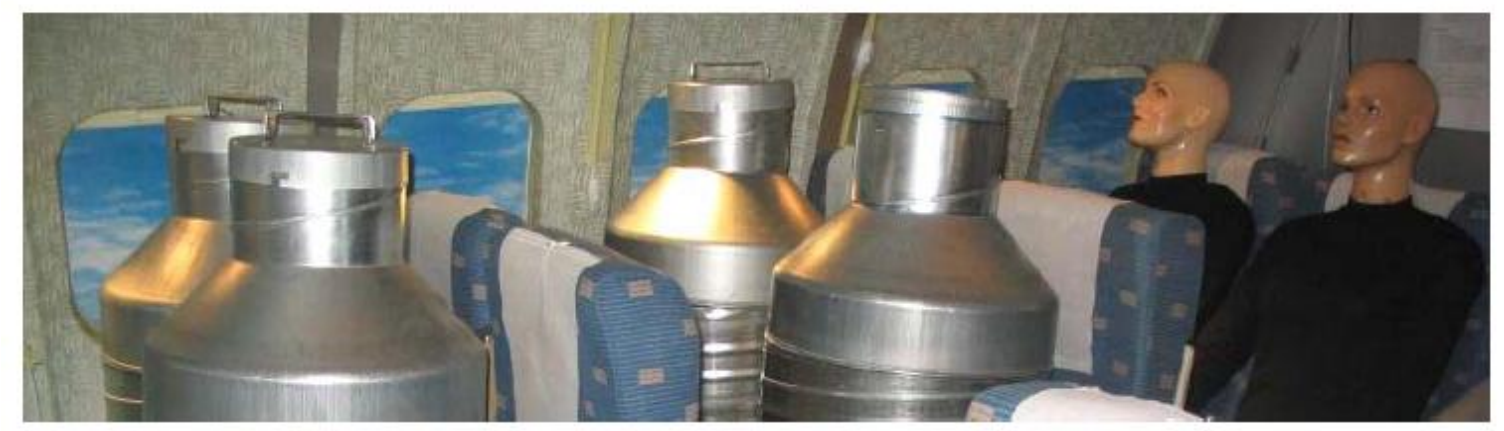

Figura 1.2 - Detalhe do mock-up mostrando os manequins e cilindros aquecidos (Strøm-Tejsen et al., 2007).

Irgens e Melikov (2004) apresentaram resultados de distribuição de temperatura e intensidade turbulenta na cabine. Strøm-Tejsen et al. (2005) apresentaram resultados de avaliação subjetiva de sensação térmica considerando diferentes temperaturas de parede e temperaturas médias do ar na cabine. Os ensaios foram realizados com quatro grupos de 17 pessoas, que participaram de vôo transatlântico simulado de 7 horas, com cada grupo submetido às mesmas condições térmicas. Recentemente, Strøm-Tejsen et al. (2007) correlacionaram resultados de medições em manequins com os resultados anteriores de avaliação subjetiva de sensação térmica em diferentes partes do corpo.

No Air Transportation Center of Excellence for Airliner Cabin Environmental Research, dos Estados Unidos, estão sendo desenvolvidos estudos experimentais e de simulação (CFD) em mock-up com quatro assentos por fileira (Fig. 1.3), para avaliar e validar simulações numéricas e avaliar a influência da distribuição de ar e do escoamento no transporte de contaminantes (Zhang e Chen, 2007; Zhang et al., 2007). 


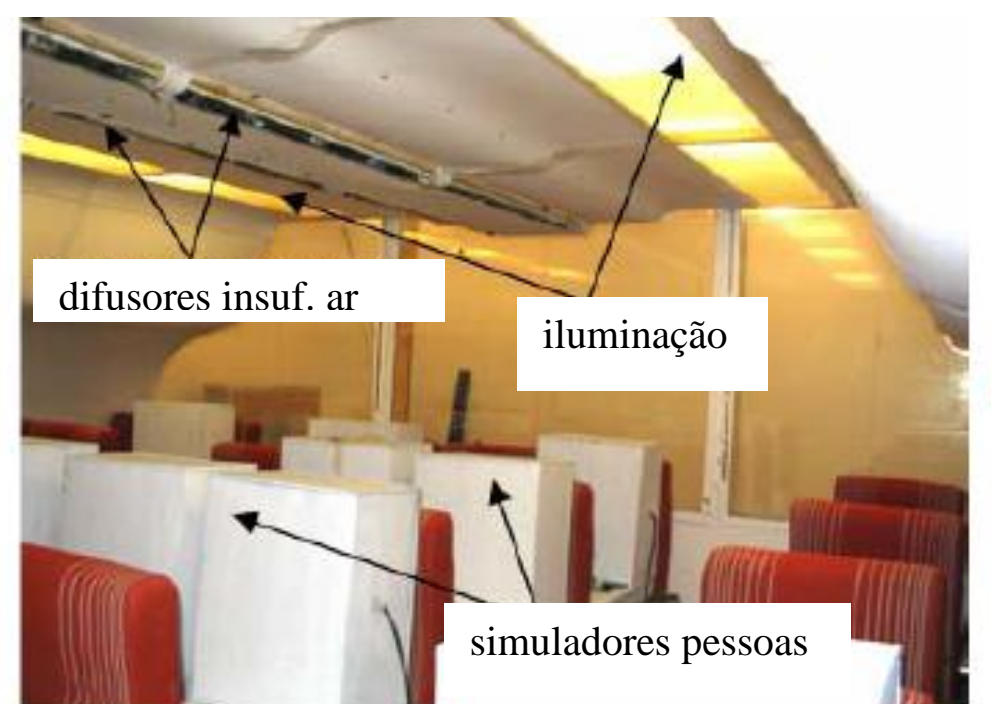

Figura 1.3 - Detalhes da cabine do mock-up (Zhang et al., 2007).

No German Aerospace Center, da Alemanha, estão sendo realizados estudos em Airbus 380. Resultados de estudo comparativo do escoamento em uma parte da fuselagem de um Airbus 380 (Fig. 1.4), utilizando simulação numérica (CFD) e medidas de velocidade com técnica PIV (particle image velocimetry), foram apresentados por Pennecot et al. (2004).

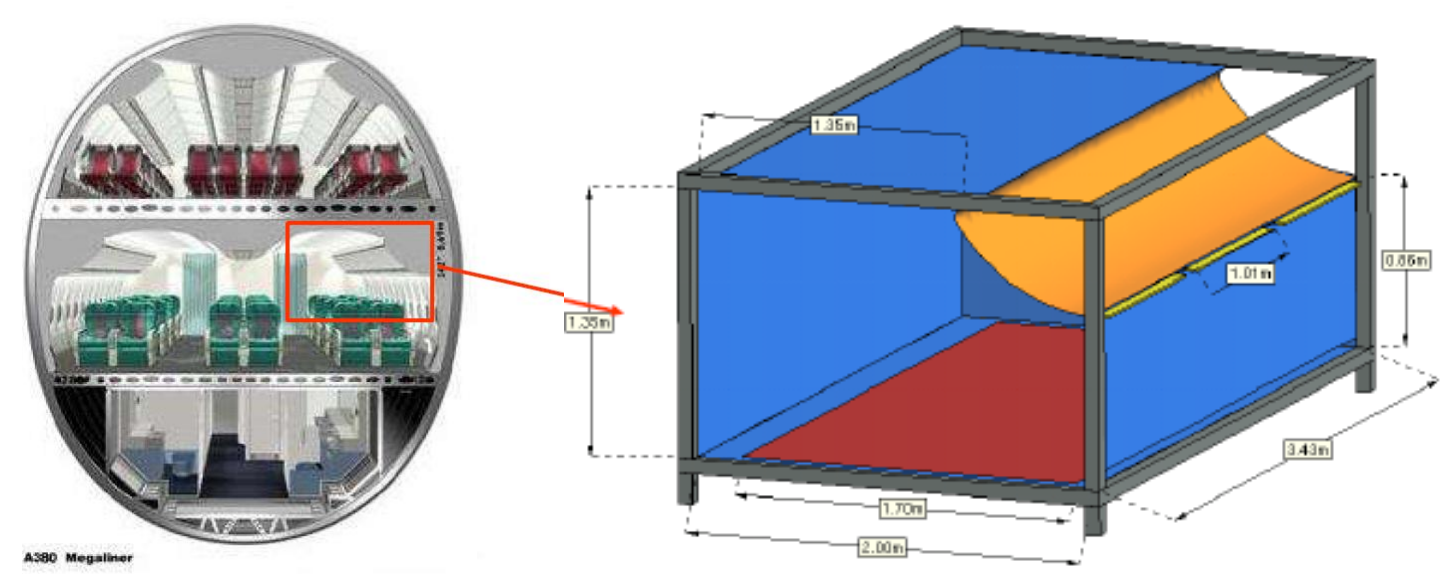

Figura 1.4 - Cabine de Airbus 380 e detalhe de região de análise (Pennecot et al., 2004)

No TNO Building and Construction Research, da Holanda, também estão sendo realizados estudos em cabines de aeronaves no âmbito de projeto da comunidade européia. Loomans et al. (2004) apresentaram resultados de estudo comparativo entre medições realizadas em vôo cruzeiro e resultados de simulação (CFD), em aeronave com sete poltronas por fileira, sem passageiros a bordo. 
Recentemente, também começaram a ser desenvolvidos estudos utilizando dispositivos de ventilação personalizada, objetivando melhoria da qualidade do ar e do conforto térmico (Jacobs e Gids, 2005; Gao e Niu, 2007; Zhang e Chen, 2007)

Jacobs e Gids (2005) construíram um dispositivo de ventilação personalizada e basearam-se em estudos do escoamento ao redor dos passageiros sentados no interior de aeronaves para proporcionar melhores condições de qualidade do ar e de conforto térmico. Os autores verificaram que um dos maiores problemas relacionados com dispositivos de ventilação individualizada é o desconforto causado pelas correntes de ar, pois o ar é insuflado próximo da face do passageiro. Assim, os autores propuseram um dispositivo que visa eliminar este problema, além de proporcionar qualidade do ar (Fig. 1.5). O experimento foi realizado primeiro em uma sala de laboratório e repetido em um mock-up simples de 30 lugares. Foi utilizado gás traçador, liberado próximo da zona de respiração, para verificar a eficiência do dispositivo de ventilação. Foram utilizados manequins aquecidos. Segundo os autores, com o projeto e ajuste adequado do dispositivo de distribuição de ar foram removidos $96 \%$ dos poluentes próximo da zona de respiração e eliminado o desconforto por correntes de ar.
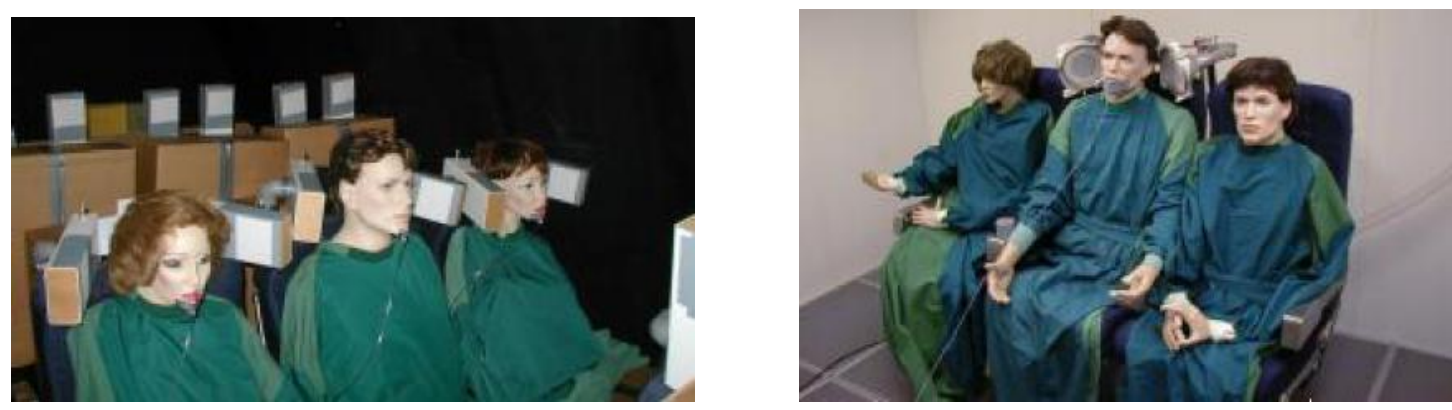

Figura 1.5 - Testes realizados em mock-up simples e em aparato experimental em sala de laboratório (Jacobs e Gids, 2005).

\subsection{Trabalhos de simulação numérica}

Com relação às simulações computacionais, na maioria das vezes os estudos são realizados com a utilização da dinâmica dos fluidos computacional (CFD). Inicialmente os estudos de distribuição de ar em cabines de aeronaves eram realizados sem considerar o mobiliário, os passageiros e nem as fontes de calor (Aboosaidi et al., 1991 apud Zhang e Chen, 2007; Mizuno e Warfield, 1992). 
Singh et al. (2002), foram uns dos primeiros a considerar passageiros simulados por cilindros aquecidos no processo de simulação. Pennecot et al. (2004), no German Aerospace Center da Alemanha, utilizaram simulação numérica (CFD) em estudos realizados em um Airbus 380. Lin et al. (2005) apresentaram resultados de distribuição de ar na simulação da cabine de um Boeing 766-300, considerando geometria e mobiliário mais realísticos. O objetivo do estudo foi a análise do transporte de contaminantes patogênicos.

Pesquisadores do Laboratório de Conforto Térmico da Escola Politécnica da USP (EPUSP) e da Empresa Brasileira de Aeronáutica (EMBRAER) realizaram trabalho conjunto no desenvolvimento de método numérico para avaliação de condições de conforto térmico em aeronaves (Stancato et al., 2006). No trabalho os autores obtiveram, por meio de simulação numérica, temperaturas equivalentes em diversos segmentos de um manequim computacional com avaliação de condições de conforto térmico em diagramas de sensação térmica ( Figs 1.6 e 1.7).

Gao e Niu (2007) estudaram um sistema de ventilação personalizada por meio de simulação numérica. Esse sistema consiste de um dispositivo fixado na poltrona do passageiro com a possibilidade de regulagem de altura e posicionamento da saída de ar próximo da zona de respiração. No estudo os autores utilizaram um código comercial de CFD e a secção de uma aeronave Boeing 767-300 com cinco fileiras (Fig. 1.8).
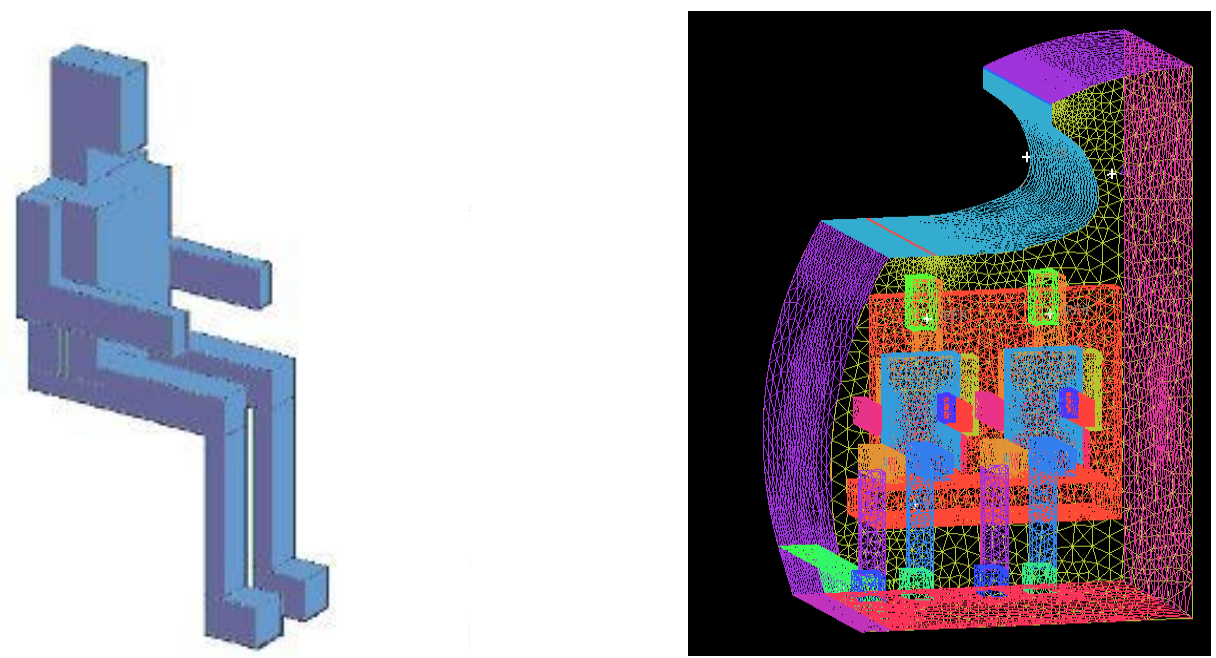

Figura 1.6 - Manequim com 18 segmentos, geometria do mock-up e malha gerada (Stancato et al., 2006). 

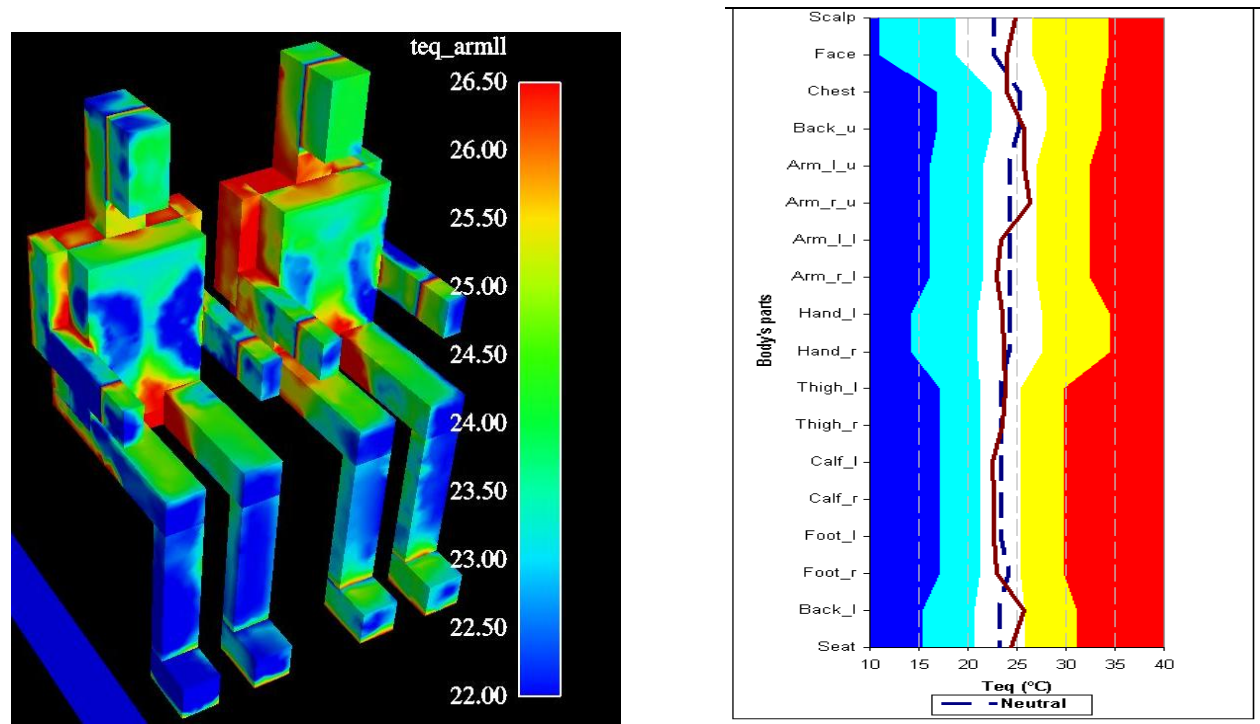

Figura 1.7 - Temperaturas equivalentes e diagrama de sensação térmica (Stancato et al., 2006).

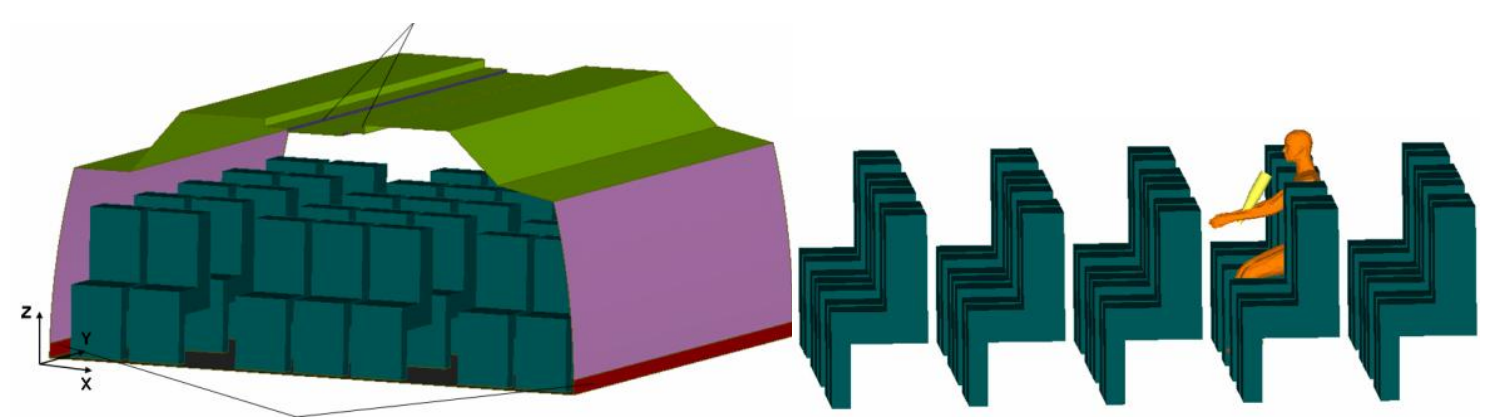

Figura 1.8 - Geometria utilizada para simulação e configuração dos manequins (Gao e Niu, 2007).

Um manequim anatômico com o dispositivo de ventilação personalizado foi modelado e colocado na parte central da quarta fileira da aeronave (Fig.1.8). As demais poltronas foram ocupadas por manequins comuns. Na Figura 1.9 são apresentados vetores velocidade obtidos pelos autores, que concluíram que, em aeronaves, o sistema convencional de insuflamento pelo teto provoca valores de idade do ar e PMV diferentes dos encontrados em ambientes de edificações, com PMV variando de $-0,5$ a 0,1. E que o sistema de ventilação personalizado pode reduzir o risco de contaminação aérea, oferecido pelo sistema convencional de insuflamento, em até $60 \%$. 


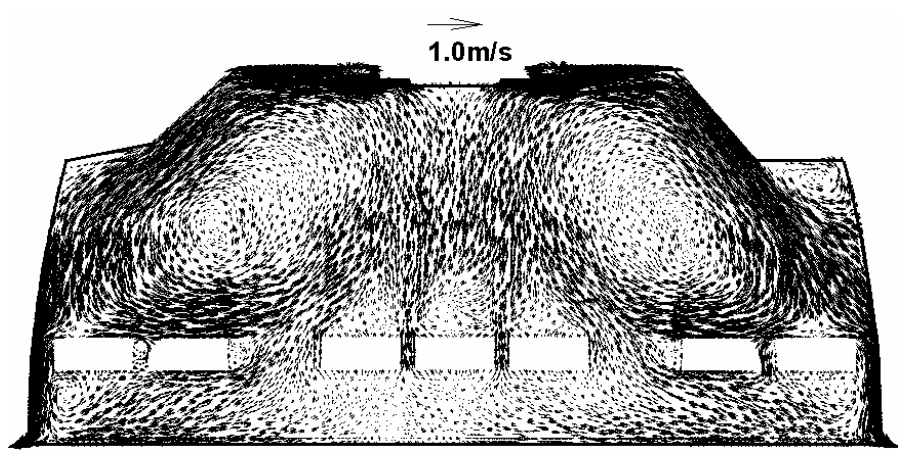

Figura 1.9 - Vetores velocidade no interior da cabine (Gao e Niu, 2007).

Utilizando também uma secção de uma aeronave Boeing 767-300 com cinco fileiras, Zhang e Chen (2007) avaliaram três formas de insuflamento por meio de simulação numérica: insuflamento convencional realizado pelo teto da cabine com retorno por baixo; insuflamento pelo piso, realizado na região do corredor, com retorno pelo teto; e insuflamento pelo piso junto com um sistema de distribuição de ar personalizado.

Dos resultados de simulação (Figs. 1.10 e 1.11), os autores concluíram que o sistema convencional proporciona temperatura mais homogênea. Porém, esse sistema oferece um risco maior de espalhar a contaminação proveniente de um local para os demais. Nos sistemas com insuflamento pelo piso o risco de contaminação diminui, pois as velocidades são baixas e o ar segue um fluxo ascendente, mais regular. O sistema de insuflamento pelo piso, dotado de sistema de distribuição de ar personalizado, proporcionou os melhores resultados de qualidade do ar, apresentando uma concentração média de $\mathrm{CO}_{2}$ na zona de respiração de 600 ppm, contra 1400 ppm do sistema convencional e 900 ppm do sistema de distribuição pelo piso.
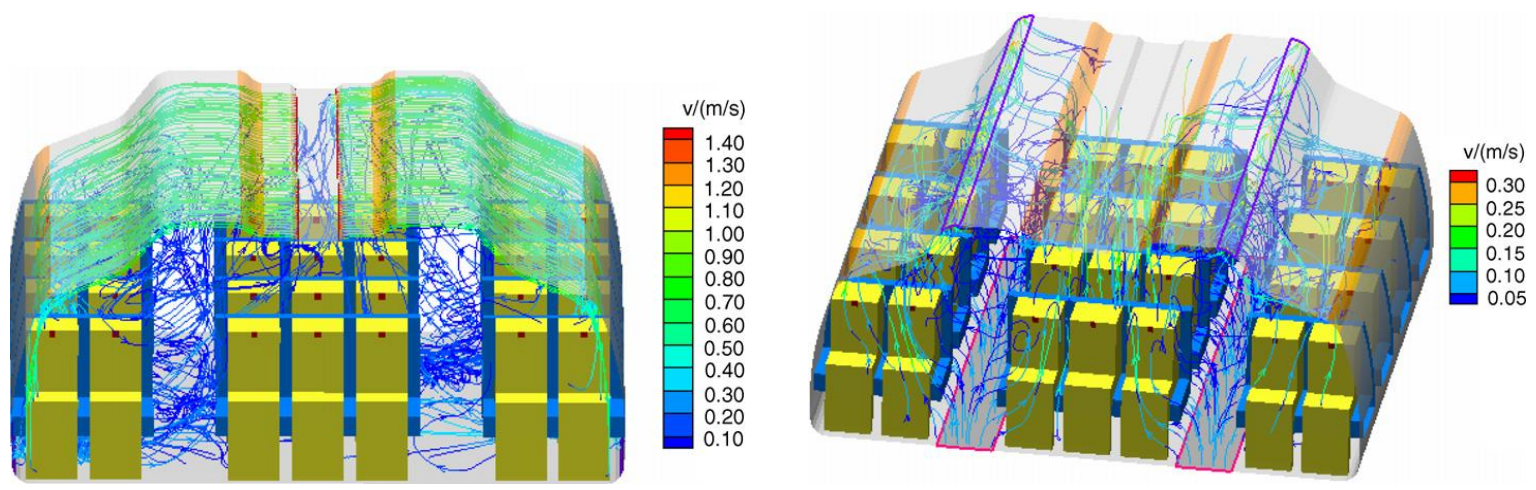

Figura 1.10. Linhas de corrente da simulação do sistema de insuflamento convencional (lado esquerdo) e do sistema com insuflamento pelo piso (Zhang e Chen, 2007) 


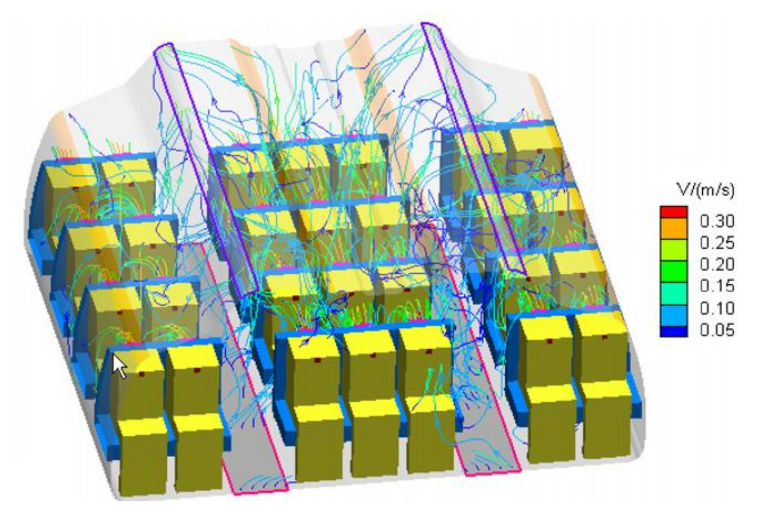

Figura 1.11. Linhas de corrente da simulação do sistema com insuflamento pelo piso e distribuição personalizada de ar (Zhang e Chen, 2007).

\subsection{Motivação do trabalho}

Atualmente, muitas pessoas gastam parte significativa do tempo de suas vidas viajando por razões profissionais ou de lazer, o que vem aumentando a demanda por conforto, seja por motivos de segurança, saúde, satisfação dos ocupantes, aumento da mobilidade ou aspectos de marketing. Estes fatos têm contribuído em muito para aumentar o interesse na avaliação de condições de conforto de passageiros em veículos automotivos. Com essa avaliação busca-se, de um lado melhorar o bem estar e preservar a saúde dos ocupantes, e por outro, agregar ao produto um diferencial importante de competitividade.

Paralelamente, a avaliação de condições de conforto em cabines de aeronaves ainda é um campo de estudos com poucos trabalhos publicados. Por se tratar de ramo de atividade em que os avanços verificados normalmente não são divulgados na literatura aberta, cada empresa acaba desenvolvendo os seus próprios métodos de avaliação.

Finalmente, a motivação maior no desenvolvimento do presente trabalho refere-se à realização de levantamentos experimentais e de avaliação de condições de conforto térmico, incluindo avaliação com pessoas, no contexto do desenvolvimento de método completo de avaliação de conforto térmico em aeronaves.

\subsection{Objetivo do trabalho}

O objetivo do trabalho é a realização de estudo do escoamento em cabine de aeronave, por meio de medição de variáveis ambientais de cabine, e de conforto térmico, utilizando manequim térmico instrumentado e avaliação com pessoas.

Para se atingir o objetivo foram desenvolvidas as seguintes atividades: 
a) Projeto e construção de mock-up de uma secção de aeronave com 12 lugares

b) Realização de medições de temperaturas e velocidades do ar no mock-up sem pessoas, utilizando manequins aquecidos (fontes de calor)

c) Realização de medições de temperaturas superficiais e de fluxos de calor em manequim térmico instrumentado para determinação de temperaturas equivalentes e avaliação de conforto térmico

d) Realização de avaliação subjetiva de conforto térmico com voluntários

\subsection{Organização do trabalho}

No capítulo 2 é apresentada uma revisão sobre a teoria de conforto térmico e de avaliação de ambientes térmicos, considerando o trabalho de Fanger (1972) e as normas ISO 7730 (2005) e ASHRAE 55 (2004).

No capítulo 3 é realizada uma revisão sobre a avaliação de conforto térmico em veículos automotivos, dando-se enfoque à norma ISO 14505-2 (2004) e o trabalho de Nilsson (2004).

No capítulo 4 é apresentado o laboratório onde foi instalado o mock-up, assim como as características construtivas do mock-up projetado e construído para a realização do trabalho.

No capítulo 5 são apresentados os métodos utilizados para a realização da avaliação experimental do escoamento do ar e de conforto térmico no mock-up e também os instrumentos utilizados nesta avaliação.

No capítulo 6 são apresentados e discutidos os resultados obtidos. No capítulo 7 são apresentadas as conclusões do trabalho e, por fim, no capítulo 8 são apresentadas as referências bibliográficas. 


\section{CAPÍTULO 2 \\ CONFORTO TÉRMICO}

Em muitas situações as pessoas ficam sujeitas a ambientes térmicos criados artificialmente para que se sintam em conforto e possam produzir melhor as suas tarefas. Isto acontece tanto em ambientes de edificações quanto em ambientes de veículos automotivos. Se o objetivo é atingido, a pessoa tem uma sensação de bem estar, expressa pela sua satisfação com aquele ambiente térmico.

O corpo humano gera energia continuamente e a sua temperatura interna deve ser controlada dentro de limites estreitos para evitar o desconforto e o estresse térmico. A energia gerada por meio da digestão e do trabalho dos músculos deve ser dissipada para o ambiente de forma a manter a temperatura interna do corpo dentro desses limites.

Em condições térmicas diferentes daquelas na qual a pessoa se sentiria confortável, o organismo provoca reações desencadeadas pelo sistema termorregulador que age no sentido de manter constante a temperatura interna do corpo frente a variações térmicas internas e externas. Esta ação mais intensa do sistema termorregulador acarreta uma sensação de desconforto.

\subsection{O sistema termorregulador}

Em condições normais a temperatura média do corpo é de $37^{\circ} \mathrm{C}$. Dentro de um certo intervalo o sistema de controle de temperatura do corpo humano se esforça para manter esta temperatura frente a perturbações térmicas internas ou externas.

Mudanças em condições climáticas produzem reações no organismo relacionadas com respostas fisiológicas autônomas, mas também com mudanças de comportamento. As respostas autônomas são controladas pelo hipotálamo, controlando as diferentes formas de perda de calor pelo sangue da pele, suor e respiração. Mudanças de comportamento podem se dar por alteração no nível de atividade e no ajuste da vestimenta.

O centro de controle de temperatura do corpo humano está no hipotálamo, que funciona como um termostato. Neuroreceptores termosensíveis enviam sinais ao centro de controle e o set-point da temperatura pode mudar durante diferentes condições fisiológicas (Nilsson, 2004). 
Em ambientes frios a excitação dos receptores sensíveis ao frio irá baixar o setpoint e a perda de calor pode diminuir por meio de vasoconstrição e de "tremores". Em ambientes quentes, por outro lado, o set-point aumenta e a perda de calor pode aumentar por meio de vaso-dilatação na pele e suor.

Uma pessoa em repouso produz aproximadamente $100 \mathrm{~W}$ de energia. Se a vestimenta e as condições do ambiente estiverem adequadas esta energia será perdida ao ambiente. Ocorrerá um balanço de energia adequado para o corpo como um todo e a pessoa se sentirá termicamente neutra. Com o aumento da temperatura ambiente, convecção e radiação (calor sensível) diminuirão, e a evaporação de suor (calor latente) terá que compensar a perda de calor para restabelecer o equilíbrio entre a geração interna de energia e a troca de calor de $100 \mathrm{~W}$. Suar é associado com uma sensação de calor e eventualmente desconforto. Em um ambiente com temperatura menor, convecção e radiação aumentarão, fazendo com que as perdas de calor sejam maiores que $100 \mathrm{~W}$. A resposta fisiológica ocorre para reduzir o fluxo de sangue na pele para diminuir o gradiente térmico externo. Neste caso as pessoas sentirão um pouco de frio ou frio e estarão desconfortáveis.

Uma revisão muito boa do assunto pode ser encontrada em Ferreira (1997) e Ferreira (2001).

\subsection{Balanço térmico do corpo humano}

A temperatura interna do corpo humano é mantida constante somente se ocorrer um equilíbrio entre a energia produzida pelo corpo e o calor perdido para o ambiente. $\mathrm{O}$ homem interage termicamente com o ambiente trocando calor pelos mecanismos da condução, convecção, radiação e evaporação. Esta interação do corpo humano com o meio envolvente é apresentada na Figura 2.1.

Do balanço térmico do corpo humano (1a. lei da termodinâmica), tem-se que:

$$
\begin{gathered}
\dot{U}=\mathrm{M}-\mathrm{W}-\mathrm{Q}_{\text {pele }}-\mathrm{Q}_{\text {respiracao }} \\
\dot{\mathrm{U}}=\mathrm{M}-\mathrm{W}-\left(\mathrm{C}+\mathrm{R}+\mathrm{E}_{\mathrm{es}}+\mathrm{E}_{\text {dif }}\right)-\left(\mathrm{E}_{\mathrm{R}}+\mathrm{C}_{\mathrm{R}}\right)
\end{gathered}
$$




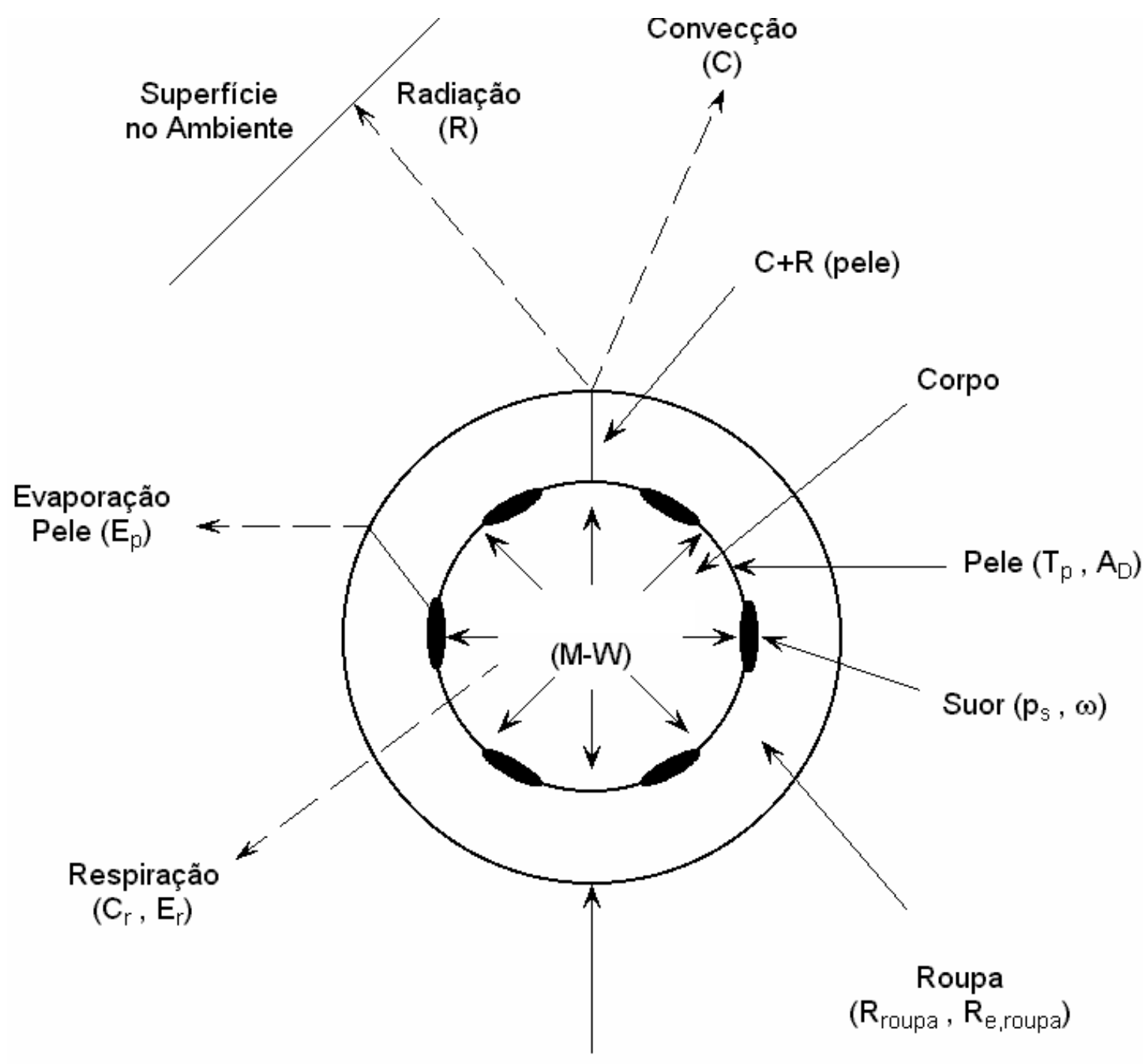

Superfície Exposta

$\left(T_{\text {roupa }}, f_{\text {roupa }}, \varepsilon\right)$

Figura 2.1 Modelo cilíndrico da interação térmica: corpo humano - meio envolvente (ASHRAE, 2005)

onde:

U Taxa de variação de energia interna por unidade de área

$\left[\mathrm{W} / \mathrm{m}^{2}\right]$

M Metabolismo

W Trabalho externo por unidade de tempo e área

Q

Q

$\mathrm{C}$

Calor perdido pela pele por convecção por unidade de tempo e área

$\mathrm{R}$

Calor perdido pela pele por radiação por unidade de tempo e área 
$\mathrm{E}_{\mathrm{es}} \quad$ Calor perdido pela pele por evaporação de suor por unidade de tempo e área

$\mathrm{E}_{\mathrm{dif}} \quad$ Calor perdido pela pele por difusão de vapor d'água por unidade de tempo e área

$\mathrm{E}_{\mathrm{R}} \quad$ Calor evaporativo perdido pela respiração por unidade de tempo e área

$\mathrm{C}_{\mathrm{R}} \quad$ Calor convectivo perdido pela respiração por unidade de tempo e área

Do balanço térmico do corpo humano e aplicando-se as equações que descrevem os mecanismos de transferência de calor, são obtidas as variáveis de conforto térmico (Fanger, 1972):

a) Parâmetros individuais: o tipo de atividade $(\mathrm{M}, \mathrm{W})$ e a isolação da vestimenta $\left(\mathrm{I}_{\mathrm{R}}\right)$;

b) Parâmetros do ambiente: a temperatura do ar ambiente $\left(\mathrm{T}_{\mathrm{ar}}\right)$; a temperatura radiante média $\left(\bar{T}_{r}\right)$; a velocidade do ar $\left(\mathrm{V}_{\text {ar }}\right)$ e a umidade relativa do ar $(\phi)$.

\subsection{Equação de conforto de Fanger}

Fanger (1972) estabeleceu três condições para que uma pessoa estivesse em condição de conforto térmico exposta a um dado ambiente por um período longo:

a) A primeira condição é que haja equilíbrio das trocas de calor entre o corpo e o ambiente, isto é,

$$
\dot{\mathrm{U}}=0
$$

b) A segunda condição é que a temperatura média da pele $\left(\mathrm{T}_{\mathrm{p}}\right)$ seja dada pela equação:

$$
T_{p}=35,7-0,0275(M-W)
$$

c) A terceira condição é que a produção de suor $\left(E_{e s}\right)$ seja igual a:

$$
E_{e s}=0,42(M-W-58,2)
$$

onde $58,2 \mathrm{~W} / \mathrm{m}^{2}$ correspondem à atividade sedentária.

Das condições de conforto de Fanger, tem-se que uma pessoa em atividade sedentária em condição de conforto térmico não produzirá suor, pois $\mathrm{E}_{\mathrm{es}}$ será igual a zero (Eq.

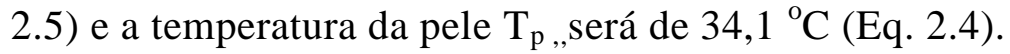


As equações (2.4) e (2.5) foram obtidas a partir de dados experimentais levantados em ensaios realizados com estudantes do sexo feminino e masculino em diferentes níveis de atividade. Inserindo as Eqs. 2.3 a 2.5, juntamente com as equações de transferência de calor, na Eq. (2.2), obtém-se a equação de conforto de Fanger (1972), dada por:

$$
\begin{aligned}
M-\mathrm{W}= & 0,42[\mathrm{M}-\mathrm{W}-58,2]+3,05\left[5,73-0,007(M-W)-p_{v_{a r}}\right]+ \\
& +0,0173\left(5,87-p_{v_{\text {ar }}}\right)+0,0014 M\left(34-T_{a r}\right)+f_{R} h_{c}\left(T_{r o u p a}-T_{a r}\right)+ \\
& +3,96 \times 10^{-8} f_{R}\left[\left(T_{\text {roupa }}+273\right)^{4}-\left(\bar{T}_{r}+273\right)^{4}\right]
\end{aligned}
$$

\begin{tabular}{|c|c|}
\hline $\mathrm{T}_{\text {roupa }}=35,7-0,0275(\mathrm{M}-\mathrm{W})-0,155$ Iroupa & $\left\{\begin{array}{l}(\mathrm{M}-\mathrm{W})-3,05\left[5,73-0,007(\mathrm{M}-\mathrm{W})-\mathrm{p}_{\mathrm{v}_{\mathrm{ar}}}\right]+ \\
-0,42(\mathrm{M}-\mathrm{W}-58,2)-0,0173 \mathrm{M}\left(5,87-\mathrm{p}_{\mathrm{v}_{\mathrm{ar}}}\right)+ \\
-0,0014 \mathrm{M}\left(34-\mathrm{T}_{\mathrm{ar}}\right)\end{array}\right.$ \\
\hline
\end{tabular}

com:

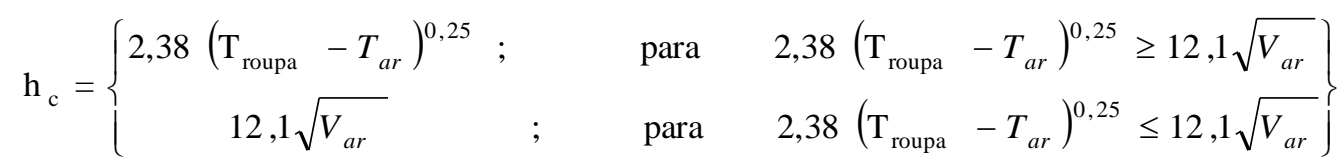

$$
\begin{aligned}
& \mathrm{f}_{\mathrm{R}}=\left\{\begin{array}{cccc}
1,0+0,2 \mathrm{I}_{\mathrm{R}} & ; & \text { para } & \mathrm{I}_{\mathrm{R}} \leq 0,5 C L O \\
1,05+0,1 \mathrm{I}_{\mathrm{R}} & ; & \text { para } & \mathrm{I}_{\mathrm{R}} \geq 0,5 \mathrm{CLO}
\end{array}\right\}
\end{aligned}
$$

onde:

$$
\begin{aligned}
\mathrm{M} & =\text { metabolismo }\left(\mathrm{W} / \mathrm{m}^{2}\right) \\
\mathrm{W} & =\text { trabalho externo }\left(\mathrm{W} / \mathrm{m}^{2}\right) \\
\mathrm{I}_{\mathrm{R}} & =\text { índice de isolamento da roupa }(\text { clo }) \\
\mathrm{T}_{\mathrm{ar}} & =\text { temperatura do ar }\left({ }^{\circ} \mathrm{C}\right) \\
\mathrm{V}_{\mathrm{ar}} & =\text { velocidade relativa do ar }(\mathrm{m} / \mathrm{s}) \\
\mathrm{p}_{\mathrm{var}} & =\text { pressão parcial do vapor d'água no ambiente }(\mathrm{kPa}) \\
\bar{T}_{r} & =\text { temperatura média radiante }\left({ }^{\circ} \mathrm{C}\right)
\end{aligned}
$$


A equação 2.6 relaciona os fatores pessoais $\left(\mathrm{M}, \mathrm{W}, \mathrm{I}_{\mathrm{R}}\right)$ e ambientais $\left(\mathrm{T}_{\mathrm{ar}}, \mathrm{V}_{\mathrm{ar}}, \mathrm{p}_{\mathrm{var}}\right.$ , $\bar{T}_{r}$ ) para conforto térmico.

O metabolismo, função da atividade, normalmente é expresso em termos de unidades de metabolismo met $^{2}$. Na Tabela 2.1 são apresentados valores de metabolismo para diferentes atividades.

Tabela 2.1 - Metabolismos para diferentes atividades (www.hku.hk/bse/bbse3004/)

\begin{tabular}{|l|c|c|}
\hline \multicolumn{1}{|c|}{ Atividade } & \multicolumn{2}{c|}{ Taxa metabólica } \\
\hline Sentado reclinado & $46 \mathrm{~W} / \mathrm{m}^{2}$ & $0,8 \mathrm{met}$ \\
\hline Sentado relaxado & $58 \mathrm{~W} / \mathrm{m}^{2}$ & $1,0 \mathrm{met}$ \\
\hline Em pé relaxado & $70 \mathrm{~W} / \mathrm{m}^{2}$ & $1,2 \mathrm{met}$ \\
\hline Dirigindo carro & $80 \mathrm{~W} / \mathrm{m}^{2}$ & $1,4 \mathrm{met}$ \\
\hline Em pé, atividade leve & $93 \mathrm{~W} / \mathrm{m}^{2}$ & $1,6 \mathrm{met}$ \\
\hline Caminhando horizontalmente $(2 \mathrm{~km} / \mathrm{h})$ & $110 \mathrm{~W} / \mathrm{m}^{2}$ & $1,9 \mathrm{met}$ \\
\hline Em pé, atividades moderadas $($ trabalho doméstico) & $116 \mathrm{~W} / \mathrm{m}^{2}$ & $2,0 \mathrm{met}$ \\
\hline Caminhando horizontalmente, $5 \mathrm{~km} / \mathrm{h}$ & $200 \mathrm{~W} / \mathrm{m}^{2}$ & $3,4 \mathrm{met}$ \\
\hline Trabalhadores da construção civil & $275 \mathrm{~W} / \mathrm{m}^{2}$ & $4,7 \mathrm{met}$ \\
\hline Esportes - correndo a $15 \mathrm{~km} / \mathrm{h}$ & $550 \mathrm{~W} / \mathrm{m}^{2}$ & $9,5 \mathrm{met}$ \\
\hline
\end{tabular}

A vestimenta representa uma resistência à troca de calor entre o corpo e o meio, e, portanto, afeta o equilíbrio térmico. A resistência térmica da roupa $\left(I_{R}\right)$ é normalmente representada pela unidade $\mathrm{clo}^{3}$.

Uma vestimenta leve (calça comprida, camisa de manga curta, sapato e meia), apresenta um clo em torno de 0,5. Já uma vestimenta mais pesada, de inverno, com calça comprida, camisa de manga comprida, gravata, sapato, meia e paletó assumem valores em torno de 1,0 clo.

Para a obtenção das variáveis ambientais: velocidade média do ar, $\mathrm{V}_{\mathrm{ar}}$, temperatura média radiante, $\bar{T}_{r}$, temperatura do ar, $\mathrm{T}_{\mathrm{ar}}$ e umidade do ar: umidade absoluta, $\omega$, e umidade relativa, $\phi$, são realizadas medições no ambiente. A norma ISO 7726 (1996) apresenta procedimentos de medição e métodos para a determinação destas variáveis ambientais.

${ }^{2} 1 \mathrm{met}=58,2 \mathrm{~W} / \mathrm{m}^{2}$ (atividade sedentária)

${ }^{3} 1 \mathrm{clo}=0,155 \mathrm{~m}^{2} \mathrm{C} / \mathrm{W}$ (vestimenta típica de inverno, pesada) 


\subsection{Avaliação de ambientes térmicos}

No item anterior foi apresentada a equação de conforto de Fanger (Eq, 2.6). que trata de situações de conforto térmico, isto é, das combinações dos parâmetros $(\mathrm{M}, \mathrm{W}$, $\mathrm{I}_{\mathrm{R}}, \mathrm{T}_{\mathrm{ar}}, \mathrm{V}_{\mathrm{ar}}, \mathrm{p}_{\mathrm{var}}, \bar{T}_{r}$ ) que causam conforto térmico. A sensação de conforto em um ambiente térmico, contudo, depende da percepção das pessoas.

Assim, há a necessidade de uma avaliação das pessoas quanto às condições de conforto que o ambiente térmico proporciona. Esta avaliação subjetiva, normalmente, é realizada por meio do voto das pessoas segundo critérios definidos na escala de sensação térmica da ASHRAE, apresentada na Tabela 2.2.

Tabela 2.2 - Escala de sensação térmica da ASHRAE (ASHRAE, 2005)

\begin{tabular}{|c|c|}
\hline+3 & muito quente \\
\hline+2 & quente \\
\hline+1 & ligeiramente quente \\
\hline 0 & neutro \\
\hline-1 & ligeiramente frio \\
\hline-2 & frio \\
\hline-3 & muito frio \\
\hline
\end{tabular}

\subsubsection{Voto médio estimado (PMV)}

Nos ensaios realizados por Fanger (1972), as pessoas, desempenhando uma certa atividade (metabolismo, M) e vestindo uma certa roupa (clo), eram colocadas em câmaras climatizadas (com determinadas condições ambientais) e davam os seus votos quanto à sensação que percebiam. Destes votos resultou a equação do voto médio estimado (PMV - Predicted Mean Vote) que correlaciona as variáveis pessoais ((M, W, $\mathrm{I}_{\mathrm{R}}$ ), as variáveis ambientais $\left(\mathrm{T}_{\mathrm{ar}}, \mathrm{V}_{\mathrm{ar}}, \mathrm{p}_{\mathrm{var}}, \bar{T}_{r}\right)$ e o voto (sensação) das pessoas.

O trabalho de Fanger (1972) é a base da norma ISO 7730 (2005) de conforto térmico. Uma vez que o cálculo do voto médio estimado (PMV) é um pouco trabalhoso, Fanger (1972) e a ISO 7730 (2005) apresentam tabelas, como a Tabela 2.3, e uma rotina para utilização em microcomputador, que permitem determinar o PMV para diferentes atividades, tipos de vestimenta e condições ambientais. 
Tabela 2.3 Determinação do voto médio estimado - PMV (ISO 7730, 2005)

Atividade sedentária $(\mathrm{MET}=1,0)$ e umidade relativa do ar de $50 \%$

\begin{tabular}{|c|c|c|c|c|c|c|c|c|c|c|}
\hline \multicolumn{2}{|c|}{ Vestimenta } & \multirow{2}{*}{$\begin{array}{c}\text { Temperatu } \\
\text { ra } \\
\text { Operativa } \\
{ }^{\circ} \mathrm{C} \\
\end{array}$} & \multicolumn{8}{|c|}{ Velocidade Relativa do ar $-\mathrm{m} / \mathrm{s}$} \\
\hline $\mathrm{CLO}$ & $\frac{\mathbf{m}^{20} \mathbf{C}}{W}$ & & $<0.10$ & 0.10 & 0.15 & 0.20 & 0.30 & 0.40 & 0.50 & 1.00 \\
\hline $\mathbf{0}$ & $\mathbf{0}$ & $\begin{array}{l}\mathbf{2 6} \\
27 \\
28 \\
29 \\
\mathbf{3 0} \\
\mathbf{3 1} \\
\mathbf{3 2} \\
\mathbf{3 3}\end{array}$ & $\begin{array}{r}-1.62 \\
-1.00 \\
-0.39 \\
0.21 \\
0.80 \\
1.39 \\
1.96 \\
2.50\end{array}$ & $\begin{array}{r}-1.62 \\
-1.00 \\
-0.42 \\
0.13 \\
0.68 \\
1.25 \\
1.83 \\
2.41\end{array}$ & $\begin{array}{r}-1.96 \\
-1.36 \\
-0.76 \\
-0.15 \\
0.45 \\
1.08 \\
1.71 \\
2.34\end{array}$ & $\begin{array}{r}-2.34 \\
-1.69 \\
-1.05 \\
-0.39 \\
0.26 \\
0.94 \\
1.61 \\
2.29\end{array}$ & & & & \\
\hline 0.25 & 0.039 & $\begin{array}{l}24 \\
25 \\
26 \\
27 \\
28 \\
29 \\
30 \\
31\end{array}$ & $\begin{array}{r}-1.52 \\
-1.05 \\
-0.58 \\
-0.12 \\
0.34 \\
0.80 \\
1.25 \\
1.71\end{array}$ & $\begin{array}{r}-1.52 \\
-1.05 \\
-0.61 \\
-0.17 \\
0.27 \\
0.71 \\
1.15 \\
1.61\end{array}$ & $\begin{array}{r}-1.80 \\
-1.33 \\
-0.87 \\
-0.40 \\
0.07 \\
0.54 \\
1.02 \\
1.51\end{array}$ & $\begin{array}{r}-2.06 \\
-1.57 \\
-1.08 \\
-0.58 \\
-0.09 \\
0.41 \\
0.91 \\
1.43\end{array}$ & $\begin{array}{r}-2.47 \\
-1.94 \\
-1.41 \\
-0.87 \\
-0.34 \\
0.20 \\
0.74 \\
1.30\end{array}$ & $\begin{array}{r}-2.24 \\
-1.67 \\
-1.10 \\
-0.53 \\
0.04 \\
0.61 \\
1.20\end{array}$ & $\begin{array}{r}-2.48 \\
-1.89 \\
-1.29 \\
-0.70 \\
-0.10 \\
0.50 \\
1.12\end{array}$ & $\begin{array}{r}-2.66 \\
-1.97 \\
-1.28 \\
-0.58 \\
0.11 \\
0.83\end{array}$ \\
\hline 0.50 & 0.078 & $\begin{array}{l}23 \\
24 \\
25 \\
26 \\
27 \\
28 \\
29 \\
30\end{array}$ & $\begin{array}{r}-1.10 \\
-0.72 \\
-0.34 \\
0.04 \\
0.42 \\
0.80 \\
1.17 \\
1.54\end{array}$ & $\begin{array}{r}-1.10 \\
-0.74 \\
-0.38 \\
-0.01 \\
0.35 \\
0.72 \\
1.08 \\
1.45\end{array}$ & $\begin{array}{r}-1.33 \\
-0.95 \\
-0.56 \\
-0.18 \\
0.20 \\
0.59 \\
0.98 \\
1.37\end{array}$ & $\begin{array}{r}-1.51 \\
-1.11 \\
-0.71 \\
-0.31 \\
0.09 \\
0.49 \\
0.90 \\
1.30\end{array}$ & $\begin{array}{r}-1.78 \\
-1.36 \\
-0.94 \\
-0.51 \\
-0.08 \\
0.34 \\
0.77 \\
1.20\end{array}$ & $\begin{array}{r}-1.99 \\
-1.55 \\
-1.11 \\
-0.66 \\
-0.22 \\
0.23 \\
0.68 \\
1.13\end{array}$ & $\begin{array}{r}-2.16 \\
-1.70 \\
-1.25 \\
-0.79 \\
-0.33 \\
0.14 \\
0.60 \\
1.06\end{array}$ & $\begin{array}{r}-2.22 \\
-1.71 \\
-1.19 \\
-0.68 \\
-0.17 \\
0.34 \\
0.86\end{array}$ \\
\hline 0.75 & 0.118 & $\begin{array}{l}21 \\
22 \\
23 \\
24 \\
25 \\
26 \\
27 \\
28\end{array}$ & $\begin{array}{r}-1.11 \\
-0.79 \\
-0.47 \\
-0.15 \\
0.17 \\
0.49 \\
0.81 \\
1.12\end{array}$ & $\begin{array}{r}-1.11 \\
-0.81 \\
-0.50 \\
-0.19 \\
0.12 \\
0.43 \\
0.74 \\
1.05\end{array}$ & $\begin{array}{r}-1.30 \\
-0.96 \\
-0.66 \\
-0.33 \\
-0.01 \\
0.31 \\
0.64 \\
0.96\end{array}$ & $\begin{array}{r}-1.44 \\
-1.11 \\
-0.78 \\
-0.44 \\
-0.11 \\
0.23 \\
0.56 \\
0.90\end{array}$ & $\begin{array}{r}-1.66 \\
-1.31 \\
-0.96 \\
-0.61 \\
-0.28 \\
0.09 \\
0.45 \\
0.80\end{array}$ & $\begin{array}{r}-1.82 \\
-1.46 \\
-1.09 \\
-0.73 \\
-0.37 \\
0.00 \\
0.36 \\
0.73\end{array}$ & $\begin{array}{r}-1.95 \\
-1.58 \\
-1.20 \\
-0.83 \\
-0.46 \\
-0.08 \\
0.29 \\
0.67\end{array}$ & $\begin{array}{r}-2.36 \\
-1.95 \\
-1.55 \\
-1.14 \\
-0.74 \\
-0.33 \\
0.08 \\
0.48\end{array}$ \\
\hline 1.00 & 0.155 & $\begin{array}{l}20 \\
21 \\
22 \\
23 \\
24 \\
25 \\
26 \\
27\end{array}$ & $\begin{array}{r}-0.85 \\
-0.57 \\
-0.30 \\
-0.02 \\
0.26 \\
0.53 \\
0.81 \\
1.08\end{array}$ & $\begin{array}{r}-0.87 \\
-0.60 \\
-0.33 \\
-0.07 \\
0.20 \\
0.48 \\
0.75 \\
1.02\end{array}$ & $\begin{array}{r}-1.02 \\
-0.74 \\
-0.46 \\
-0.18 \\
0.10 \\
0.38 \\
0.66 \\
0.95\end{array}$ & $\begin{array}{r}-1.13 \\
-0.84 \\
-0.55 \\
-0.27 \\
0.02 \\
0.31 \\
0.60 \\
0.89\end{array}$ & $\begin{array}{r}-1.29 \\
-0.99 \\
-0.69 \\
-0.39 \\
-0.09 \\
0.21 \\
0.51 \\
0.81\end{array}$ & $\begin{array}{r}-1.41 \\
-1.11 \\
-0.80 \\
-0.49 \\
-0.18 \\
0.13 \\
0.44 \\
0.75\end{array}$ & $\begin{array}{r}-1.51 \\
-1.19 \\
-0.88 \\
-0.56 \\
-0.25 \\
0.07 \\
0.39 \\
0.71\end{array}$ & $\begin{array}{r}-1.81 \\
-1.47 \\
-1.13 \\
-0.79 \\
-0.46 \\
-0.12 \\
0.22 \\
0.56\end{array}$ \\
\hline 1.50 & 0.233 & $\begin{array}{l}14 \\
16 \\
18 \\
20 \\
22 \\
24 \\
26 \\
28\end{array}$ & $\begin{array}{r}-1.36 \\
-0.94 \\
-0.52 \\
-0.09 \\
0.35 \\
0.79 \\
1.23 \\
1.67\end{array}$ & $\begin{array}{r}-1.36 \\
-0.95 \\
-0.54 \\
-0.13 \\
0.30 \\
0.74 \\
1.18 \\
1.62\end{array}$ & $\begin{array}{r}-1.48 \\
-1.07 \\
-0.64 \\
-0.22 \\
0.23 \\
0.68 \\
1.13 \\
1.56\end{array}$ & $\begin{array}{r}-1.58 \\
-1.15 \\
-0.72 \\
-0.28 \\
0.18 \\
0.63 \\
1.09 \\
1.56\end{array}$ & $\begin{array}{r}-1.72 \\
-1.27 \\
-0.82 \\
-0.37 \\
0.10 \\
0.57 \\
1.04 \\
1.52\end{array}$ & $\begin{array}{r}-1.82 \\
-1.36 \\
-0.90 \\
-0.44 \\
0.04 \\
0.52 \\
1.01 \\
1.48\end{array}$ & $\begin{array}{r}-1.89 \\
-1.43 \\
-0.96 \\
-0.49 \\
0.00 \\
0.49 \\
0.98 \\
1.47\end{array}$ & $\begin{array}{r}-2.12 \\
-1.63 \\
-1.14 \\
-0.65 \\
-0.14 \\
0.37 \\
0.89 \\
1.40\end{array}$ \\
\hline 2.00 & 0.310 & $\begin{array}{l}10 \\
12 \\
14 \\
16 \\
18 \\
20 \\
22 \\
24\end{array}$ & $\begin{array}{r}-1.38 \\
-1.03 \\
-0.68 \\
-0.32 \\
0.03 \\
0.40 \\
0.76 \\
1.13\end{array}$ & $\begin{array}{r}-1.39 \\
-1.05 \\
-0.70 \\
-0.35 \\
-0.00 \\
0.36 \\
0.72 \\
1.09\end{array}$ & $\begin{array}{r}-1.49 \\
-1.14 \\
-0.79 \\
-0.43 \\
-0.07 \\
0.30 \\
0.67 \\
1.05\end{array}$ & $\begin{array}{r}-1.56 \\
-1.21 \\
-0.85 \\
-0.48 \\
-0.11 \\
0.26 \\
0.54 \\
1.02\end{array}$ & $\begin{array}{r}-1.67 \\
-1.30 \\
-0.93 \\
-0.56 \\
-0.18 \\
0.20 \\
0.59 \\
0.98\end{array}$ & $\begin{array}{r}-1.74 \\
-1.37 \\
-0.99 \\
-0.61 \\
-0.23 \\
0.16 \\
0.55 \\
0.95\end{array}$ & $\begin{array}{r}-1.80 \\
-1.42 \\
-1.04 \\
-0.65 \\
-0.26 \\
0.13 \\
0.53 \\
0.93\end{array}$ & $\begin{array}{r}-1.96 \\
-1.57 \\
-1.17 \\
-0.77 \\
-0.37 \\
\mathbf{0 . 0 4} \\
\mathbf{0 . 4 5} \\
0.87\end{array}$ \\
\hline
\end{tabular}

OBS: 1) Valores de PMV em torno de zero indicam condições de conforto térmico.

2) Valores de clo igual a 0,5 representam uma vestimenta leve de verão (calça comprida com camisa de mangas curtas), enquanto valores de clo igual a 1,0 representam uma vestimenta pesada de inverno. 
Considerando a abrangência do estudo realizado por Fanger (1972), o uso de PMV para a avaliação do conforto térmico deve se restringir à faixa $-2 \leq P M V \leq+2$ e os principais parâmetros devem estar dentro dos seguintes intervalos:

$$
\begin{aligned}
& M=46 \text { a } 232 \mathrm{~W} / \mathrm{m}^{2}(0,8 \text { a } 4 \text { met }) \\
& I_{R}=0 \text { a } 0,310 \mathrm{~m}^{2 \circ} \mathrm{C} / \mathrm{W}(0 \text { a } 2 \text { clo }) \\
& T_{a r}=10 \text { a } 30^{\circ} \mathrm{C} \\
& \bar{T}_{r}=10 \text { a } 40^{\circ} \mathrm{C} \\
& V_{a r}=0 \text { a } 1 \mathrm{~m} / \mathrm{s} \\
& p_{v a r}=0 \text { a } 2700 \mathrm{~Pa} \\
& \phi=30 \text { a } 70 \%
\end{aligned}
$$

A ASHRAE também apresenta gráficos para a determinação das condições de conforto térmico em ambientes climatizados - as Cartas de Conforto da ASHRAE. A Figura 2.2 mostra uma carta psicrométrica com as zonas de conforto representadas por áreas hachuradas (ASHRAE 55, 2004; ASHRAE, 2005).

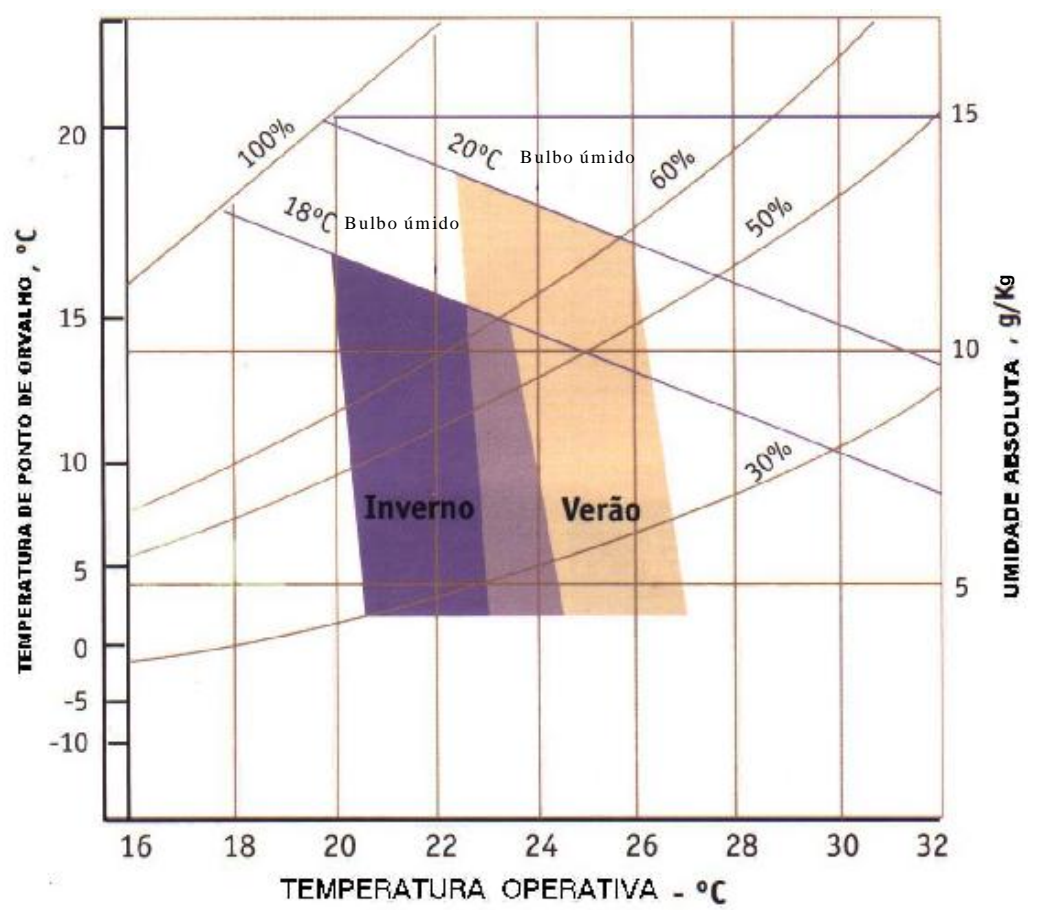

Figura 2.2 Zonas de conforto da ASHRAE para atividade sedentária (ASHRAE 55, 2004; ASHRAE, 2005) 
As cartas de conforto da ASHRAE são de aplicação limitada, pois foram obtidas para condições ambientais e pessoais específicas. A carta da Figura 2.2, por exemplo, é válida somente para atividade sedentária, roupa leve, temperatura radiante média, $\overline{\mathrm{T}}_{\mathrm{r}} \approx \mathrm{T}_{\mathrm{ar}}$, temperatura do ar (temperatura de bulbo seco), velocidade relativa, $\mathrm{V}_{\mathrm{ar}}<0,2 \mathrm{~m} / \mathrm{s}$ e umidade relativa do ar, $\phi$, em torno de $50 \%$.

Verifica-se na Tabela 2.3 e na Figura 2.2 que os resultados são apresentados em função da temperatura operativa, $\mathrm{T}_{\mathrm{o}}{ }^{4}$, que é função da temperatura média radiante, $\bar{T}_{r}$, e da temperatura do ar, $\mathrm{T}_{\mathrm{ar}}$, dado pela Equação $(2.10)^{5}$ :

$$
T_{o}=a \cdot T_{a r}+(1-a) \cdot \bar{T}_{r}
$$

onde a constante $\boldsymbol{a}$ varia de acordo com a velocidade do ar $\left(V_{a r}\right)$ :

$$
\begin{array}{cccc}
V_{a r}(\mathrm{~m} / \mathrm{s}) & 0-0,2 & 0,2-0,6 & 0,6-1,0 \\
a & 0,5 & 0,6 & 0,7
\end{array}
$$

\subsubsection{Percentagem de pessoas insatisfeitas (PPD)}

Os valores de PMV não são suficientes para definir a sensação de desconforto, pois, "ligeiramente frio ou quente" ou qualquer outro valor da escala, não indicam o quão insatisfeitas as pessoas estão. Para isto, Fanger (1972), associou aos índices de voto médio estimado (PMV) com a percentagem de pessoas insatisfeitas (PPD Predicted Percentage of Dissatisfied).

Na Figura 2.3 é mostrada a relação entre PMV e PPD. Verifica-se nesta figura que, mesmo com PMV igual a zero (neutralidade térmica), 5\% estão insatisfeitos.

\footnotetext{
${ }^{4} \mathrm{~T}_{\mathrm{o}}=$ temperatura operativa $\left({ }^{\circ} \mathrm{C}\right)$ : temperatura de um meio imaginário (envolvendo ar e superfícies) com o qual a pessoa troca a mesma quantidade de calor por convecção e radiação que aquela trocada com o meio real.

5 ANSI/ASHRAE 55 (2004) e ISO 7730 (2005).
} 


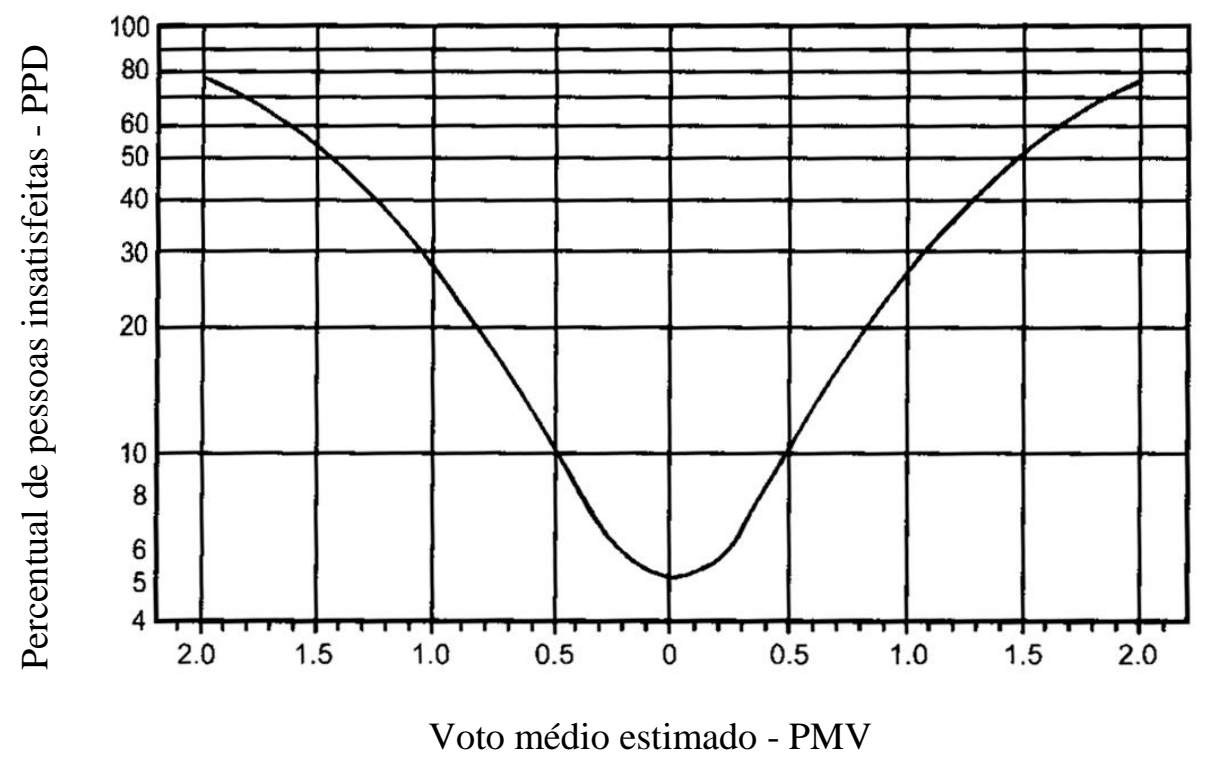

Figura 2.3 Relação entre PMV e PPD

\subsubsection{Desconforto térmico local}

As condições de conforto térmico de Fanger foram obtidas para o corpo como um todo. Contudo, uma pessoa pode estar em condições de neutralidade térmica $(P M V=0)$, mas pode não estar confortável se uma parte do corpo estiver "quente" e uma outra "fria". Portanto, para se ter condições de conforto é necessário também que não haja desconforto local (quente ou frio) em diferentes partes do corpo.

Este desconforto térmico local pode ser causado por:

$>$ Correntes de ar (draft);

$>$ Assimetria de radiação;

$>$ Diferença de temperatura vertical do ar entre os pés e a cabeça;

$>$ Diferença de temperatura entre os pés e o piso.

Limites máximos previstos para cada uma das causas de desconforto térmico local são apresentados nas normas ASHRAE 55 (2004) e ISO 7730 (2005). 
Capítulo 3

\section{AVALIAÇÃO DE CONFORTO TÉRMICO EM VEÍCULOS AUTOMOTIVOS}

O modelo mais aceito mundialmente para a análise de conforto térmico é o de Fanger (1972), que correlaciona parâmetros pessoais e ambientais na obtenção do voto médio estimado (PMV - Predicted Mean Vote) e do percentual de pessoas insatisfeitas (PPD - Predicted Percentage of Dissatisfied) em um ambiente térmico. Os índices PMV e PPD foram obtidos para condições de regime permanente, mas podem ser aplicados com boa aproximação se ocorrerem "flutuações pequenas" de uma ou mais variáveis, em ambientes que possam ser considerados homogêneos (ambientes de edificações e residências).

Por não permitir a verificação de desconforto em regiões localizadas do corpo humano, uma vez que o PMV e PPD foram obtidos a partir do balanço de energia para uma pessoa como um todo, Fanger et al. (1988) estabeleceram um índice complementar que leva em consideração o risco de desconforto por correntes de ar (risco de draft), denominado PD (Percentage of Dissatisfied). Além disso, as normas ISO 7730 (2005), baseada no trabalho de Fanger, e ASHRAE 55 (2004) estabelecem condições de conforto térmico e condições complementares com relação à diferença de temperatura entre os pés e a cabeça, assimetria de radiação e velocidades máximas do ar.

Essas especificações, porém, não são suficientes e adequadas para a avaliação de conforto térmico em ambientes não homogêneos, como aqueles que ocorrem em veículos automotivos. Principalmente em função de se tratar de espaços confinados, nesses tipos de ambientes podem ocorrer gradientes de temperatura e velocidade do ar significativos, com assimetrias de temperatura, velocidade do ar e temperaturas radiantes.

Um relato importante dos problemas de medição das variáveis ambientais no habitáculo e de análise das condições térmicas, função das assimetrias e não uniformidade de temperaturas e velocidades em cabines de automóveis, é apresentado por Cisternino (1999). O autor salienta que esses fatos aumentam a complexidade da avaliação de conforto em cabines, comparado com metodologias usadas em edificações. Segundo o autor, alguns requisitos são necessários para a avaliação de conforto em cabines de 
veículos como: avaliação subjetiva realizada com júri, avaliação de condições transientes e estacionárias, possibilidade de medida de desconforto local e uso de manequins para a modificação do ambiente devido ao volume ocupado.

\subsection{Temperatura equivalente}

Para ambientes não homogêneos, onde diferentes partes do corpo experimentam diferentes condições térmicas, o conceito mais amplamente utilizado (Gameiro da Silva, 2002; Guan et al., 2003a; Nilsson, 2004) é o de temperatura equivalente ( $\mathrm{T}_{\mathrm{eq}}$ ), definida como sendo a temperatura uniforme de um ambiente imaginário com velocidade do ar igual a zero, no qual a pessoa troca a mesma quantidade de calor sensível, por radiação e convecção, que no ambiente real (Fig. 3.1).

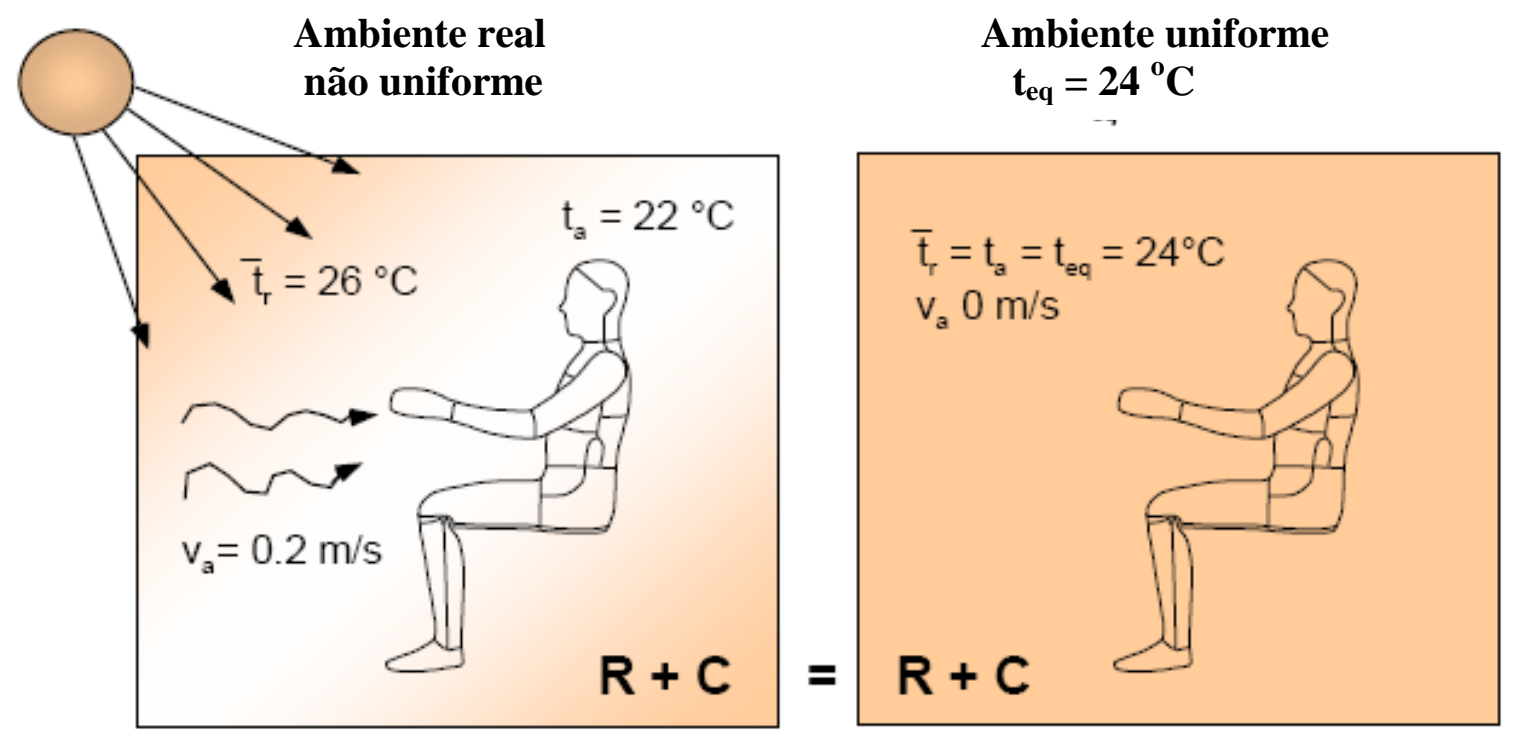

Figura 3.1 Ilustração da definição de temperatura equivalente (adapt. de Nilsson, 2004)

Entre as equações para o cálculo de temperatura equivalente, $t_{\text {eq }}$, em ambientes internos, o equacionamento apresentado por Madsen (1976), função das variáveis ambientais $\left(\mathrm{T}_{\mathrm{ar}}, \mathrm{V}_{\mathrm{ar}}, \bar{T}_{r}\right)$ e da vestimenta $\left(\mathrm{I}_{\mathrm{R}}\right)$, é o mais utilizado, sendo:

$$
\begin{array}{cl}
T_{e q}=0,55 \mathrm{~T}_{\mathrm{ar}}+0,45 \overline{\mathrm{T}}_{\mathrm{r}}+\frac{0,24-0,75 \sqrt{\mathrm{V}_{\mathrm{ar}}}}{1+\mathrm{I}_{\mathrm{R}}}\left(36,5-\mathrm{T}_{\mathrm{ar}}\right) & \left(V_{a r}>0,1 \mathrm{~m} / \mathrm{s}\right) \\
T_{e q}=T_{o}=\frac{T_{a r}+\bar{T}_{r}}{2} & \left(V_{a r} \leq 0,1 \mathrm{~m} / \mathrm{s}\right)
\end{array}
$$

onde $\mathrm{T}_{\mathrm{o}}$ é a temperatura operativa (ver Cap. 2). 
É importante observar que a temperatura equivalente é derivada da temperatura operativa com a inclusão do efeito da velocidade do ar sobre um corpo aquecido. A temperatura operativa somente considera a temperatura do ar e a temperatura radiante média, e é definida para a velocidade real do ar, enquanto a temperatura equivalente é definida para uma velocidade padronizada, próximo de zero.

Em alguns trabalhos da literatura aparecem algumas variações com relação à denominação da temperatura equivalente, tais como ELT - equivalent living-room temperature (temperatura equivalente do "ambiente") e EHT - equivalent homogeneous temperature (temperatura equivalente homogênea), mas o conceito é o mesmo.

Desde 1932, quando Duffon (1932 apud Nilsson, 2004) propôs medir temperatura equivalente utilizando um cilindro, modernos e sofisticados métodos de medir temperatura equivalente têm sido propostos: Madsen (1976); Madsen et al (1986) e Olesen (1988 apud Gameiro da Silva, 2002); Nilsson (2004).

Segundo Gameiro da Silva (2002), o manequim térmico seria o único instrumento capaz de avaliar simultaneamente os efeitos da temperatura do ar local, velocidades do ar, trocas de calor por radiação e radiação solar em um veículo.

\subsection{Manequins}

Um manequim deve ter algumas características para poder ser usado em avaliação de conforto térmico no interior de veículos automotivos. Este deve ter o tamanho e o formato de um corpo humano, ser capaz de ser colocado na posição sentada, ser capaz de ser vestido com roupas e permitir a determinação da influência dos parâmetros físicos relevantes ao conforto térmico ao longo de todo o corpo e com a possibilidade de dividir este corpo em partes ou zonas (Fig. 3.2)

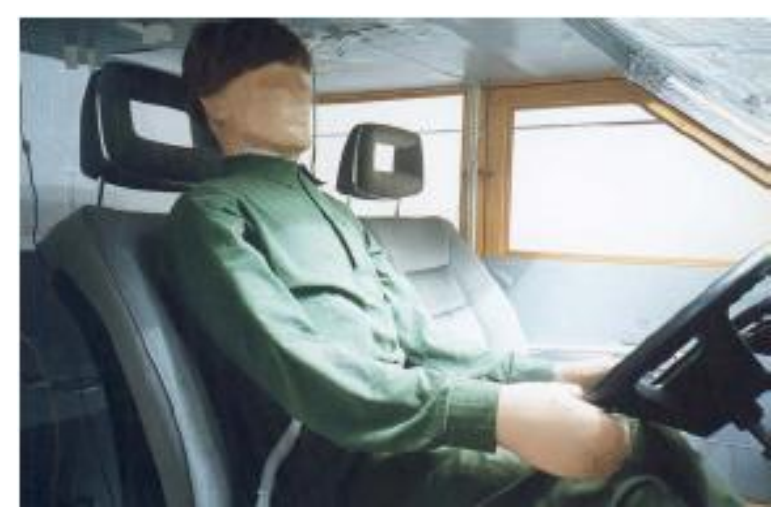

Figura 3.2 Manequim instalado em ambiente simulando cabine de automóvel (Nilsson, 2004). 
Os manequins atualmente utilizados são divididos em 16 zonas ou mais, até um limite de 32 zonas, independentemente controladas. Para reduzir custos e peso são utilizados materiais como alumínio e plástico. Os controles de regulação de troca de calor dos manequins mais modernos são do tipo digital, mas ainda existem muitos manequins com controles de regulação analógicos (Nilsson, 2004).

\section{2,1 Manequins térmicos}

Um manequim térmico típico, que não simula sudorese, é construído com estrutura em alumínio revestida por espuma plástica. Cada zona aquecida independentemente é coberta por resistências elétricas, que depois são cobertas por uma resina plástica. $\mathrm{Na}$ superfície do manequim são montados sensores de temperatura. Cada uma das zonas é regulada para uma temperatura constante e a potência requerida para manter esta temperatura é indicada pelo sistema de regulação do manequim; ou é regulada para um fluxo de calor constante e a temperatura superficial resultante é indicada pelo sistema.

O manequim térmico requer um determinado tempo para responder a uma alteração no equilíbrio de troca de calor. Dependendo da construção do manequim e do sistema de regulação utilizado, este tempo pode variar entre 20 e 30 minutos.

Uma vez que os manequins térmicos atuais só permitem determinar a perda de calor sensível, em condições ambientais onde o ser humano começar a suar para perder calor por evaporação do suor haverá uma subestimação do calor total perdido. Entretanto, para pesquisas de conforto térmico realizadas próximo da zona de neutralidade térmica em atividades leves, onde a perda de calor por evaporação representa uma parte mínima da perda de calor total, não haverá um desvio muito grande se for utilizado um manequim térmico que não seja capaz de reproduzir a sudorese humana (Nilsson, 2004).

Um manequim térmico determina a perda de calor de uma maneira relevante, confiável e com acurácia. É um método rápido, facilmente padronizado e reproduzível . Atualmente existe um grande número de manequins térmicos sendo construídos e utilizados no mundo inteiro, mas a falta de uma norma padronizando sua construção ainda dificulta a comparação entre resultados obtidos por diferentes manequins em diferentes ambientes (Nilsson, 2004).

Adicionalmente, as desvantagens de se utilizar manequins térmicos são o custo desses equipamentos, a dificuldade de manuseá-los e são equipamentos delicados e difíceis de manter. Além disso, manequins que não são capazes de simular a sudorese humana, quando expostos a ambientes muito quentes, não serão capazes de avaliar as condições de 
conforto térmico de tal ambiente, pois o manequim não irá perder calor para o ambiente e sim ganhar calor do ambiente e o sistema de regulação destes manequins não é capaz de medir corretamente este ganho de calor. Acrescente-se que a demora em responder a alterações de condições no ambiente limita a utilização do manequim térmico apenas a condições de equilíbrio térmico, não sendo possível avaliar condições transientes (Guan et al., 2003a; 2003b).

\section{2,2 Manequins com sensores aquecidos}

Uma outra forma de se avaliar condições de conforto térmico é com a utilização de manequins com sensores aquecidos. Neste caso o manequim não é aquecido como no caso do manequim térmico. Em vez de se fazer a avaliação das trocas de calor em diversos segmentos do corpo aquecido, sensores aquecidos são colocados nestes segmentos do corpo (16 ou 32 segmentos).

Embora a utilização de manequins aquecidos seja mais adequada, por reproduzir mais fielmente as trocas de calor do corpo humano, a utilização de manequins com sensores aquecidos é uma boa ferramenta para a realização de estudos comparativos de condições de conforto térmico em veículos, prevista na norma ISO 14505-2 (2004).

\subsection{Avaliação de conforto térmico utilizando temperaturas equivalentes}

O procedimento para avaliação de condições de conforto térmico utilizando manequins e o conceito de temperatura equivalente requer o equacionamento das trocas de calor entre os diversos segmentos do manequim e o ambiente, a calibração do manequim e a utilização de diagramas de sensação térmica, conforme será visto nos próximos itens.

Para a avaliação de condições de conforto térmico em automóveis este procedimento está normalizado e encontra-se na norma ISO 14505-2 (2004).

\subsection{Equacionamento das trocas de calor}

Para manequins sem sudorese a determinação de temperaturas equivalentes, $t_{\text {eq }}$, é baseada somente na transferência de calor por convecção e radiação, dada por:

$$
\begin{aligned}
& R=h_{r}\left(T_{s}-\bar{T}_{r}\right) \\
& C=h_{c}\left(T_{s}-T_{a r}\right)
\end{aligned}
$$

onde: 
$\mathrm{C}=$ troca de calor por condução

$\mathrm{R}=$ troca de calor por radiação

$h_{r}=$ coeficiente de transferência de calor por radiação

$h_{c}=$ coeficiente de transferência de calor por convecção

$\mathrm{T}_{\mathrm{S}}=$ temperatura da superfície

$\bar{T}_{r}=$ temperatura radiante média

$\mathrm{T}_{\mathrm{ar}}=$ temperatura do ar ambiente
$\left[\mathrm{W} / \mathrm{m}^{2}\right]$

$\left[\mathrm{W} / \mathrm{m}^{2}\right]$

$\left[\mathrm{W} / \mathrm{m}^{2 \mathrm{o}} \mathrm{C}\right]$

$\left[\mathrm{W} / \mathrm{m}^{2 \mathrm{o}} \mathrm{C}\right]$

$\left[{ }^{\circ} \mathrm{C}\right]$

$\left[{ }^{\circ} \mathrm{C}\right]$

Uma vez que as trocas de calor por convecção e radiação ocorrem simultaneamente, a temperatura equivalente, $\mathrm{T}_{\mathrm{eq}}$, é função destas trocas de calor e é dada por:

$$
T_{e q}=T_{s}-\frac{\dot{Q}}{h}
$$

onde:

$\dot{Q}=\mathrm{R}+\mathrm{C}=$ troca de calor por radiação e convecção

$\mathrm{T}_{\mathrm{eq}}=$ temperatura equivalente

$\mathrm{T}_{\mathrm{s}}=$ temperatura da superfície

$\mathrm{h}=$ coeficiente de transferência de calor combinado, convecção e radiação $\left[\mathrm{W} / \mathrm{m}^{2 o} \mathrm{C}\right]$

\subsubsection{Procedimento de calibração do manequim}

Para se aplicar o conceito de temperatura equivalente o manequim precisa ser calibrado em um ambiente térmico padrão com as mesmas vestimentas e na mesma posição que será usado para avaliar o ambiente térmico em estudo. As vestimentas afetam o coeficiente de transferência de calor sensível e, portanto, devem ser escolhidas adequadamente para a situação ambiental a ser avaliada e devem ser mantidas durante todo o processo de avaliação.

O procedimento de calibração consiste na determinação de coeficientes de transferência de calor combinado, h, da Equação (3.5), para os diversos segmentos do corpo em um ambiente padrão. Para satisfazer o conceito de temperatura equivalente, o ambiente padrão é um ambiente homogêneo com temperatura de bulbo seco igual à 
temperatura radiante média, $\mathrm{T}_{a r}=\bar{T}_{r}$, e com velocidade do ar próximo de zero $(\mathrm{V}<0,1 \mathrm{~m} / \mathrm{s})$. Nestas condições tem-se: $\mathrm{T}_{a r}=\bar{T}_{r}=\mathrm{T}_{\mathrm{eq}}$.

Uma vez satisfeitas estas condições em ensaio realizado em câmara climatizada e obtidas condições de regime permanente nas trocas de calor do manequim com o ambiente, são realizadas leituras de temperaturas superficiais, $\mathrm{T}_{\mathrm{s}}$, e de fluxo de calor, $\dot{Q}$, para cada segmento do corpo e calculados valores de coeficientes de troca de calor, $\mathrm{h}_{\mathrm{cal}}$, que são os coeficientes de troca de calor da calibração, dados pela equação:

$$
h_{c a l}=\frac{\dot{Q}}{T_{s}-T_{e q}}
$$

Os valores de coeficientes de transferência de calor da calibração, $h_{c a l}$, serão os valores de coeficiente de troca de calor, $h$, da Equação 3.5 no cálculo das temperaturas equivalentes no ambiente real.

Uma vez calibrado o manequim para a posição e vestimenta do ensaio real, o método de avaliação consiste em posicionar o manequim no ambiente real e medir os fluxos de calor e as temperaturas superficiais de cada segmento. Por meio da Equação 3.5 é possível determinar a $t_{\text {eq }}$ para cada segmento ou para o corpo todo utilizando os valores de $\mathrm{h}_{\text {cal }}$ da calibração e os novos valores de $\dot{Q}$ e $\mathrm{T}_{\text {s. }}$.

$$
T_{e q}=T_{s}-\frac{\dot{Q}}{h_{c a l}}
$$

As temperaturas equivalentes assim determinadas são indicadores do nível de afastamento entre as condições do ambiente e as condições correspondentes a uma sensação térmica de neutralidade.

\subsubsection{Diagramas de sensação térmica}

Para se avaliar quão distantes as condições do ambiente se encontram de condições correspondentes a uma sensação térmica de neutralidade, a norma ISO 14505-2 (2004) apresenta diagramas para avaliação de $T_{\text {eq }}$, em função da sensação térmica, para manequim com 16 segmentos (Fig. 3.3). 

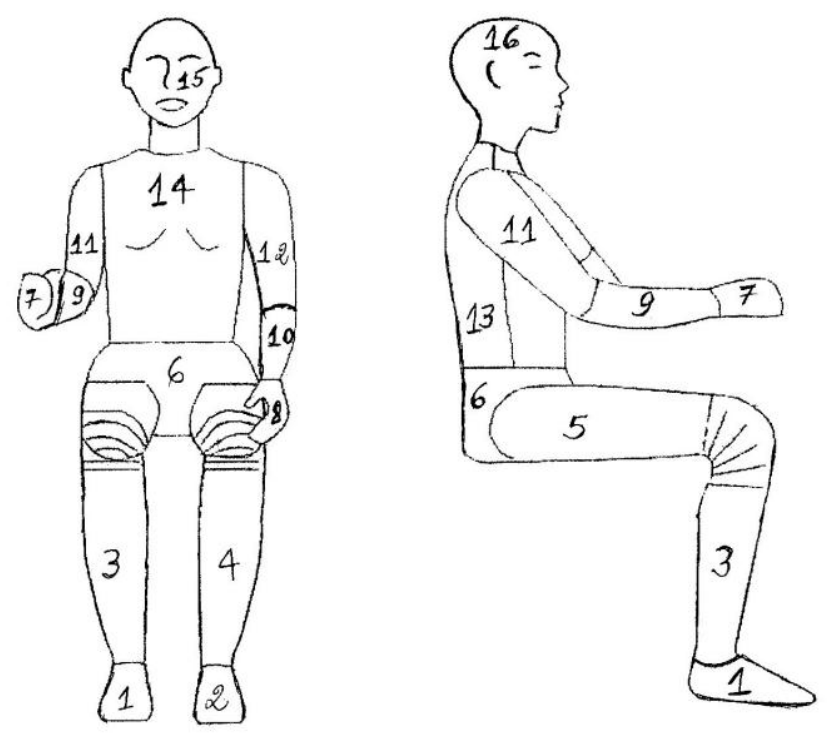

Figura 3.3 Manequim com 16 segmentos

Os diagramas apresentados na norma ISO 14505-2 (2004) se referem a uma condição de verão, com o sistema de climatização operando na condição de resfriamento e pessoas usando roupas leves com clo igual a 0,6 (Fig. 3.4) e a uma condição de inverno, com o sistema operando na condição de aquecimento e pessoas usando roupas pesadas com clo igual a 1,0 (Fig. 3.5).

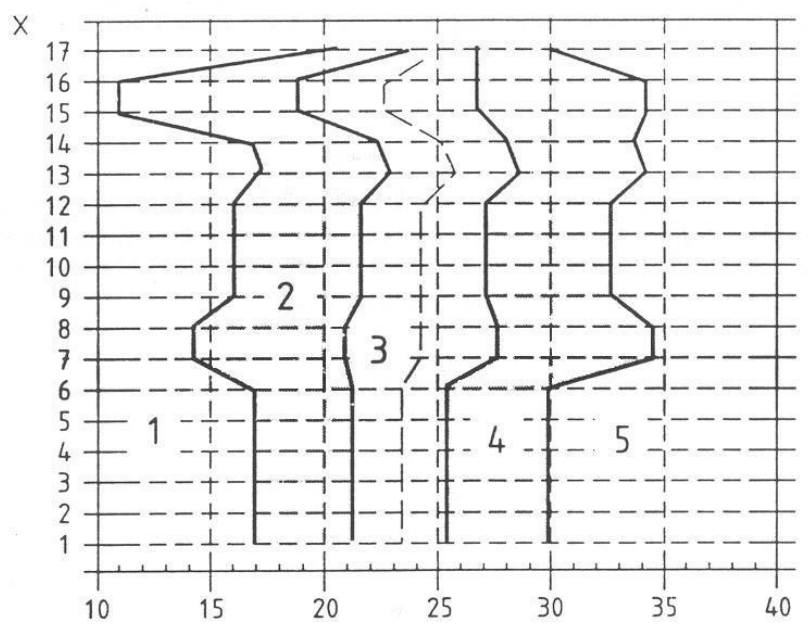

Figura 3.4 Diagrama para avaliação de $\mathrm{T}_{\mathrm{eq}}$ em função da sensação térmica: condição de verão, resfriamento (ISO 14505-2,2004). 


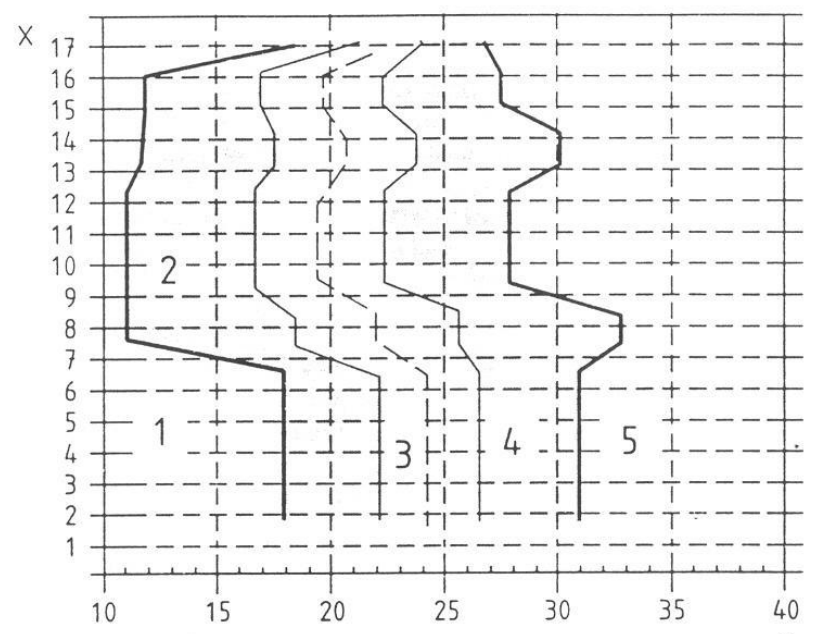

Figura 3.5 Diagrama para avaliação de $\mathrm{T}_{\mathrm{eq}}$ em função da sensação térmica: condição de inverno, aquecimento (ISO 14505-2, 2004).

Os valores de Y nas Figuras 3.4 e 3.5 correspondem às temperaturas equivalentes, $\mathrm{T}_{\text {eq }}$, e os valores de $\mathrm{X}$ aos segmentos do corpo (manequim). $\mathrm{O}$ segmento 17 corresponde à $\mathrm{T}_{\text {eq }}$ para o corpo como um todo. Os números 1 a 5 representam as faixas de sensação térmica, conforme apresentado na Tabela 3.1 , onde 1 representa sensação de frio, 2 levemente frio, 3 neutro, 4 levemente quente e 5 quente

Tabela 3.1 Escala de sensação térmica da norma ISO 14502-2 (2004).

\begin{tabular}{|c|c|c|c|c|}
\hline \multicolumn{5}{|c|}{ Escala de sensação térmica } \\
\hline $\mathbf{1}$ & $\mathbf{2}$ & $\mathbf{3}$ & $\mathbf{4}$ & $\mathbf{5}$ \\
\hline Frio & Levemente frio & Neutro & Levemente quente & Quente \\
\hline
\end{tabular}




\section{Capítulo 4}

\section{O LABORATÓRIO E DETALHES DO MOCK-UP}

A maioria dos estudos experimentais de conforto em cabines de aeronaves estão sendo realizados em mock-ups de uma seção da cabine ou em aeronaves paradas simulando condições de escoamento em vôo. Isto porque estudos experimentais em condições reais de vôo, quando conduzidos com razoável resolução espacial para obtenção de resultados confiáveis, são extremamente caros (Zhang e Chen, 2007).

A utilização de mock-ups instrumentados possibilita uma flexibilidade maior no controle e configuração de experimentos, uma vez que se está em solo e o pesquisador terá a autonomia de modificar as condições de testes de forma a atingir o objetivo requerido, sem custos tão elevados; o que não ocorreria em vôo.

Neste capitulo são apresentados o laboratório e o mock-up construído para a realização do trabalho.

\subsection{Configuração do laboratório}

Uma das etapas do presente trabalho consistiu na elaboração do projeto e instalação do mock-up de forma a aproveitar a estrutura já existente no laboratório de conforto térmico do Departamento de Engenharia Mecânica da Escola Politécnica da USP (EPUSP), que possui:

$>$ um chiller

$>$ um fan-coil

$>$ um sistema de exaustão e renovação de ar

$>$ um sistema de controle e automação, responsável pelo controle da climatização do ambiente de testes.

que eram utilizados para a realização de trabalhos de avaliação de conforto térmico em ambientes de escritório (Figs. 4.1 e 4.2), com insuflamento de ar pelo piso ou pelo teto. 


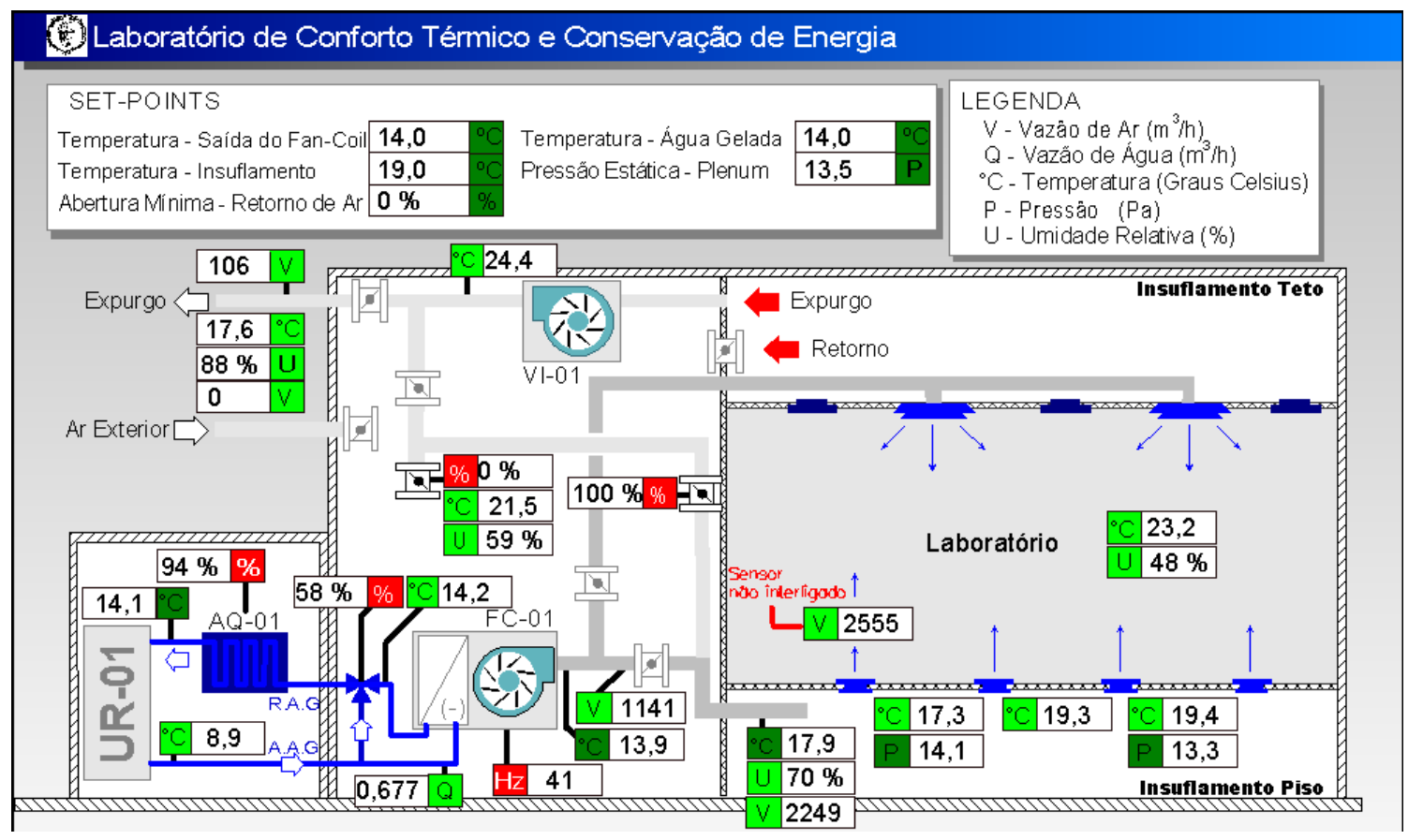

Figura 4.1. Tela do sistema de controle, mostrando o chiller, a sala do fan-coil e o ambiente de testes (Leite, 2003).

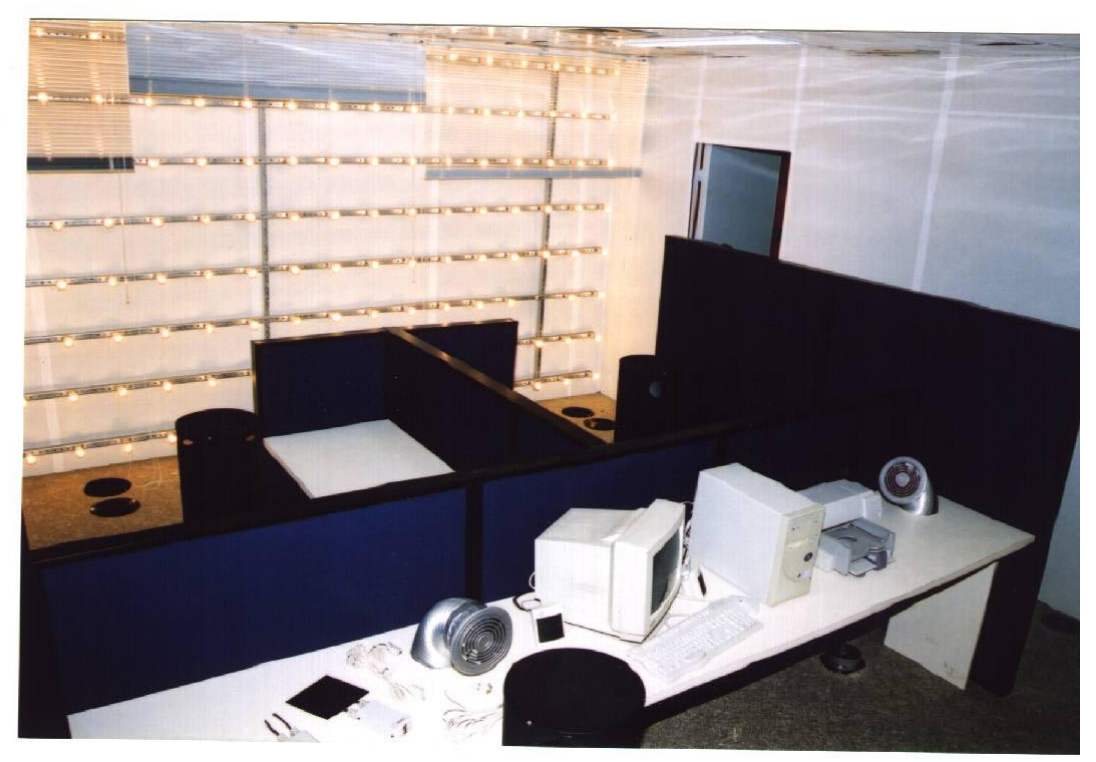

Figura 4.2. Ambiente de testes antes da instalação do mock-up (Leite e Tribess, 2001)

\subsection{Ambiente de testes}

Para a alimentação de ar na cabine do mock-up o laboratório foi modificado de forma a atender as necessidades de insuflamento e retorno do ar. Devido à configuração inicial do laboratório, também foi necessário realocar um sensor de temperatura do sistema de controle, instalado no centro geométrico do laboratório, para o interior da cabine do 
mock-up. Este sensor foi instalado de forma a, se necessário, ser facilmente recolocado na sua posição original.

A Figura 4.3 mostra o fluxograma de distribuição e circulação do ar na cabine. Por meio dessa figura é possível verificar que o ar proveniente do fan-coil é levado até o bin (bagageiro), que funciona como um plenum, e dos bins este ar é insuflado na cabine. $\mathrm{O}$ retorno é executado pela parte inferior lateral que expurga o ar para o laboratório, de onde é retirado através de um sistema de exaustão e renovação de ar, para voltar a ser resfriado no fan-coil e insuflado no mock-up.

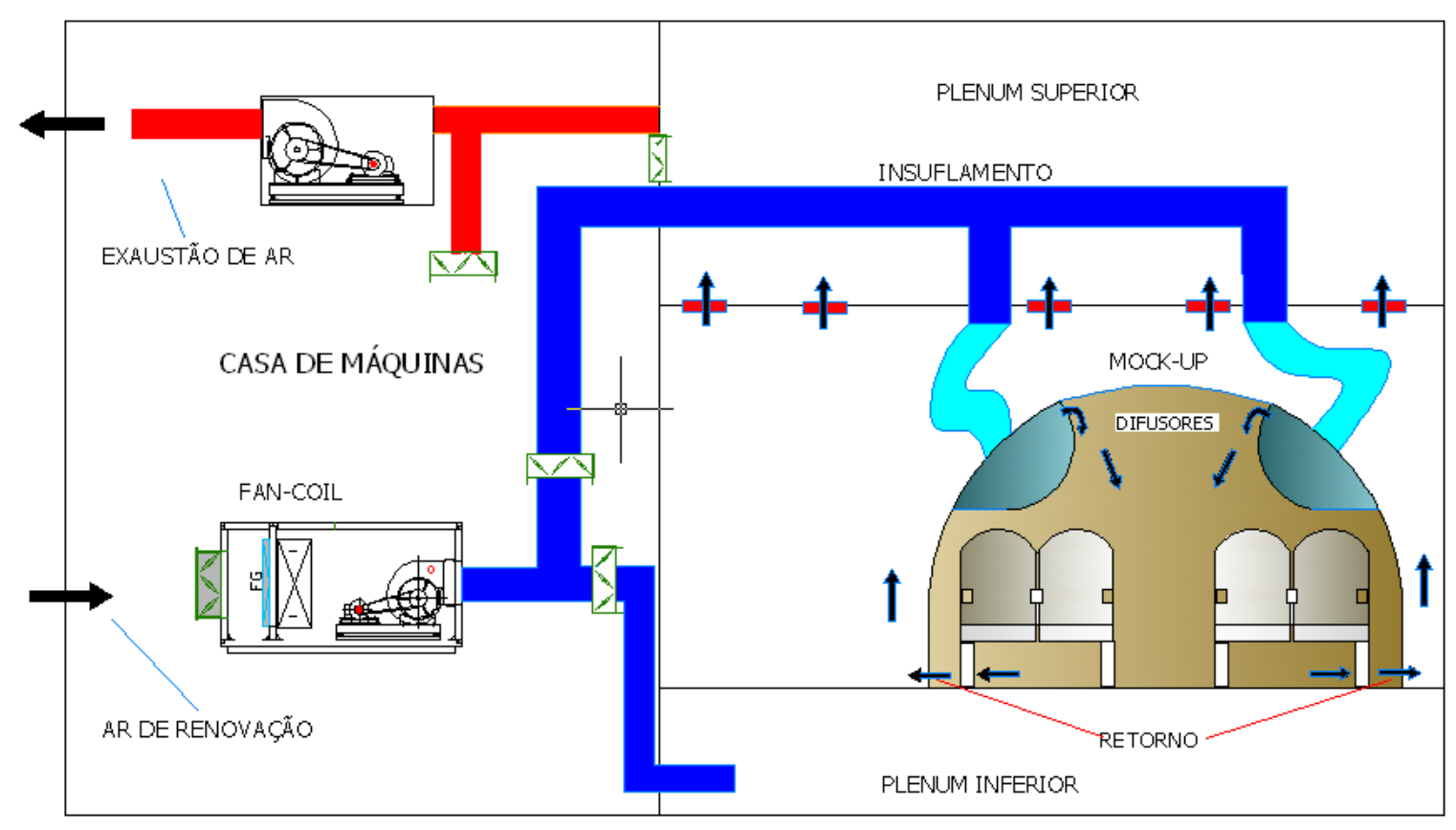

Figura 4.3 Fluxograma do ar da cabine do mock-up

No Laboratório também foi instalada uma câmara para calibração do manequim térmico, conforme apresentado na Figura 4.4. Esta câmara é de forma cúbica com 1,80 m de lado e permite reproduzir ambiente padrão para aplicação do conceito de temperatura equivalente, com a temperatura do ar, $\mathrm{T}_{\mathrm{ar}}=\bar{T}_{r}$, temperatura radiante média e velocidade do ar, $\operatorname{Var} \approx 0 \mathrm{~m} / \mathrm{s}$ (insuflamento pelo piso).

Conforme pode ser verificado na Figura 4.4, o laboratório possui ainda um aparelho de ar condicionado tipo split no interior do ambiente de testes. Este aparelho possibilita que o ambiente externo ao mock-up seja resfriado durante os ensaios. Há também a possibilidade de se aquecer um dos lados do mock-up, por meio de um painel de lâmpadas que simulam carga térmica de radiação solar. 


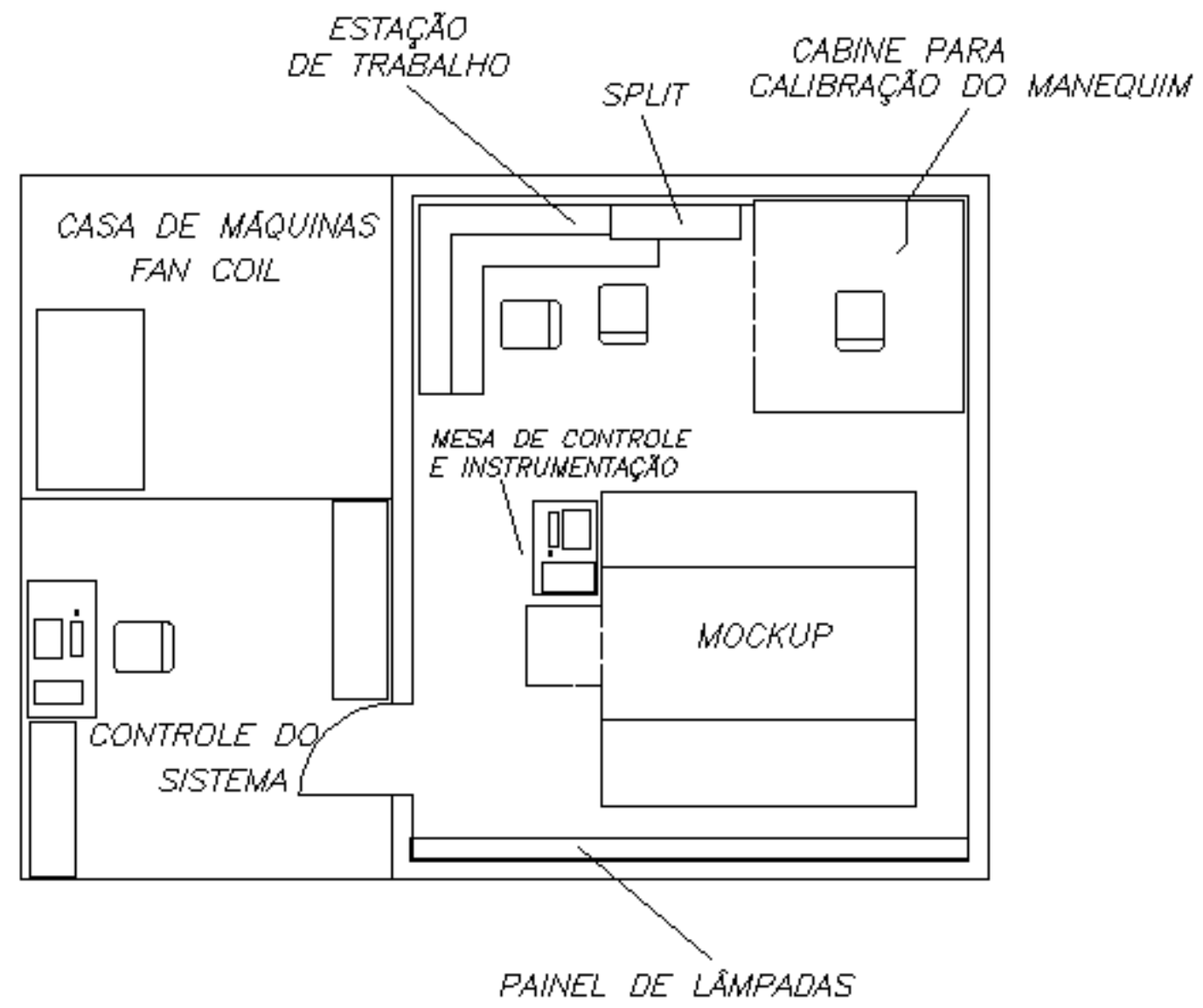

Figura 4.4 Planta baixa do laboratório após modificações

\subsection{Projeto e configuração do mock-up}

O mock-up foi projetado com 12 lugares, distribuídos em três fileiras de quatro assentos. As dimensões aproximadas são 3 × 3 × 2,5m de altura. O insuflamento de ar é realizado pela parte superior e lateral dos bins e o retorno pela parte inferior lateral (Fig. 4.5), com possibilidade de insuflamento pelo piso. Na Figura 4.6 é possível observar a porta de entrada da cabine, assim como uma visão geral externa do mock-up. Na Figura 4.7 é apresentada uma visão interna da cabine. 


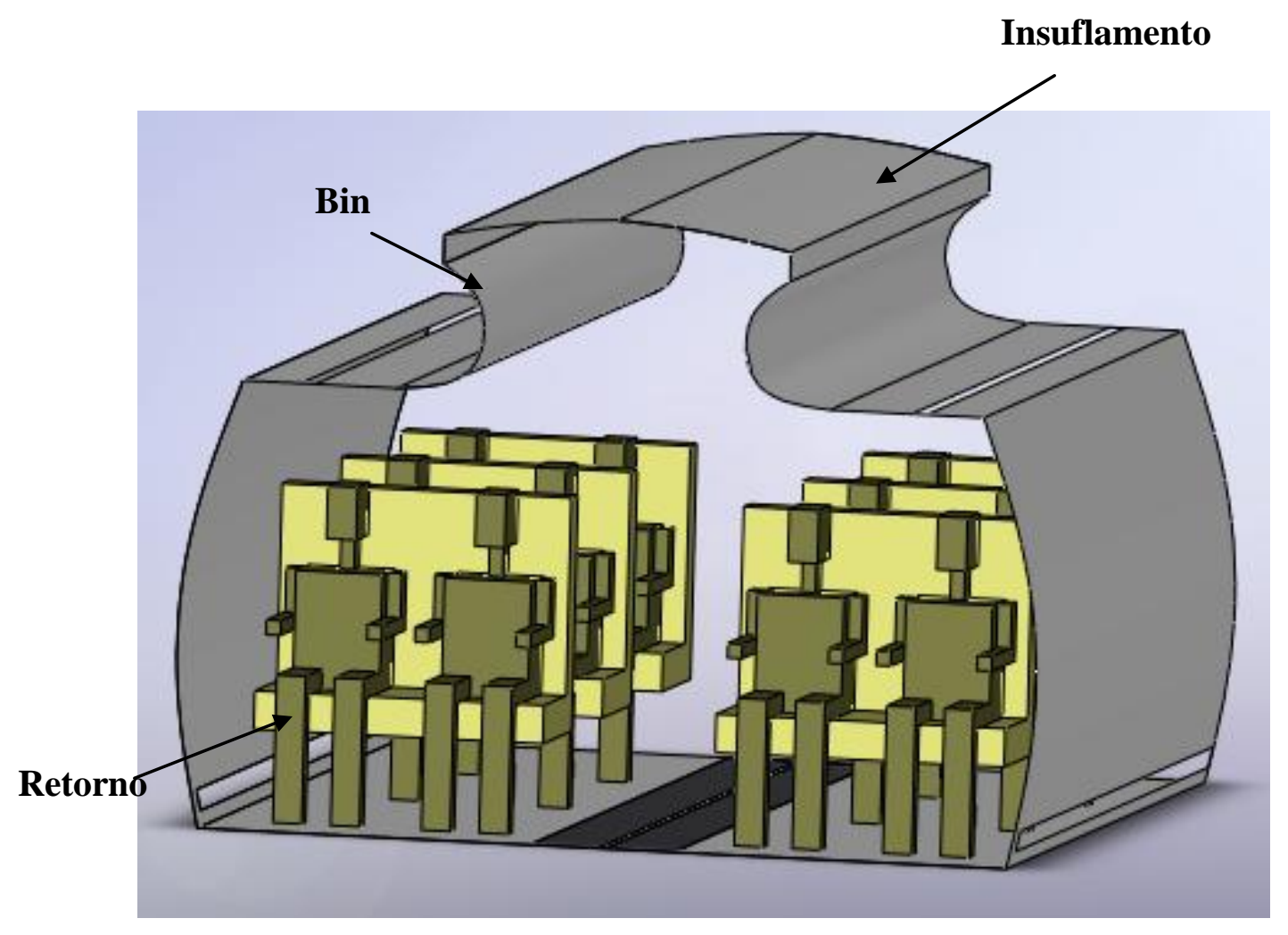

Figura 4.5 Configuração do mock-up.

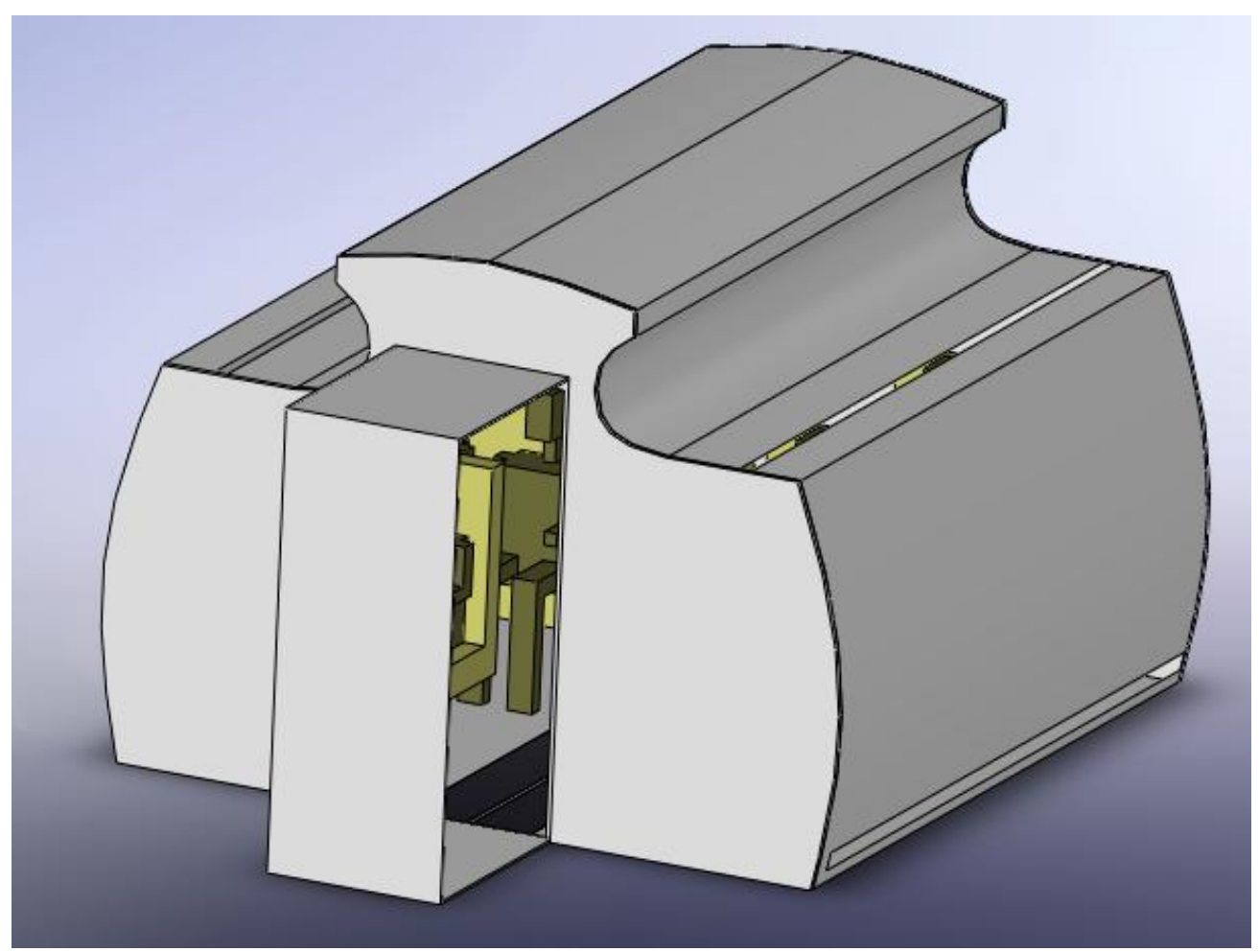

Figura 4.6 Vista esquemática exterior do mock-up mostrando o módulo de entrada 


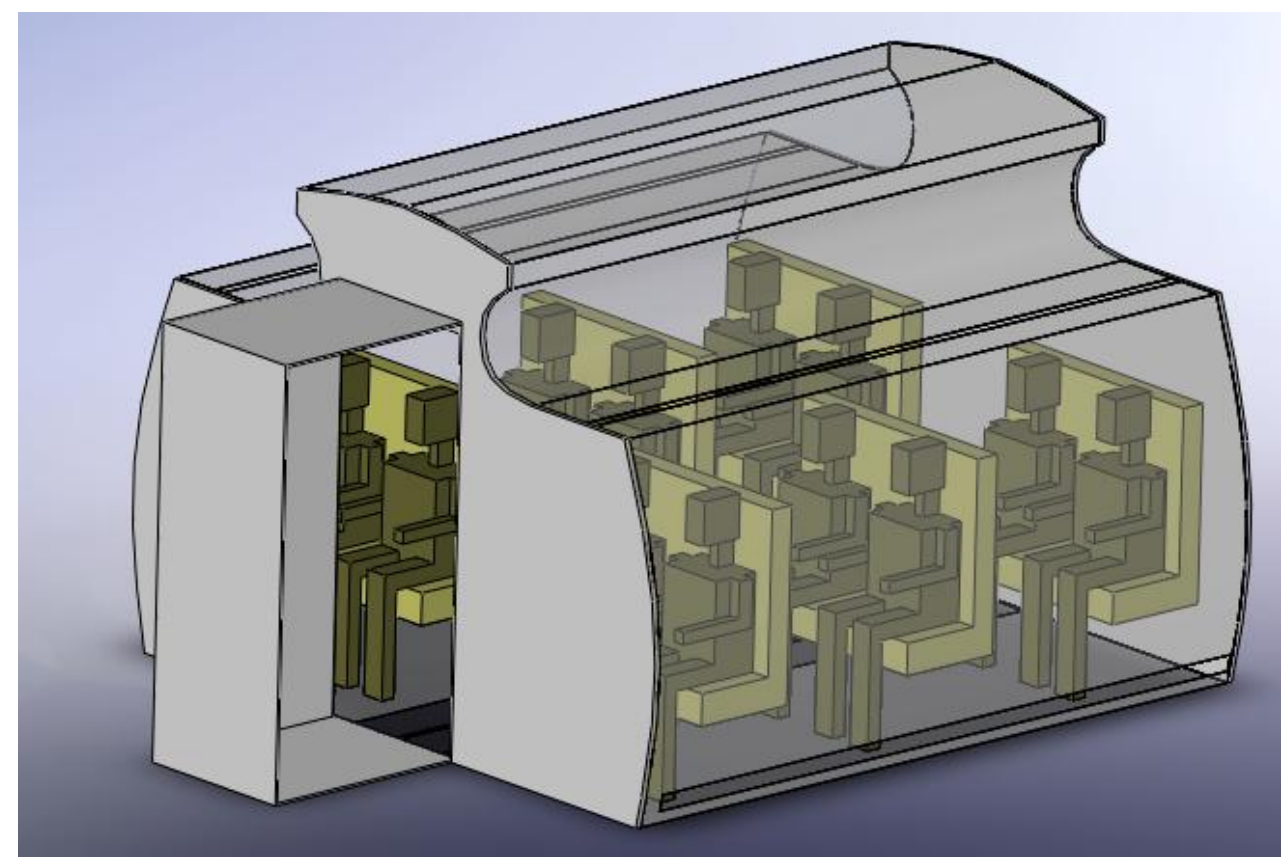

Figura 4.7 Vista esquemática do interior do mock-up

Procurou-se construir o mock-up de forma a que seu interior representasse adequadamente o interior de uma aeronave (Fig 4.8). Para isso, as curvas internas de bins e paredes foram construídas em tubo de aço estrutural e chapa metálica, com acabamento interno em revestimento melamínico e tecido automotivo.

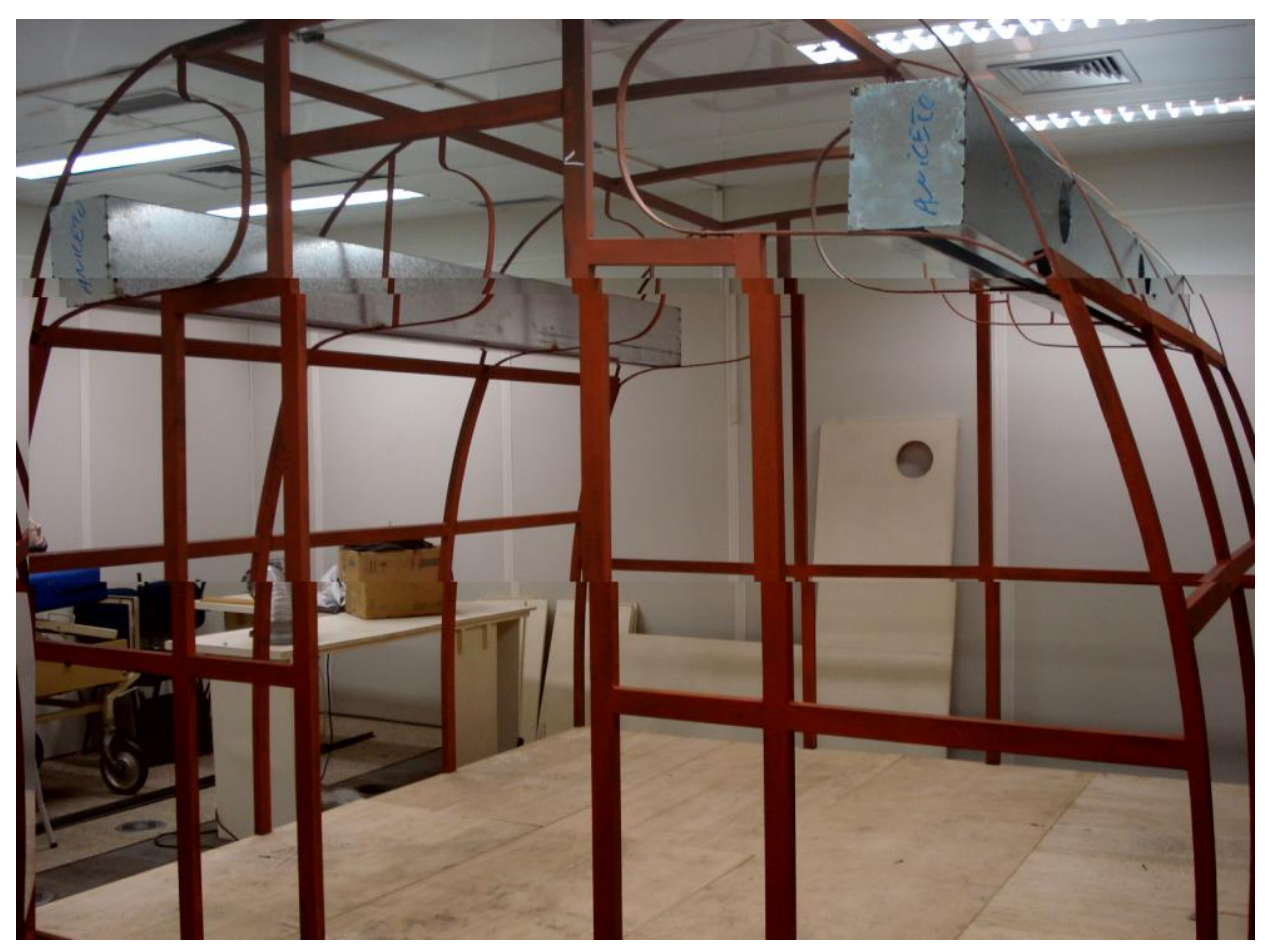

Figura 4.8 Detalhe da estrutura metálica do mock-up 
Os bancos utilizados são de aeronave comercial (Fig. 4.9). O piso foi confeccionado em madeira devido ao fácil manuseio, uma vez que ele deverá ter flexibilidade para alterações futuras quanto à utilização de configuração de insuflamento pelo piso. Na Figura 4.10 é apresentado detalhe da estrutura metálica parcialmente chapeada.

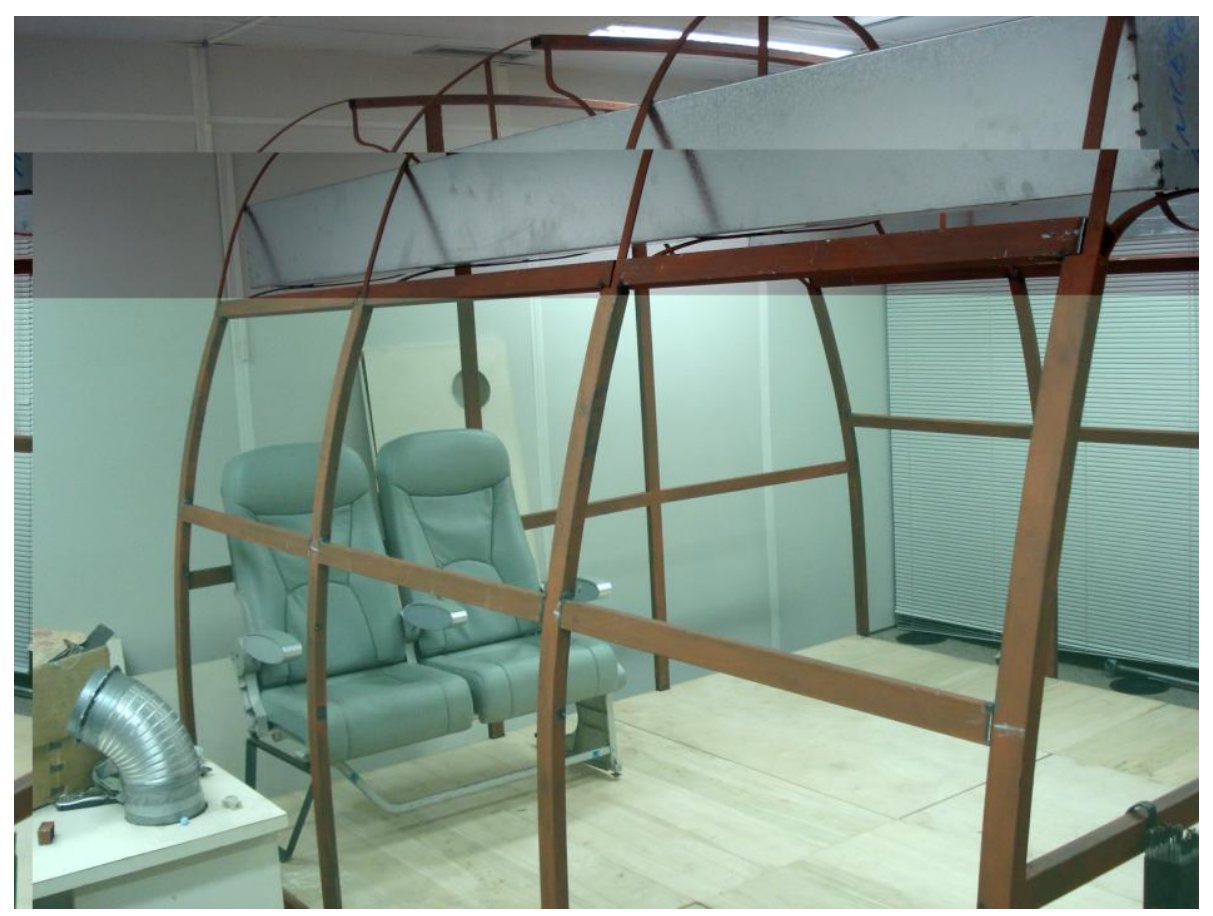

Figura 4.9 Detalhe da estrutura metálica do mock-up e do banco

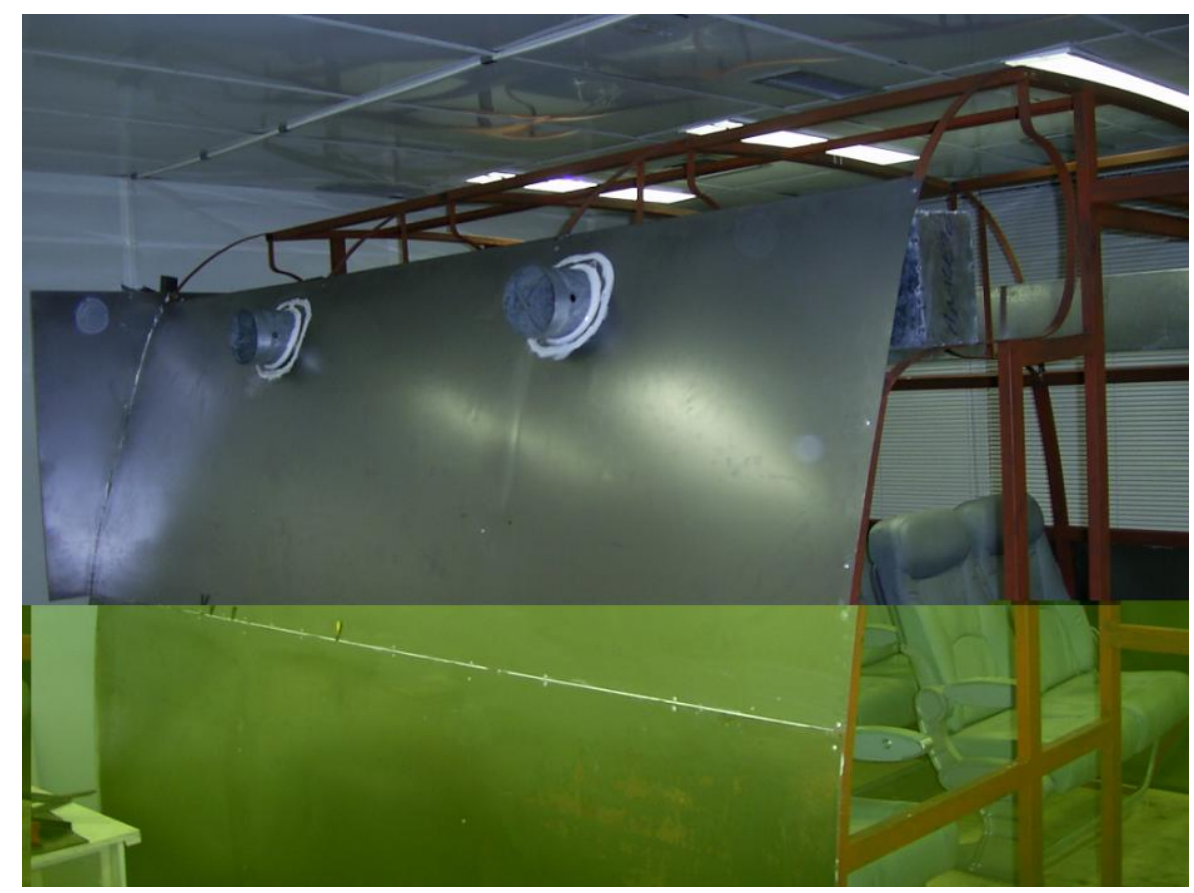

Figura 4.10 Detalhe da estrutura metálica parcialmente chapeada 
As Figuras 4.11 e 4.12 mostram detalhes da parte externa do mock-up e os dutos de alimentação de ar para a cabine. Estes dutos possuem dampers para a regulagem da vazão de ar.

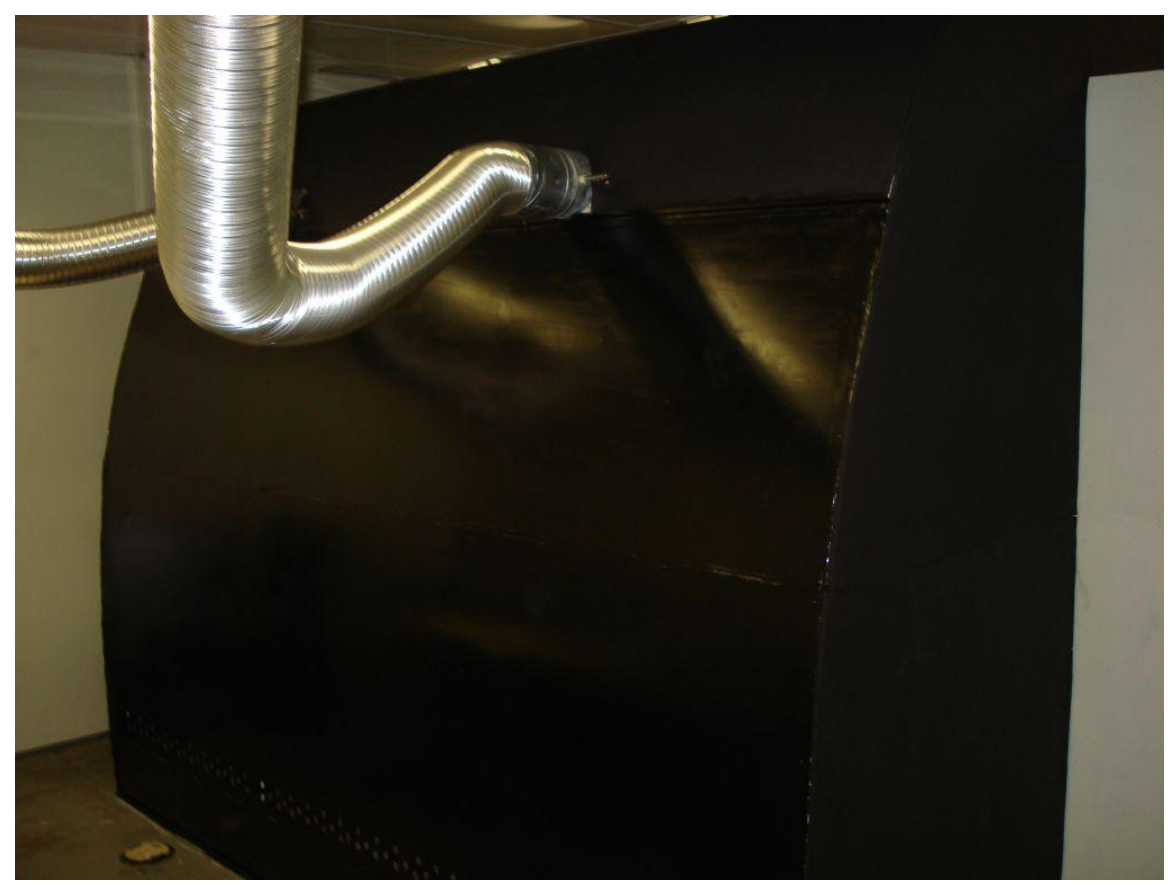

Figura 4.11 Detalhe da parte externa do mock-up e dutos de alimentação de ar

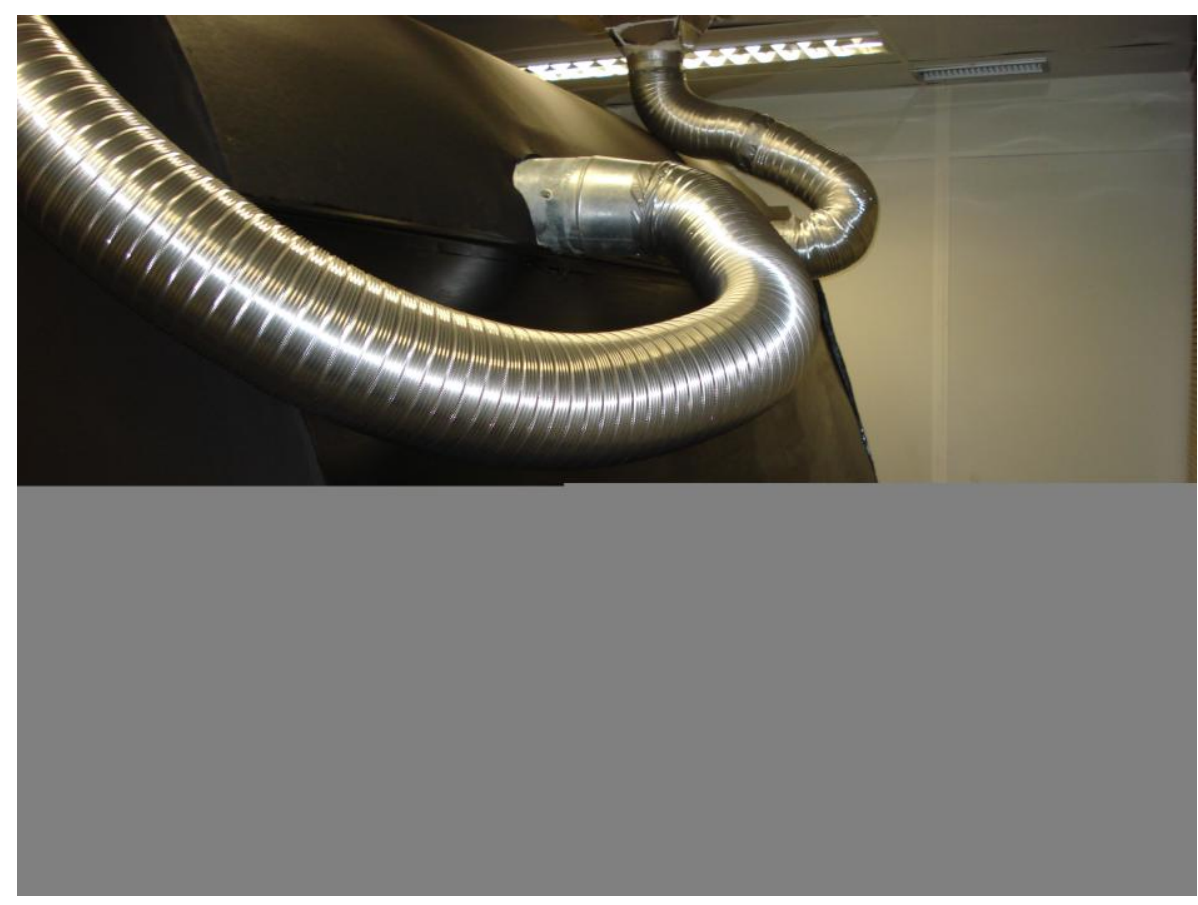

Figura 4.12 Detalhe da parte externa do o mock-up e dutos de alimentação de ar 
A seguir são apresentados detalhes do interior deste mock-up. Na Figuras 4.13 e 4.14 são mostrados detalhes referentes aos difusores de insuflamento na parte superior e do retorno do ar na parte inferior do mock-up, respectivamente.

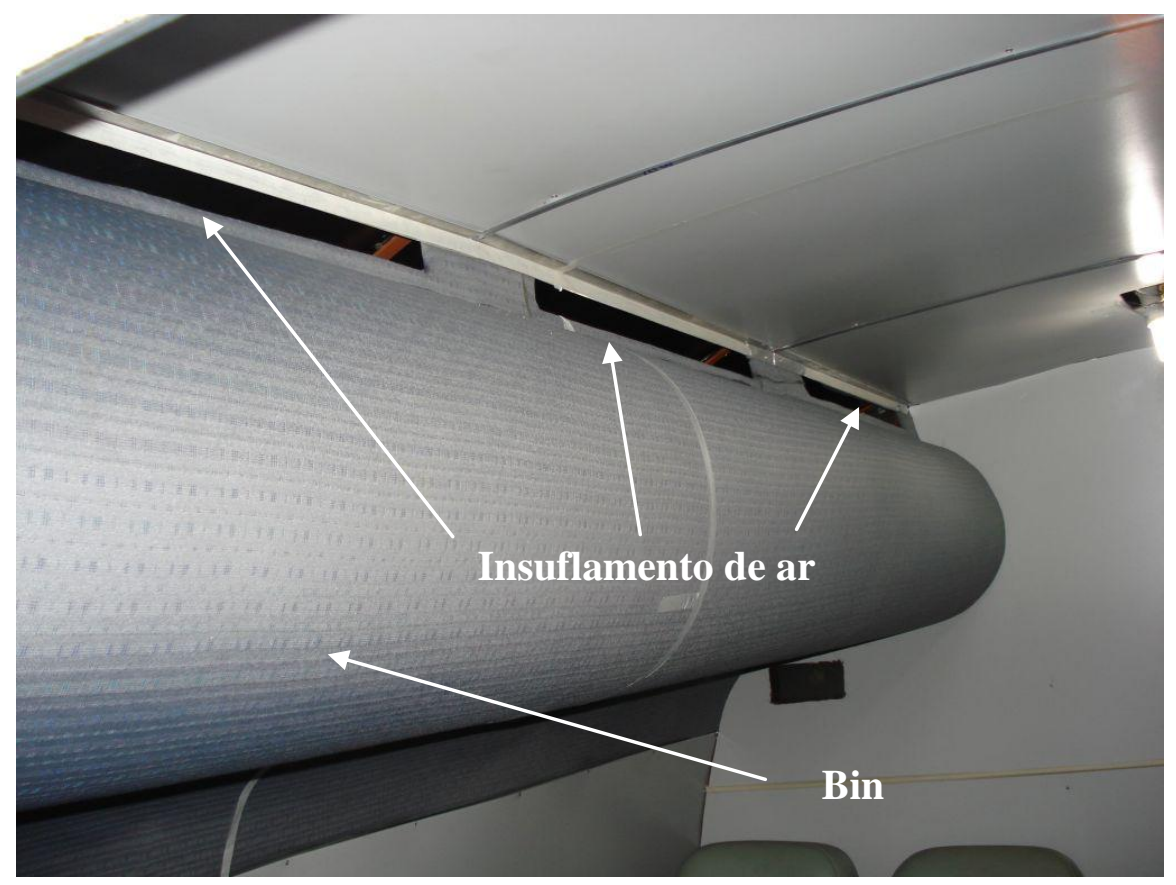

Figura 4.13 Detalhes do bin e de difusores de ar do mock-up

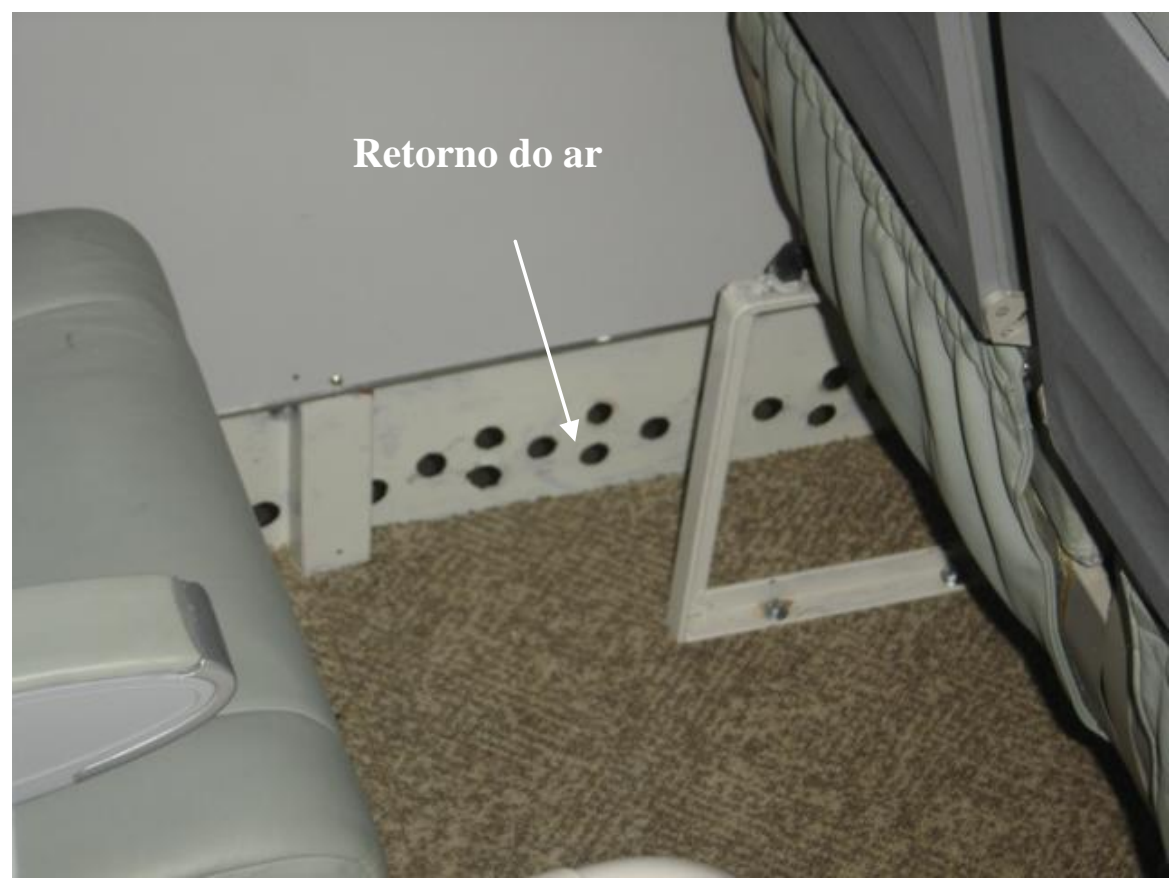

Figura 4.14 Detalhes do retorno de ar 
Na Figura 4.15 é apresentada uma visão geral da parte interior do mock-up, com inclusão de um manequim instrumentado. Na Figura 4.16 é mostrada a cabine ocupada por manequins aquecidos.
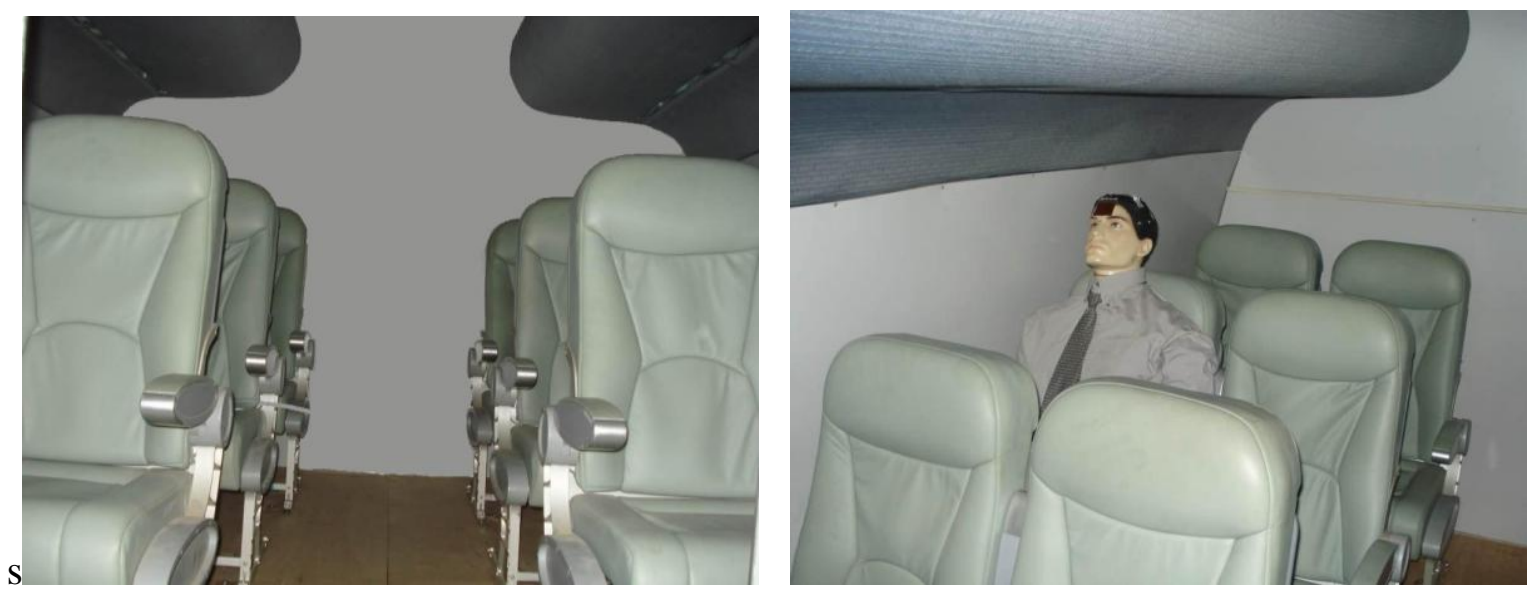

Figura 4.15 Vistas internas do mock-up instalado, mostrando as poltronas, o bin e um manequim instrumentado.

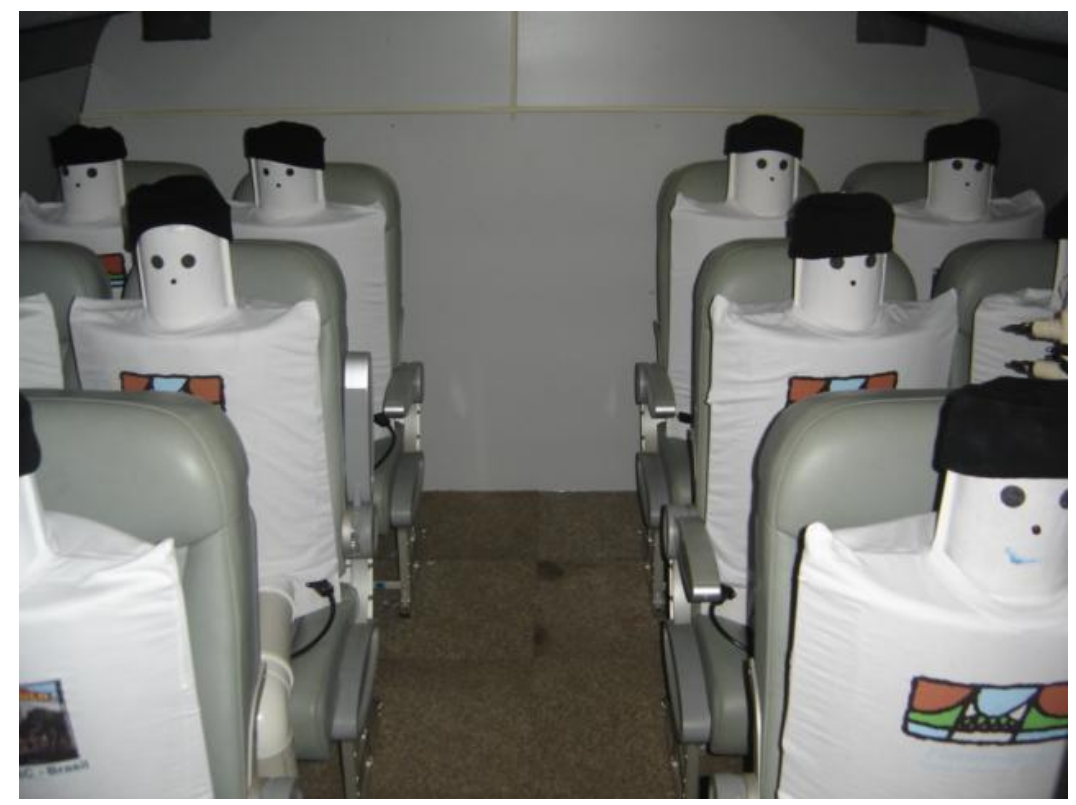

Figura 4.16 Vista do mock-up com manequins aquecidos 
Capítulo 5

\section{AVALIAÇÃO EXPERIMENTAL DO ESCOAMENTO E DE CONFORTO TÉRMICO EM}

CABINE DE AERONAVE

Neste capítulo são apresentados os métodos utilizados na avaliação experimental de conforto térmico e do escoamento no interior da cabine do mock-up construído para a realização do trabalho. Também são apresentados os equipamentos e instrumentos utilizados.

\subsection{Condições de teste}

Com o objetivo de analisar duas condições distintas de cabine na avaliação de conforto térmico pelo júri e com manequim térmico instrumentado, os ensaios foram executados considerando-se duas temperaturas de cabine, medidas no retorno do ar no centro do lado direito da cabine:

1) Temperatura de $24^{\circ} \mathrm{C} \pm 0,5^{\circ} \mathrm{C}$.

2) Temperatura de $19^{\circ} \mathrm{C} \pm 0,5^{\circ} \mathrm{C}$.

Embora a umidade do ar seja uma variável ambiental importante em cabines de aeronaves, principalmente em vôos de longa duração em que costuma assumir valores muito baixos, a influência desta variável não foi possível de ser analisada, pois foi utilizada instalação que foi projetada inicialmente para avaliação de condições de conforto térmico em ambientes de escritórios climatizados, com umidade relativa do ar em torno de 40 a $50 \%$.

\subsection{Levantamento de variáveis do escoamento.}

O mock-up construído possui 12 lugares. Para a medição das variáveis do escoamento todas as poltronas foram ocupadas por manequins aquecidos e foram utilizados pedestais com sensores de velocidade e temperatura, com a possibilidade de medição em quatro alturas. Dois pedestais com sensores nas alturas de 0,$1 ; 0,6 ; 0,9$ e 
1,10m (pessoa sentada) foram colocados na posição central das poltronas, um de cada lado. Um terceiro pedestal foi posicionado no corredor central da mesma fileira com os sensores nas alturas de 0,$6 ; 1,1 ; 1,7 \mathrm{~m}$ (pessoa em pé), conforme mostrado na Figura 5.1. Os manequins aquecidos foram programados com uma dissipação de $70 \mathrm{~W}$ correspondentes à taxa de liberação de calor sensível de uma pessoa sentada em atividade leve (ASHRAE, 2005).

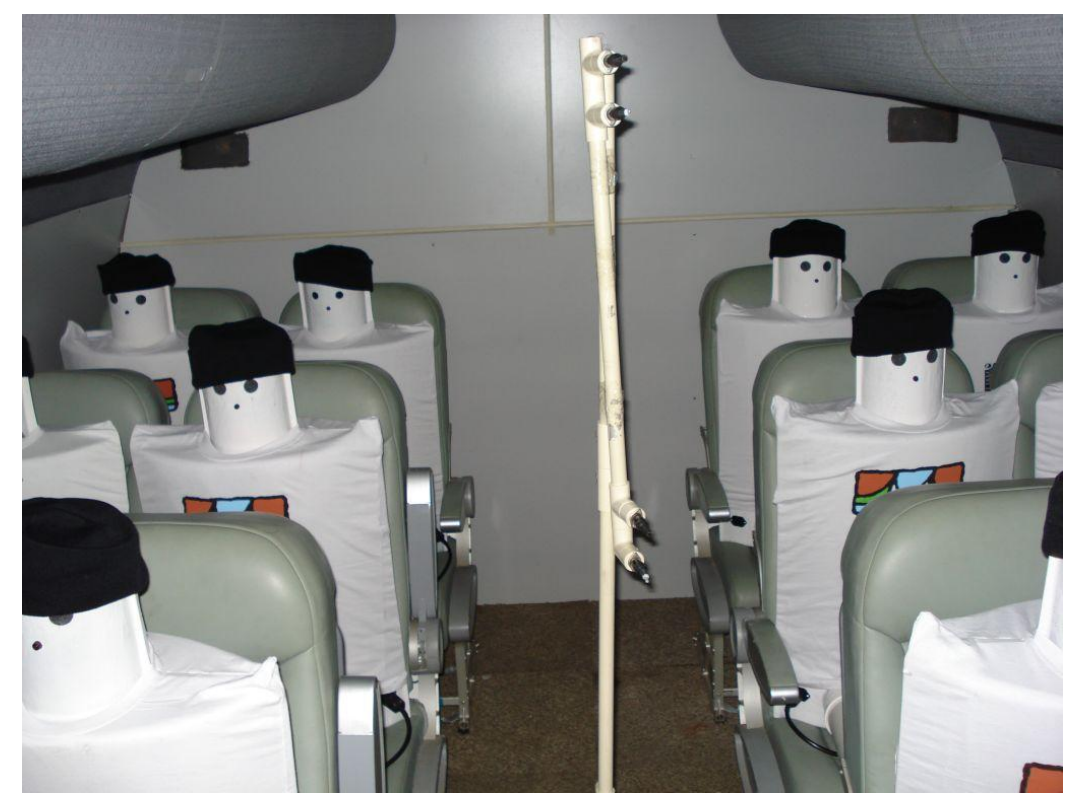

Figura 5.1- Posicionamento dos manequins aquecidos e de um dos pedestais no mock-up.

\subsubsection{Instrumentos de medição}

Os sensores para medição de velocidade do ar são do tipo omnidirecional (fio quente). Para medição de temperaturas foram utilizados termômetros de resistência PT100 A Figura 5.2 mostra um par de sensores para medição de velocidade e de temperatura do ar.

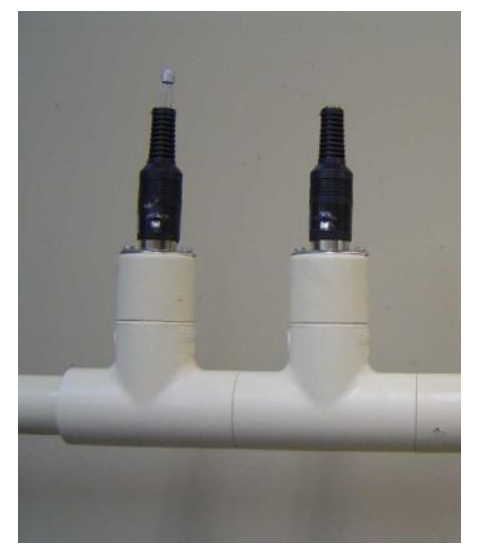

Figura 5.2 - Sensores de temperatura e de velocidade do ar. 
Os sensores de temperatura e velocidade do ar são conectados a um sistema de aquisição de dados, conectado ao computador, que realiza a aquisição dos dados em intervalos de 1 minuto. Além de medições de temperatura e velocidade do ar, foram realizadas medições de umidade do ar, utilizando sensor capacitivo. A Tabela 5.1 apresenta as características dos instrumentos que foram utilizados nas medições.

Tabela 5.1 Características dos instrumentos de medição

\begin{tabular}{|l|c|c|}
\hline \multicolumn{1}{|c|}{ Quantidade } & Faixa de medição & Precisão \\
\hline Temperatura do ar, ${ }^{0} \mathrm{C}$ & 10 a 40 & $\pm 0,5{ }^{\circ} \mathrm{C}$ \\
\hline Velocidade do ar, $\mathrm{m} / \mathrm{s}$ & 0 a 1 & $\pm\left(0,04+3 \% \mathrm{~V}_{\mathrm{ar}}\right)$ \\
\hline Umidade do ar, $\%$ & 20 a $90 \%$ & $\pm 3 \%$ \\
\hline
\end{tabular}

\subsubsection{Especificações e características dos manequins aquecidos}

Os manequins aquecidos são construídos em fibra de vidro e PVC, com forma semelhante a um corpo humano sentado, conforme mostrado na Figura 5.3. Internamente existe um dispositivo que libera calor e um ventilador que propicia uma distribuição uniforme de temperatura ao longo de toda a superfície. A potência é controlável via software, podendo variar de 30 a $120 \mathrm{~W}$.

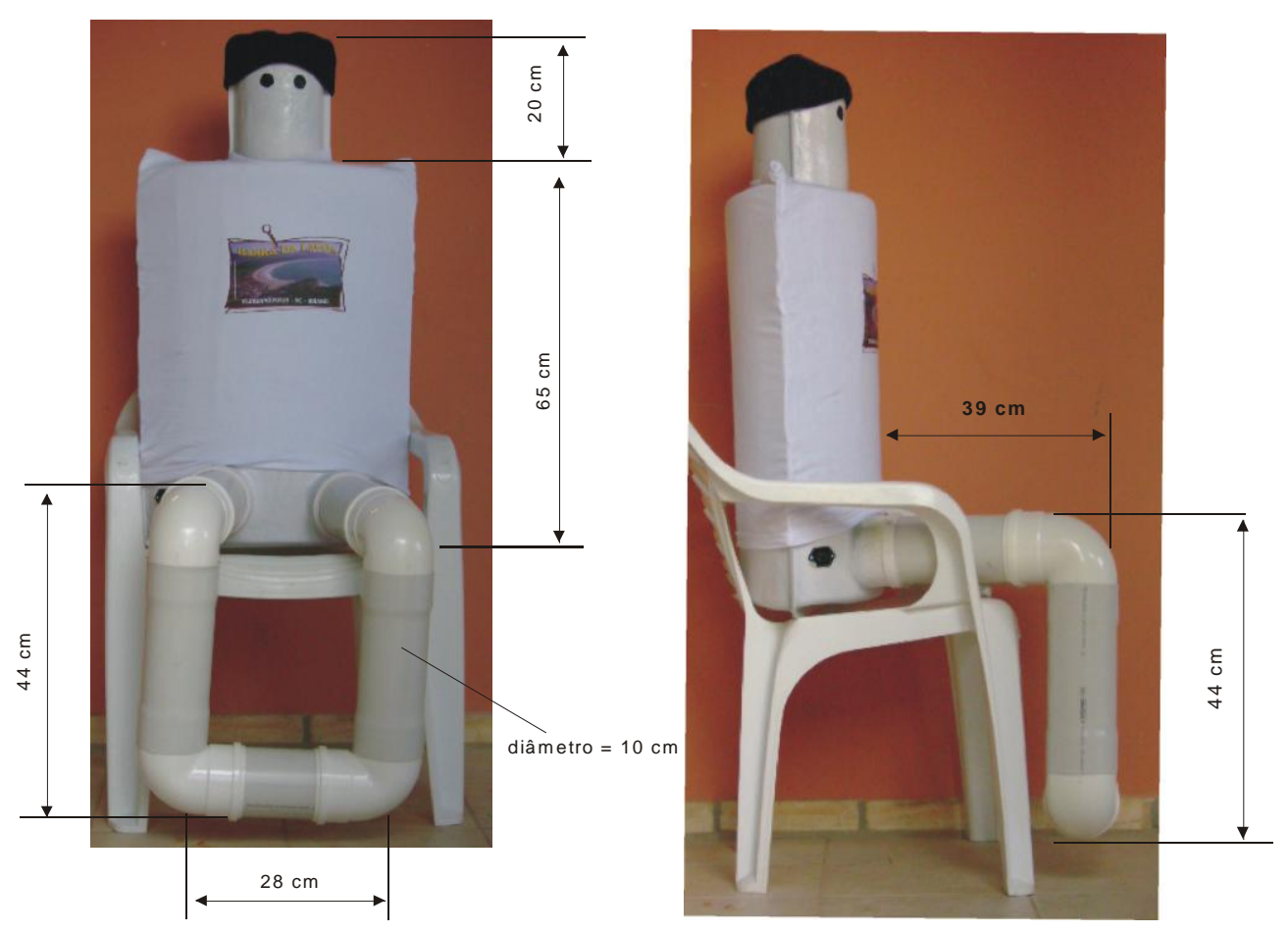

Figura 5.3 - Vista esquematizada do manequim aquecido 
O manequim é acoplado a uma unidade de potência, conectada a um computador via porta serial. Vários manequins podem ser interligados por um cabo tripolar.

\subsection{Medições com manequim térmico instrumentado}

Após a definição do escoamento, um manequim térmico instrumentado foi posicionado na fileira do meio para o levantamento de temperaturas equivalentes. Foram realizadas medições, com o manequim térmico instrumentado, na poltrona do corredor.

Durante os ensaios as seguintes variáveis foram medidas:

$>$ Umidade relativa do ar

$>$ Temperatura do ar na cabine

$>$ Temperaturas superficiais nos segmentos do manequim

$>$ Fluxos de calor nos segmentos do manequim

O fluxo de calor e temperatura superficial dos segmentos do manequim térmico foram medidos por meio de sensores posicionados na superfície de cada segmento do manequim.

\subsubsection{Especificações e características do manequim térmico instrumentado}

O manequim térmico instrumentado foi confeccionado em material siliconado, articulado, com proporções similares a um corpo humano adulto (1,77 $\mathrm{m}$ de altura), composto por 21 regiões de análise, conforme descrito na Tabela 5.2 e mostrado na Figura 5.4 .

Cada seção pode ser controlada de forma independente, via software, de 03 maneiras distintas:

$>$ modo temperatura constante (regulável de 25 a $40{ }^{\circ} \mathrm{C}$ )

$>$ modo potência constante (regulável de 30 a $120 \mathrm{~W} / \mathrm{m}^{2}$, em intervalos de $\left.2 \mathrm{~W} / \mathrm{m}^{2}\right)$

modo equação de conforto (correlacionando diferentes variáveis)

O manequim possui aquecimento e medição de temperaturas superficiais distribuídos em toda a zona de análise, tendo como um importante diferencial o fato da fiação de aquecimento ser independente da fiação de medição. Dessa forma tem-se a medição da temperatura média, contribuindo para a redução da incerteza global. 
O manequim é conectado a um módulo de controle através de um cabo tipo Flat, que por sua vez é conectado a um computador via cabo serial.

Tabela 5.2 - Localização das regiões de análise do manequim (segmentos)

\begin{tabular}{|c|l|}
\hline Seção & \multicolumn{1}{|c|}{ Localização } \\
\hline 1 & pé direito \\
\hline 2 & pé esquerdo \\
\hline 3 & canela direita \\
\hline 4 & canela esquerda \\
\hline 5 & coxa direita frontal \\
\hline 6 & coxa direita posterior \\
\hline 7 & coxa esquerda frontal \\
\hline 8 & coxa esquerda posterior \\
\hline 9 & mão direita \\
\hline 10 & mão esquerda \\
\hline 11 & braço direito \\
\hline 12 & braço esquerdo \\
\hline 13 & antebraço direito \\
\hline 14 & antebraço esquerdo \\
\hline 15 & nádegas \\
\hline 16 & pélvis \\
\hline 17 & peito \\
\hline 18 & costas inferior \\
\hline 19 & costas superior \\
\hline 20 & face direita \\
\hline 21 & face esquerda \\
\hline
\end{tabular}
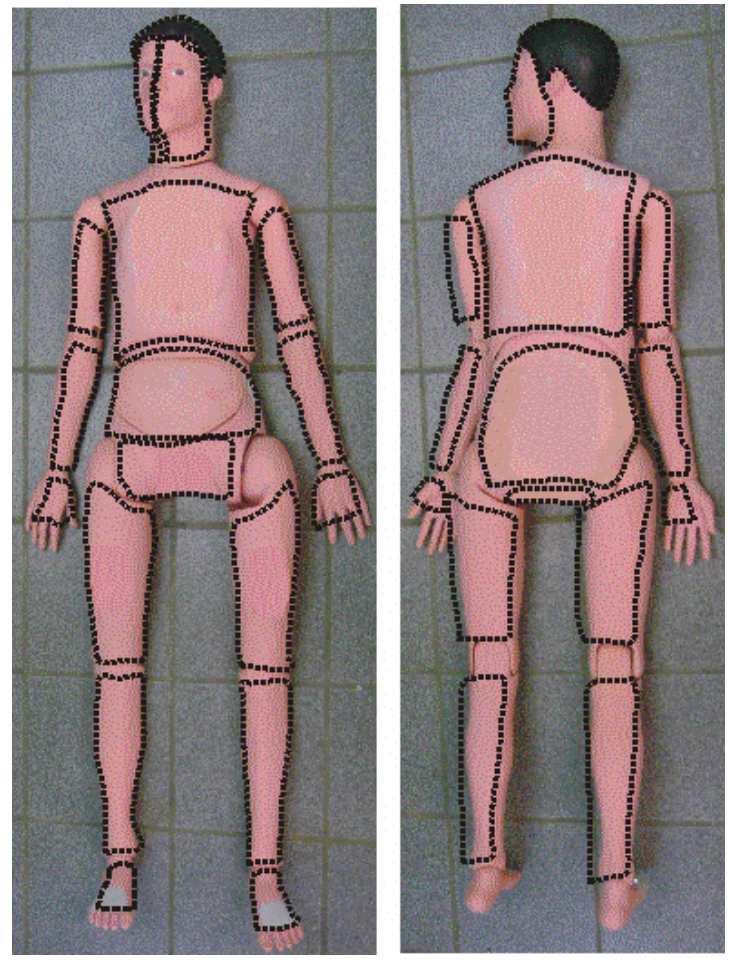

Figura 5.4 - Detalhes do manequim térmico 
O software de aquisição roda em sistema Windows, onde pode ser selecionado o modo de funcionamento (potência, temperatura ou equação), e visualizados os valores de cada região (segmento), conforme mostrado na Figura 5.5.

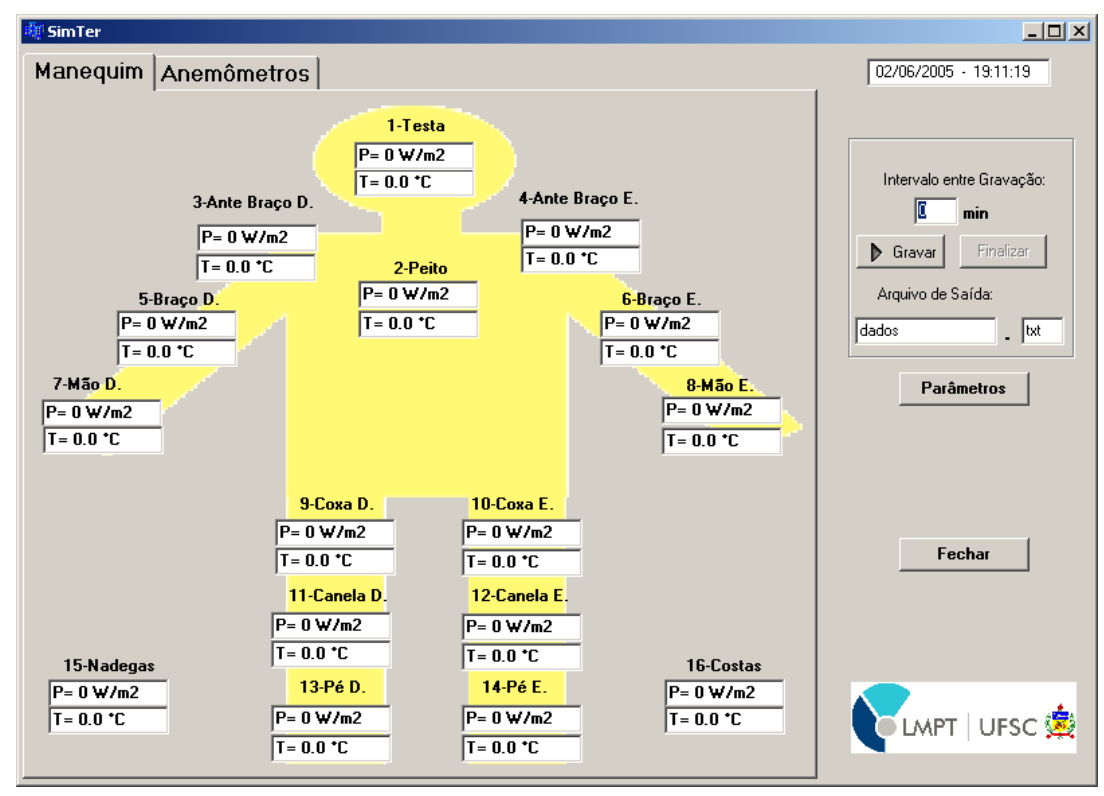

Figura 5.5 - Visualização de segmentos e variáveis medidas

Os dados podem ser registrados no disco rígido em intervalo definido pelo usuário. Os valores registrados são as médias do período. A Tabela 5.4 apresenta as características dos equipamentos de medição do manequim.

Tabela 5.4 Características dos equipamentos de medição do manequim.

\begin{tabular}{|c|c|c|}
\hline Quantidade & Faixa de medição & Precisão \\
\hline Temperatura superficial, ${ }^{\circ} \mathrm{C}$ & 0 a 50 & $\pm 0,2 \mathrm{~K}$ \\
\hline Potência dissipada, $\mathrm{W} / \mathrm{m}^{2-}$ & 30 a 120 & $\pm 3 \%$ \\
\hline
\end{tabular}

\subsubsection{Calibração do manequim térmico}

Inicialmente foi feita a calibração do manequim térmico de acordo com procedimento previsto na norma ISO 14505-2 (2004), apresentado no Capítulo 3. A calibração foi realizada em ambiente climatizado da câmara descrita no item 4.2, com condições controladas, construída para este fim. O manequim foi colocado no ambiente de calibração (Fig. 5.6) com a mesma vestimenta e posição no banco em que seria posteriormente colocado no mock-up para teste. 


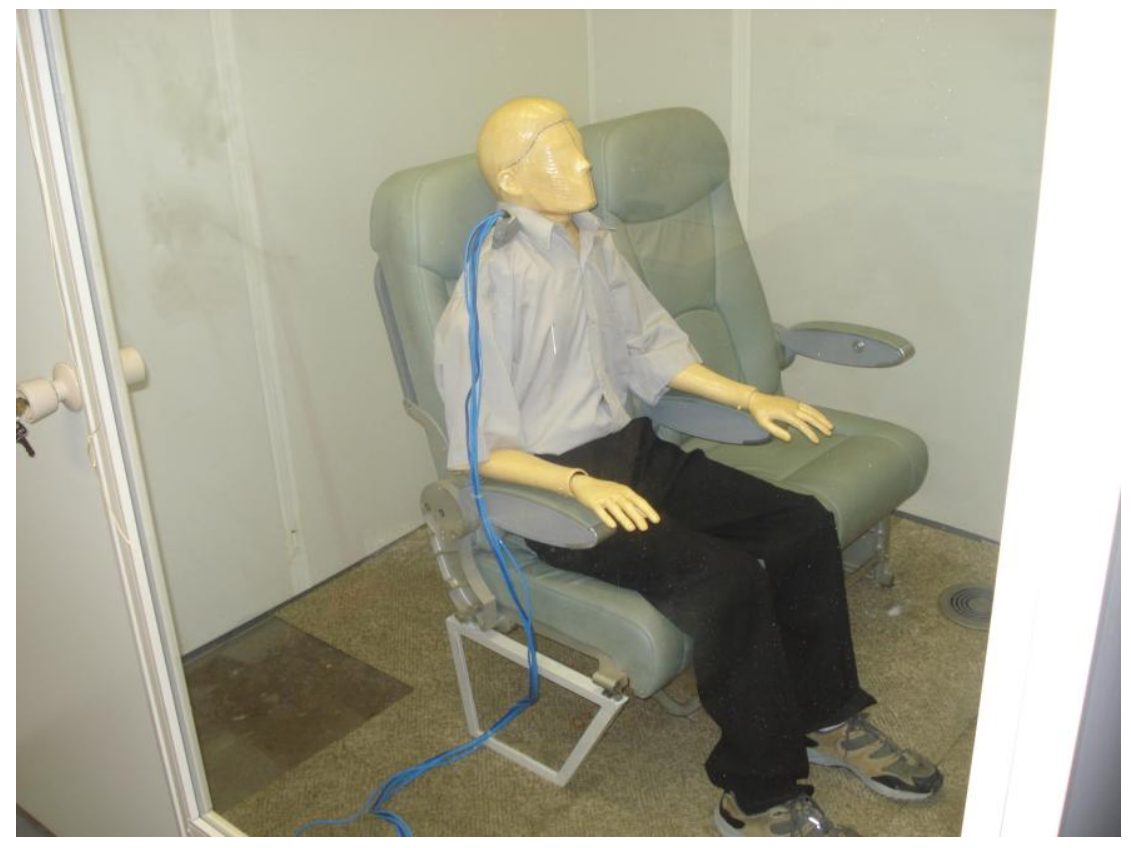

Figura 5.6 Manequim térmico na câmara de calibração

A temperatura da câmara foi monitorada durante os ensaios, bem como a velocidade, que permaneceram nos valores previstos na norma: em torno de $24^{\circ} \mathrm{C}$, com $\mathrm{V}<0,1 \mathrm{~m} / \mathrm{s}$.

A calibração foi executada com o manequim trajando vestimenta com aprox. 0,6 clo, correspondente a uma vestimenta de condições de verão (resfriamento) e fluxo de calor constante de $70 \mathrm{~W} / \mathrm{m}^{2}$ em todos os segmentos, conforme previsto na norma ISO 14505-2 (2004).

Uma vez atingidas condições de regime permanente (tanto do ambiente, quanto da troca de calor no manequim), foram realizadas as medições de temperatura em cada segmento do corpo. Com isso foram obtidos os valores de coeficientes de troca de calor calibrados, $h_{\text {cal }}$, aplicando a Eq. (3.6) (reapresentada aqui):

$$
h_{c a l}=\frac{\dot{Q}}{T_{s}-T_{e q}}
$$

cujos valores são apresentados na Tabela 5.5. 
Tabela 5.5 - Resultados da calibração do manequim.

\begin{tabular}{|c|l|r|c|}
\hline Seção & \multicolumn{1}{|c|}{ Localização } & Area $(\mathbf{m} 2)$ & $\mathbf{h}_{\text {cal }}\left(\mathbf{W} / \mathbf{m}^{\mathbf{2}} \mathbf{C}\right)$ \\
\hline 1 & corpo como todo & 1,1234 & 4,3 \\
\hline 2 & face & 0,0192 & 7,6 \\
\hline 3 & tórax & 0,144 & 3,2 \\
\hline 4 & costas & 0,144 & 2,7 \\
\hline 5 & braço esquerdo & 0,0625 & 3,1 \\
\hline 6 & braço direito & 0,0625 & 4,9 \\
\hline 7 & antebraço esquerdo & 0,0728 & 5,1 \\
\hline 8 & antebraço direito & 0,0728 & 6,0 \\
\hline 9 & mão esquerda & 0,0238 & 9,4 \\
\hline 10 & mão direita & 0,0238 & 9,1 \\
\hline 11 & coxa esquerda & 0,09 & 6,0 \\
\hline 12 & coxa direita & 0,09 & 5,2 \\
\hline 13 & canela esquerda & 0,104 & 6,3 \\
\hline 14 & canela direita & 0,104 & 5,9 \\
\hline 15 & pé esquerdo & 0,044 & 4,1 \\
\hline 16 & pé direito & 0,044 & 3,4 \\
\hline 17 & nádegas & 0,022 & 3,5 \\
\hline
\end{tabular}

\subsection{Avaliação com pessoas}

A avaliação de conforto térmico com pessoas em aeronaves ainda é um vasto campo a ser explorado. Dos trabalhos da literatura verifica-se que apenas Strøm-Tejsen et al. (2005) realizaram avaliações com pessoas em cabine de aeronave.

No presente trabalho o mock-up no qual foi realizada a parte experimental foi pensado e construído de forma a contemplar avaliações com pessoas. Para tanto, na ocasião dos ensaios os manequins aquecidos foram retirados e o mock-up foi ocupado por pessoas.

As condições de ensaio com pessoas são as mesmas daquelas quando da realização de ensaios com o manequim térmico instrumentado. Este procedimento possibilita relacionar temperaturas equivalentes com os votos das pessoas quanto à sensação de conforto nos diversos segmentos do corpo.

As pessoas que participaram do ensaio estavam vestidas com roupas que proporcionam um isolamento térmico referente a 0,6 clo (condição de verão). Cada ensaio teve a duração de duas horas e as pessoas responderam perguntas sobre a 
sensação térmica e desconforto local durante uma hora.

A avaliação subjetiva foi realizada por meio do voto das pessoas segundo critérios definidos na escala de sensação térmica da ISO 14505-3 (2006), apresentada nas Tabelas 5.6 e 5.7. O procedimento de teste e o questionário aplicado também foram baseados na norma ISO 14505-3 (2006) de avaliação de conforto térmico com pessoas em veículos, com algumas alterações em sua configuração. O questionário completo é apresentado no Anexo A.

Tabela 5.6 Escala de sensação térmica da ISO 14505-3 (2006).

\begin{tabular}{|c|c|}
\hline+3 & muito quente \\
\hline+2 & quente \\
\hline+1 & ligeiramente quente \\
\hline 0 & neutro \\
\hline-1 & ligeiramente frio \\
\hline-2 & frio \\
\hline-3 & muito frio \\
\hline
\end{tabular}

Tabela 5.7- Escala de desconforto local da ISO 14505-3 (2006)

\begin{tabular}{|c|c|}
\hline+3 & muito agradável \\
\hline+2 & agradável \\
\hline+1 & ligeiramente agradável \\
\hline 0 & não faz diferença \\
\hline-1 & ligeiramente desagradável \\
\hline-2 & desagradável \\
\hline-3 & muito desagradável \\
\hline
\end{tabular}

A norma ISO 14505-3 (2006) prevê o mínimo de 8 votos realizados em cabines de veículos automotivos para avaliação subjetiva. Em função do pouco tempo disponível para a realização de testes com pessoas, foram realizados testes subjetivos com 11 voluntários do sexo masculino somente. Dos voluntários, 8 já haviam realizado vôos em aeronave comercial. A Figura 5.7 mostra os voluntários posicionados na cabine. 


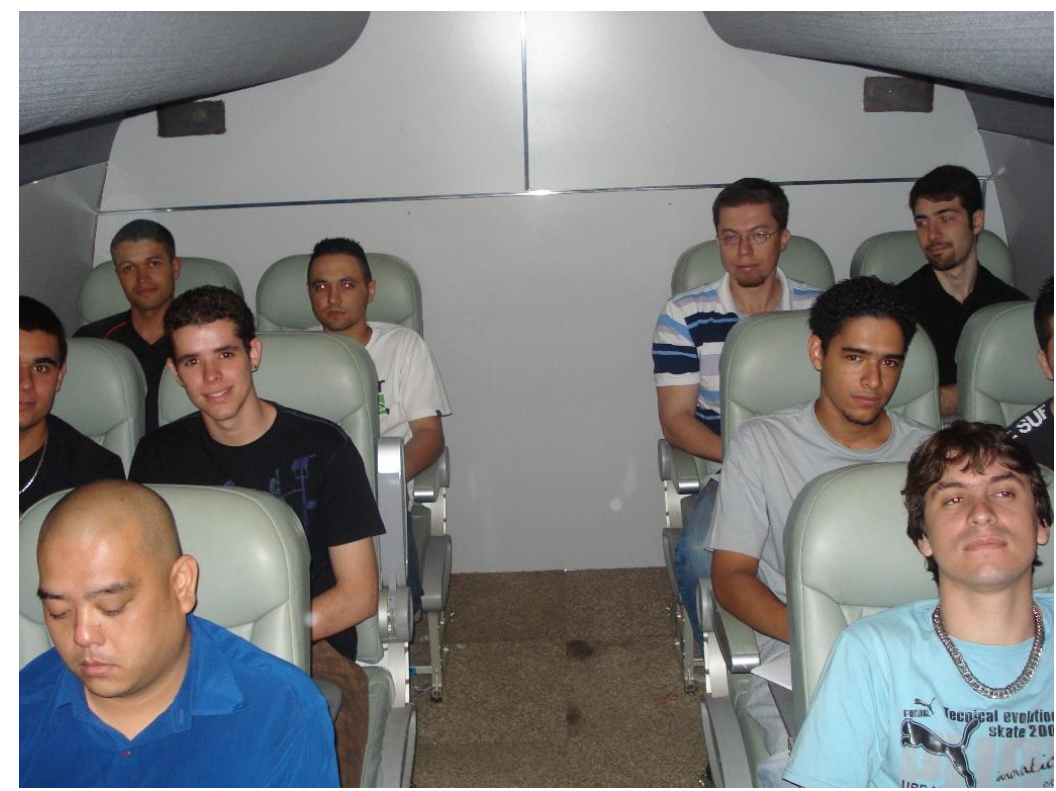

Figura 5.7 - Voluntários posicionados na cabine para testes

Com os votos coletados é possível construir um diagrama que relacione as diferentes partes do corpo com o voto térmico das pessoas. Para tanto é realizada a média aritmética dos votos dados por todos participantes, obtendo-se o voto térmico médio (VTM) para cada segmento do corpo. Este voto é plotado em diagrama de acordo com a escala utilizada no experimento e apresentada na Tabela 5.6.

Procedimento similar é utilizado para a construção de diagrama que relaciona as diferentes partes do corpo com o desconforto local percebido pelas pessoas, o voto de conforto médio (VCM). 


\section{Capítulo 6}

\section{RESULTADOS}

Neste capítulo são apresentados os resultados da avaliação experimental do escoamento do ar no interior da cabine e resultados da avaliação de conforto térmico realizada com manequim térmico instrumentado e com pessoas.

\subsection{Medições de velocidades do ar e determinação das vazões nos difusores}

A cabine do mock-up possui três difusores de ar em cada lado, conforme apresentado no capítulo 4. Para as medições de velocidade os difusores foram numerados, conforme apresentado na Figura 6.1.

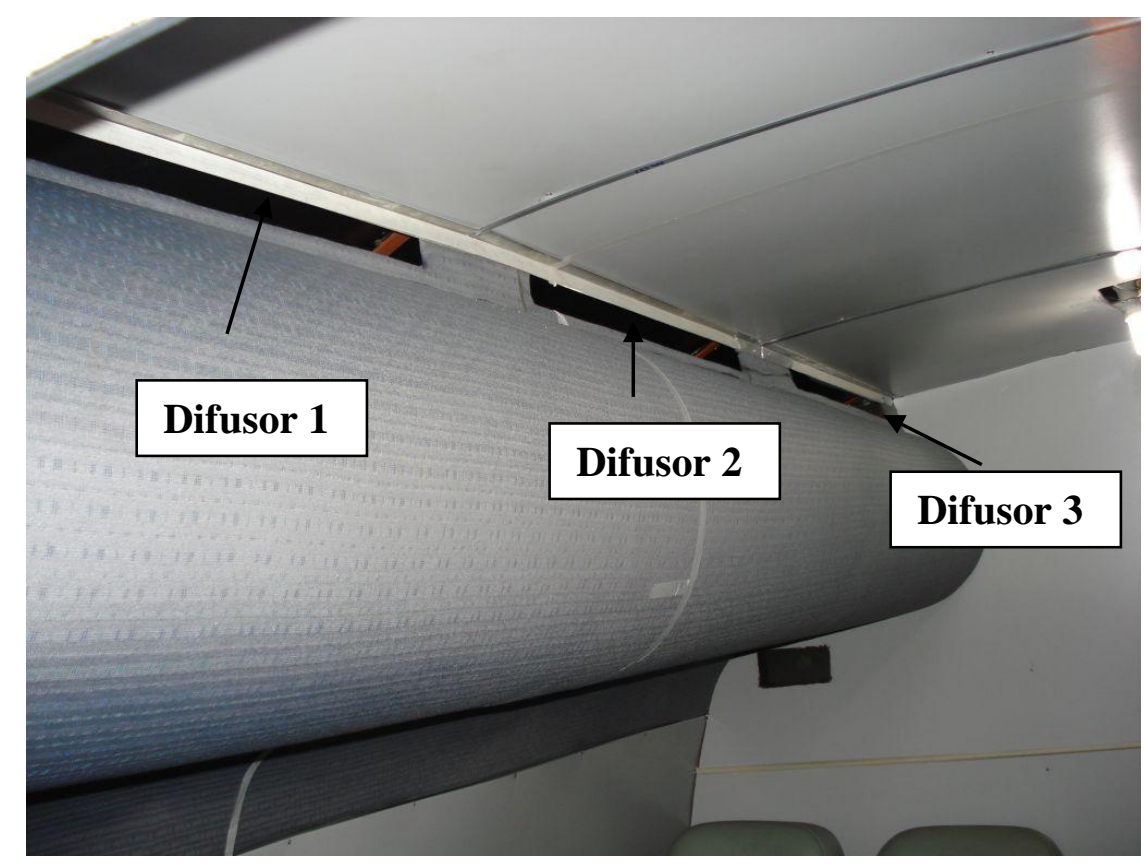

Figura 6.1- Numeração dos difusores para medição de velocidade

As velocidades foram medidas em cada difusor e as vazões calculadas. Para a medição das velocidades a área dos difusores foi dividida em seis partes e com um anemômetro de fio quente as velocidades no centro de cada divisão foram medidas. Com isso, as médias das velocidades dos difusores foram calculadas. 
Para verificação da correta medição das velocidades e respectivas vazões utilizando este procedimento, foram realizadas medições adicionais de velocidades e vazões nos dutos de alimentação dos difusores, utilizando procedimento preconizado na norma ASHRAE 111 (1998).

A Tabela 6.1 apresenta os resultados da vazão em cada difusor e a vazão de ar na cabine.

Tabela 6.1 - Valores de velocidade nos difusores

\begin{tabular}{|c|c|c|c|c|c|}
\hline & \multicolumn{2}{|c|}{ LADO DIREITO } & \multicolumn{2}{|c|}{ LADO ESQUERDO } & \multicolumn{1}{|c|}{ Difusor } \\
\cline { 1 - 4 } & $\begin{array}{c}\text { velocidade } \\
\text { média (m/s) }\end{array}$ & vazão $\mathrm{m}^{3} / \mathrm{h}$ & $\begin{array}{c}\text { velocidade } \\
\text { média }(\mathrm{m} / \mathrm{s})\end{array}$ & vazão $\mathrm{m}^{3} / \mathrm{h}$ & $\begin{array}{c}\text { Vazão na cabine } \\
\left(\mathrm{m}^{3} / \mathrm{h}\right)\end{array}$ \\
\hline 1 & 0,97 & 142,12 & 0,85 & 124,54 & \\
\hline 2 & 1,10 & 161,17 & 0,92 & 135,34 & \\
\hline 3 & 0,97 & 141,39 & 0,85 & 124,54 & \\
\hline Total & & 444,69 & & 384,42 & 829,11 \\
\hline
\end{tabular}

Para a vazão total apresentada na Tabela 6.1 e considerando cabine do mock-up com 12 pessoas, tem-se uma vazão de 19 1/s/pessoa na cabine. Essa vazão atende o critério de vazão mínima estabelecido pela ANSI/ASHRAE 62.1 (2004) de 15 1/s/pessoa em veículos.

\subsection{Perfis de temperatura e velocidade do ar}

A seguir são apresentados perfis de temperatura e velocidade do ar entre as poltronas de todas as fileiras, lado direito e esquerdo, e no corredor, para condição de cabine a $24^{\circ} \mathrm{C}$ e $19{ }^{\circ} \mathrm{C}$. Os lados direito e esquerdo foram considerados, conforme apresentado na Figura 6.2. Os perfis de temperatura e de velocidade do ar são apresentados nas Figuras 6.3 a 6.8 e 6.9 a 6.14 , respectivamente.

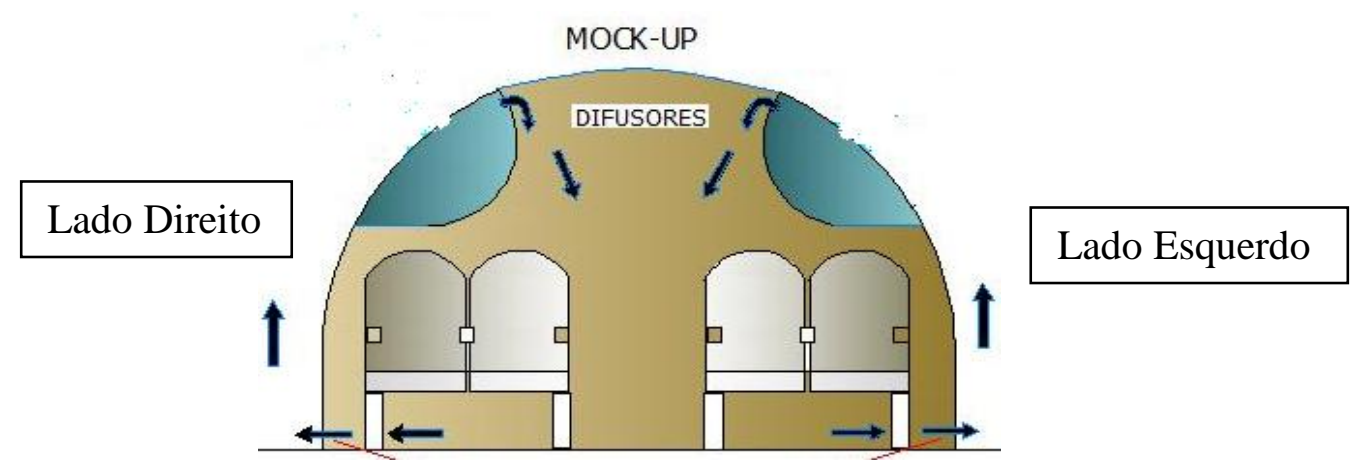

Figura 6.2- Orientação de lados, direito esquerdo, na cabine 


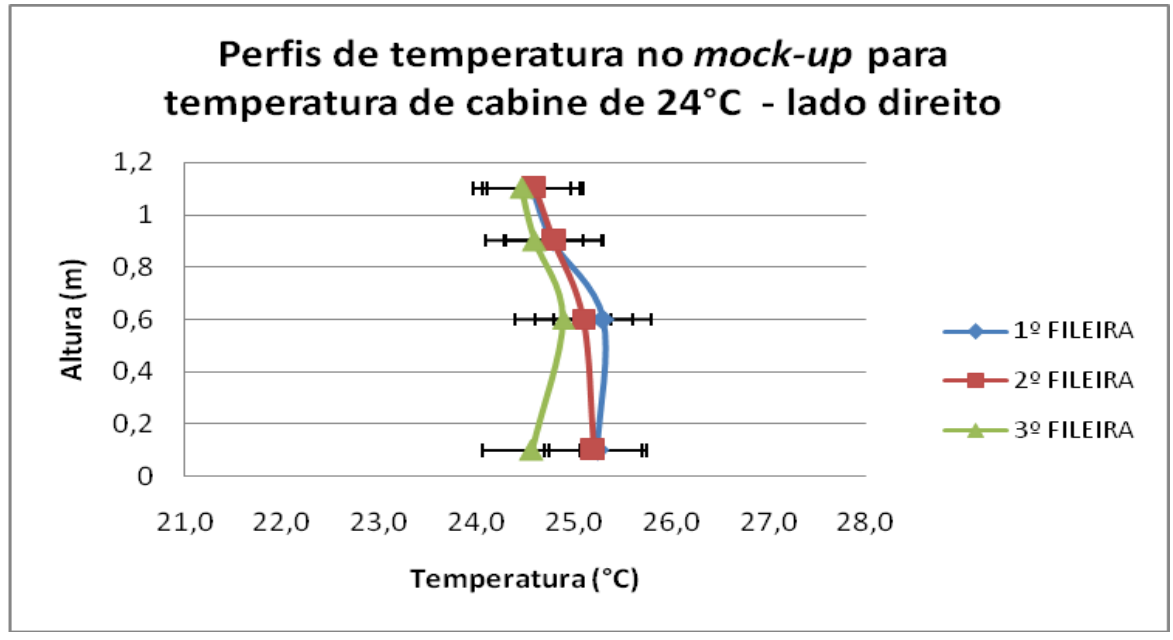

Figura 6.3- Perfis de temperatura: lado direito do mock-up com temperatura de cabine de $24^{\circ} \mathrm{C}$

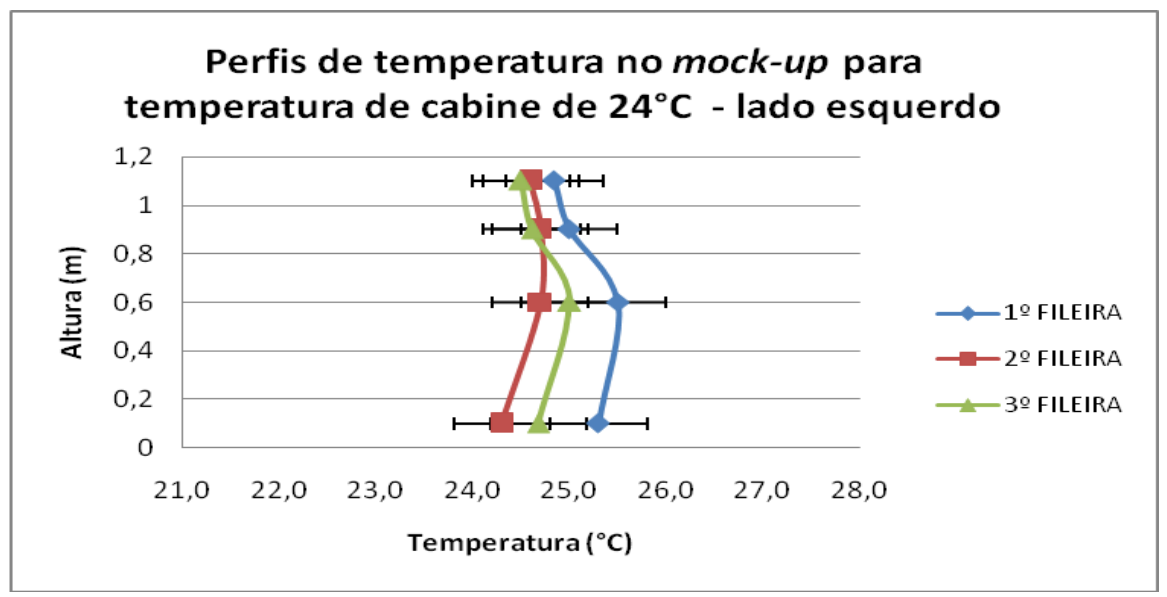

Figura 6.4- Perfis de temperatura: lado esquerdo do mock-up com temperatura de cabine de $24^{\circ} \mathrm{C}$

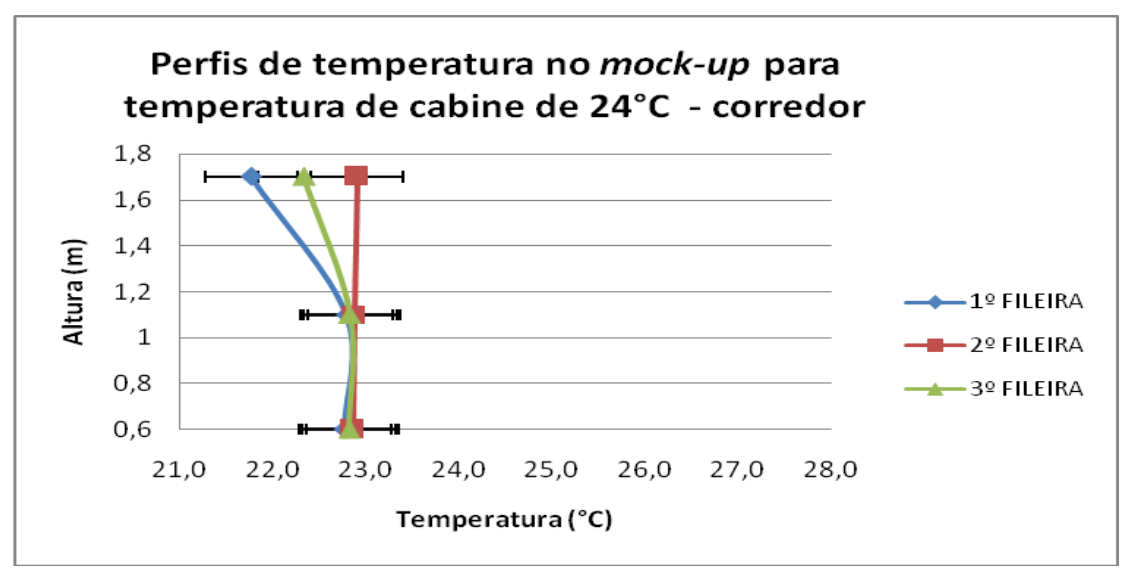

Figura 6.5- Perfis de temperatura: corredor do mock-up com temperatura de cabine de $24^{\circ} \mathrm{C}$ 


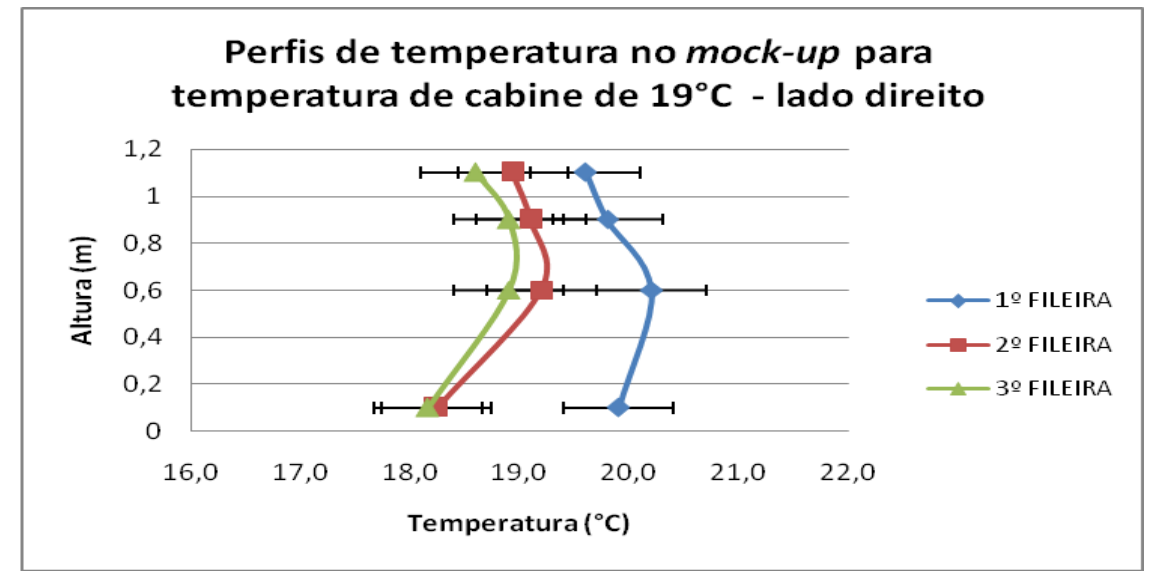

Figura 6.6- Perfis de temperatura: lado direito do mock-up com temperatura de cabine de $19^{\circ} \mathrm{C}$

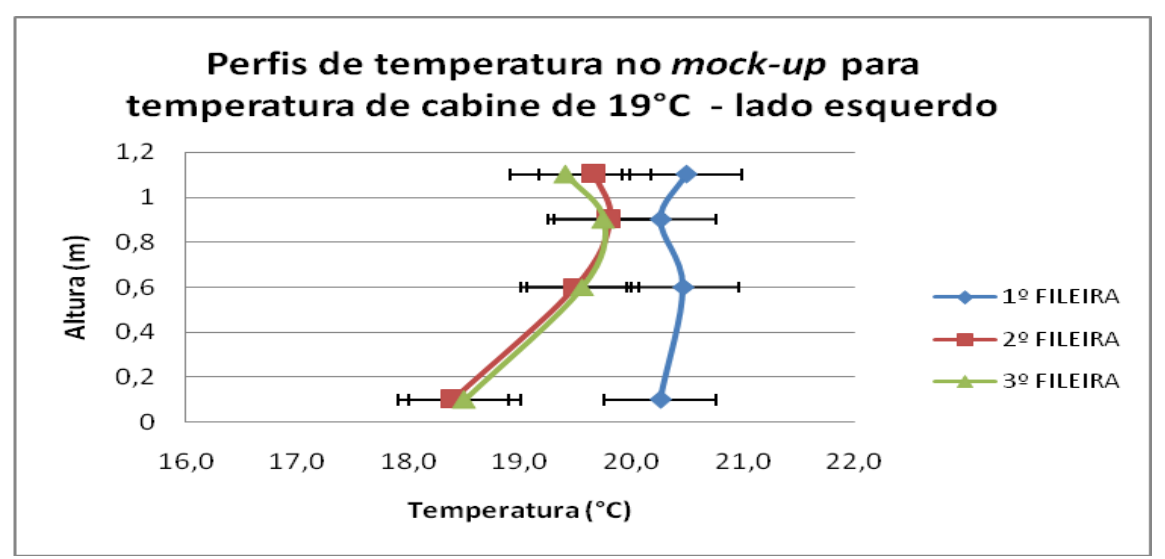

Figura 6.7- Perfis de temperatura: lado esquerdo do mock-up com temperatura de cabine de $19^{\circ} \mathrm{C}$

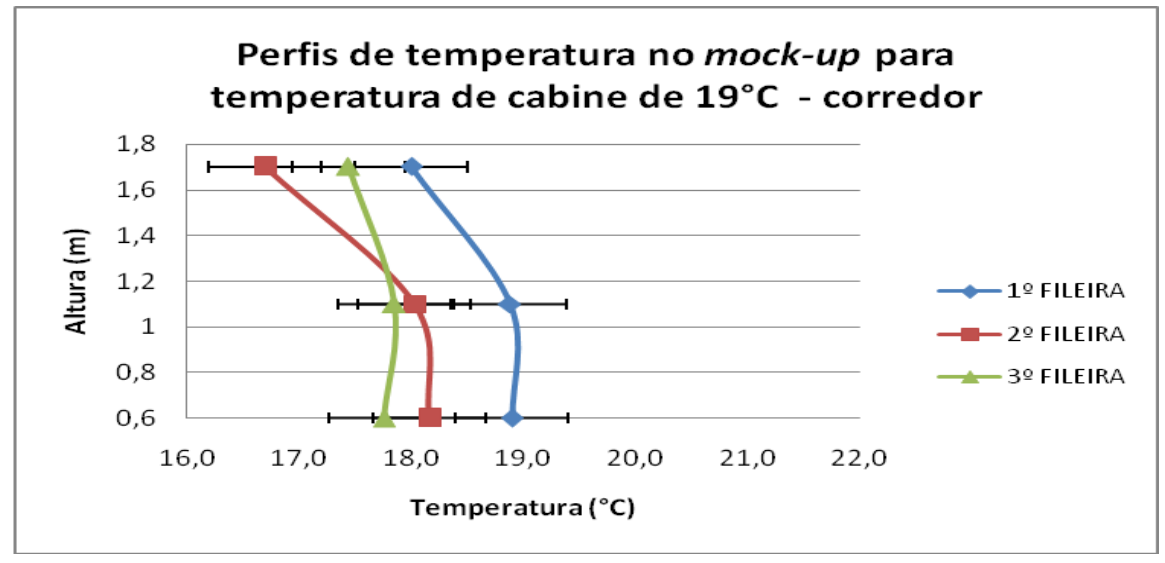

Figura 6.8 - Perfis de temperatura: corredor do mock-up com temperatura de cabine de $19^{\circ} \mathrm{C}$ 
Da análise das Figuras 6.3 a 6.8 verifica-se que:

a) A região de maior temperatura, em ambos os lados nas duas temperaturas de cabine $\left(24^{\circ} \mathrm{C}\right.$ e $\left.19^{\circ} \mathrm{C}\right)$, ocorre na altura entre 0,6 e $0,8 \mathrm{~m}$. Essa região é a região do tórax do manequim aquecido, onde é maior o efeito da pluma térmica ascendente.

b) Próximo a 1,2m as temperaturas seguem uma tendência de diminuição, pois, nessa região os efeitos da troca de calor do ar com o manequim térmico são minorados.

c) Entre os pés e a cabeça, 0,1 e 1,1m, observa-se, em ambos os lados nas duas temperaturas consideradas, uma diferença de temperatura de menos de $1^{\circ} \mathrm{C}$. Este valor não proporciona desconforto devido à assimetria vertical de temperatura, que segundo as normas ASHRAE 55 (2004) e ISO 7730 (2005) pode ser de até $3{ }^{\circ} \mathrm{C}$.

Nas Figuras 6.5 e 6.8, que mostram o perfil de temperatura no corredor para as duas temperaturas ensaiadas, é possível verificar que o ar próximo ao piso possui uma temperatura maior do que o ar da região próxima ao teto, onde ocorre o insuflamento (ar mais frio). E por não existirem fontes de calor nessa região, na altura de $1,7 \mathrm{~m}$ a temperatura do ar tende a se aproximar da temperatura de insuflamento. Nesta região também é possível observar uma assimetria vertical de temperatura maior que $1^{\circ} \mathrm{C}$, porém esta região não é ocupada, é apenas uma região de circulação, não sendo significativa para a análise de conforto.

Os perfis de velocidade para essas mesmas posições e temperaturas são apresentados nas Figuras 6.9 a 6.14, onde se verifica que o comportamento das curvas é mais irregular. Isto se dá devido à complexidade do ambiente com mobiliário e fontes térmicas que geram fluxos ascendentes e recirculações, além da interação dos jatos de insuflamento provenientes dos dois lados da cabine.

Não foi observado nenhum ponto com velocidade superior a $0,25 \mathrm{~m} / \mathrm{s}$, limite máximo de velocidade em ambientes climatizados segundo normas ASHRAE 55 (2004) e ISO 7730 (2005), e apenas uma região de estagnação do lado direito na terceira fileira e altura de $0,1 \mathrm{~m}$.

Um fator que dificulta uma análise mais apurada é a incerteza de medição dos anemômetros, que é de $\pm\left(0,04+3 \% \mathrm{~V}_{\mathrm{ar}}\right) \mathrm{m} / \mathrm{s}$. Inclusive, em algumas situações, a velocidade do ar medida encontra-se na faixa de incerteza de medição. 


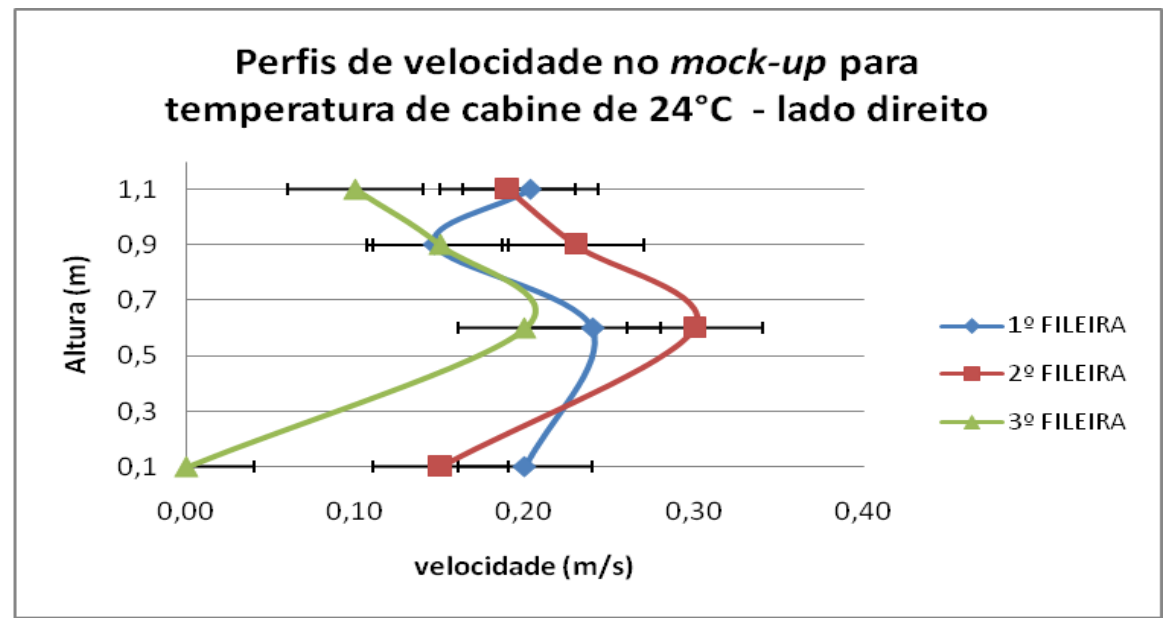

Figura 6.9- Perfis de velocidade: lado direito do mock-up com temperatura de cabine de $24^{\circ} \mathrm{C}$

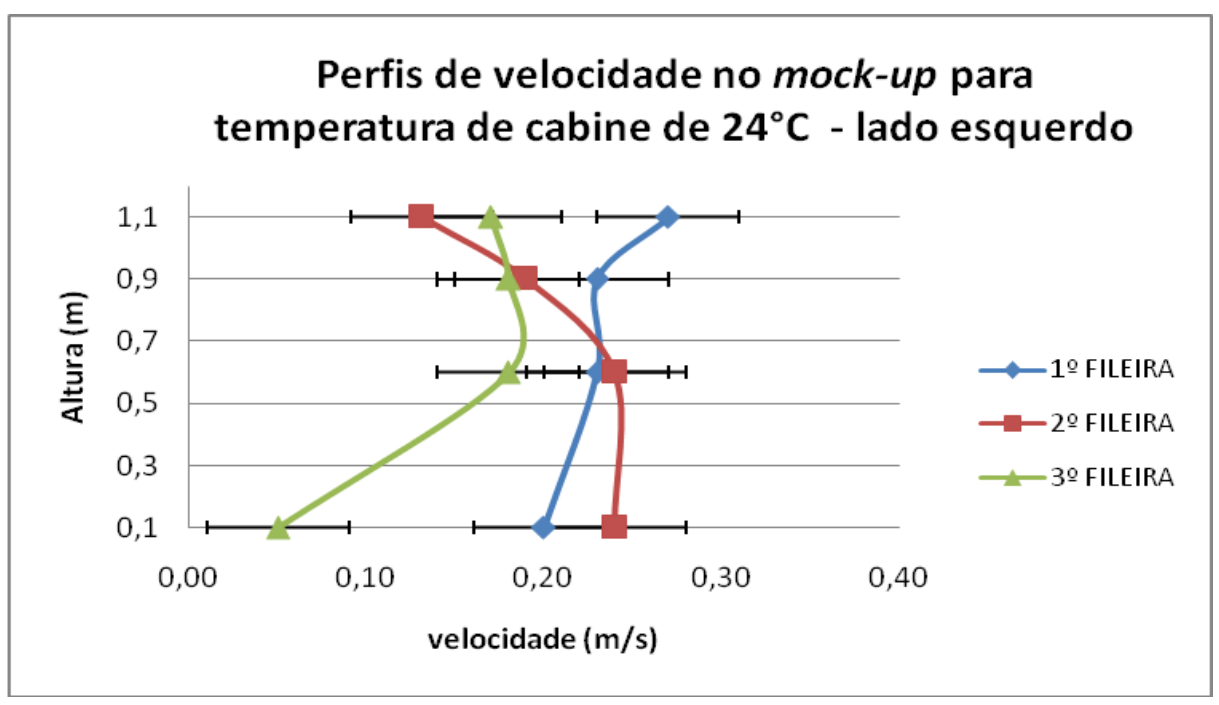

Figura 6.10- Perfis de velocidade: lado esquerdo do mock-up com temperatura de cabine de $24^{\circ} \mathrm{C}$

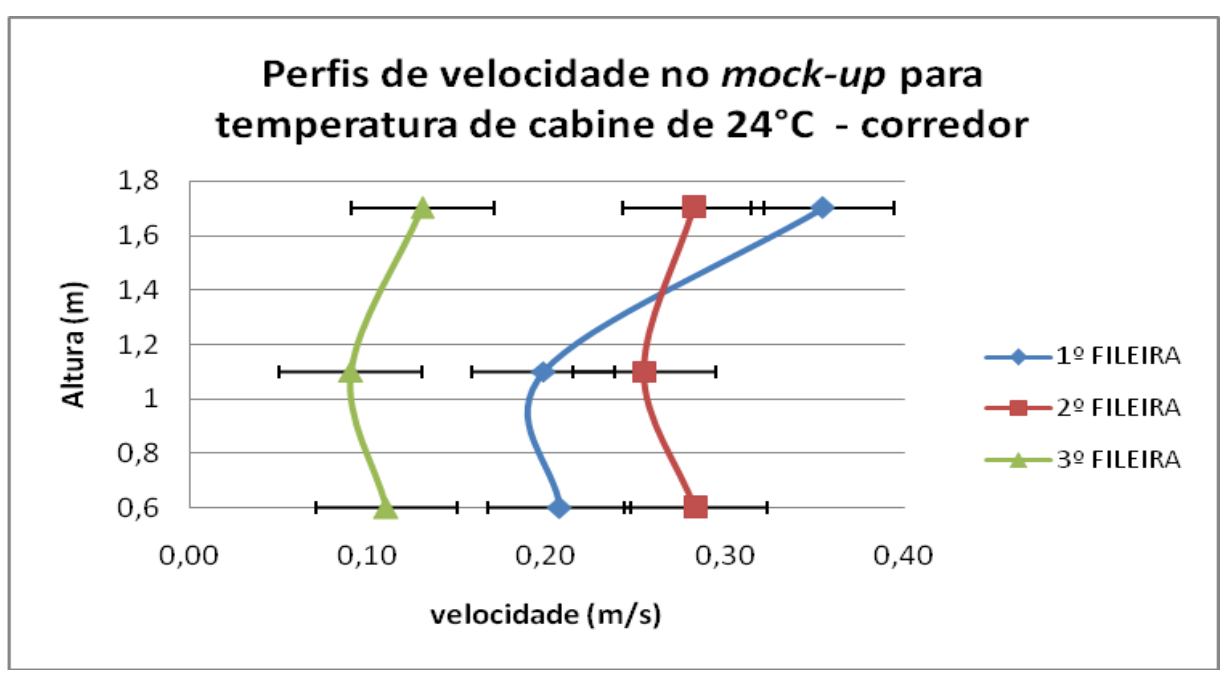

Figura 6.11- Perfis de velocidade: corredor do mock-up com temperatura de cabine de $24^{\circ} \mathrm{C}$ 


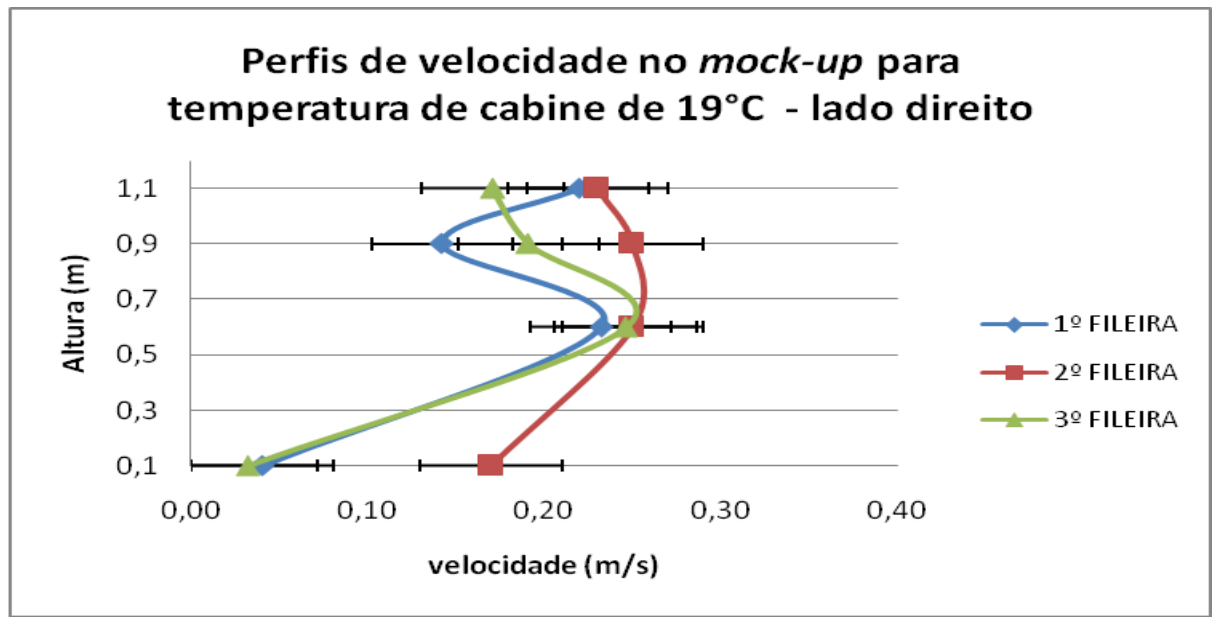

Figura 6.12- Perfis de velocidade: lado direito do mock-up com temperatura de cabine de $19^{\circ} \mathrm{C}$

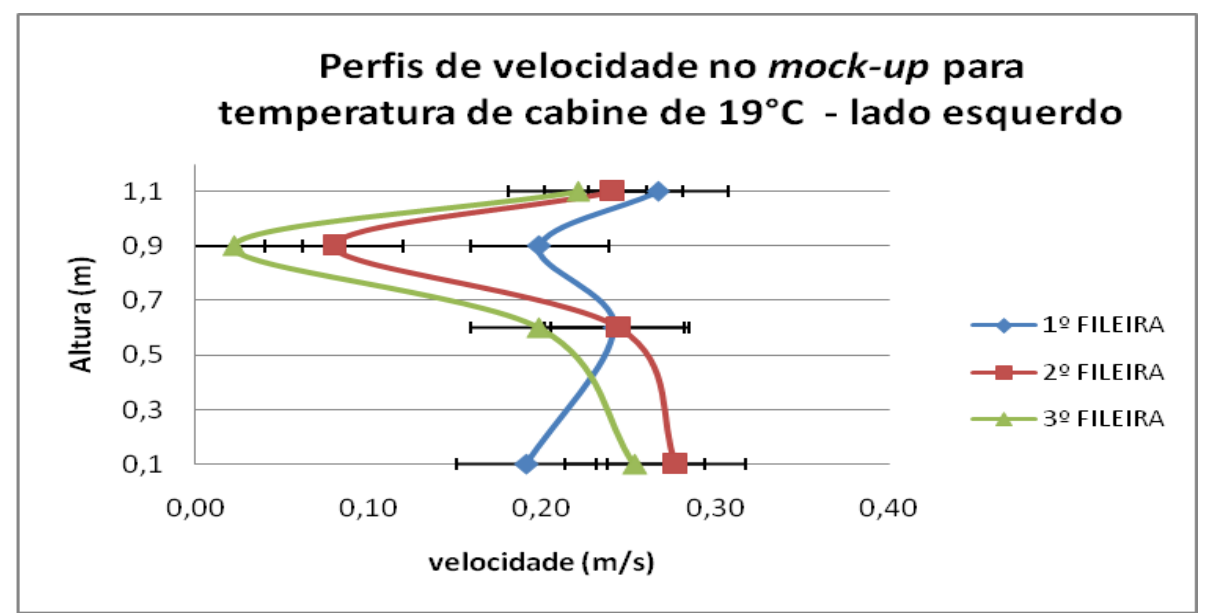

Figura 6.13- Perfis de velocidade: lado esquerdo do mock-up com temperatura de cabine de $19^{\circ} \mathrm{C}$

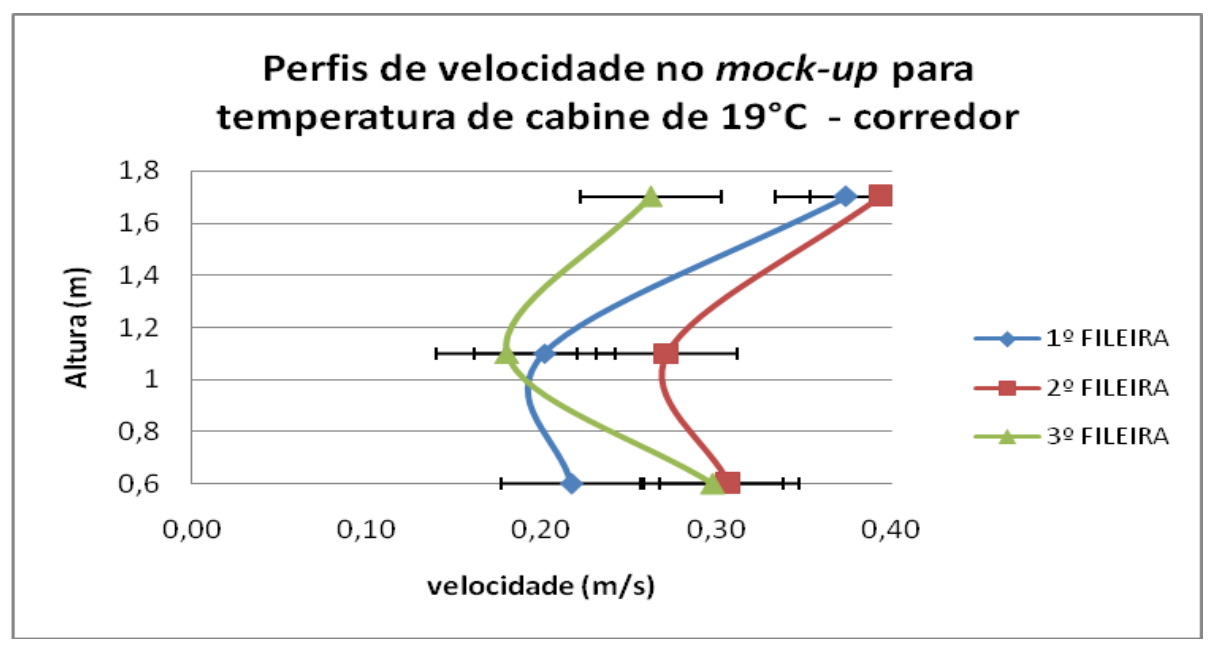

Figura 6.14- Perfis de velocidade: corredor do mock-up com temperatura de cabine de $19^{\circ} \mathrm{C}$ 
O perfil de velocidade no corredor apresenta um comportamento mais regular (Figuras 6.11 e 6.14). Isso pode ser explicado devido à configuração dessa região, que não apresenta ocupação nem mobiliário que possam ocasionar recirculações e fluxos ascendentes devido à liberação de calor das pessoas. Pode se observar também velocidades maiores próximo à região dos difusores.

\subsection{Temperaturas equivalentes obtidas com manequim térmico instrumentado}

Para a avaliação de condições de conforto térmico o manequim térmico foi posicionado na cabine com a mesma vestimenta $(0,6$ clo) e dissipando o mesmo fluxo de calor em cada segmento $\left(70 \mathrm{~W} / \mathrm{m}^{2}\right)$ que no ambiente de calibração. O manequim térmico juntamente com os manequins aquecidos são mostrados na Figura 6.15

Uma vez posicionado o manequim na cabine e atingidas condições estáveis foram levantadas temperaturas superficiais nos diversos segmentos do manequim térmico, nas duas condições de temperatura da cabine, para o cálculo das temperaturas equivalentes.

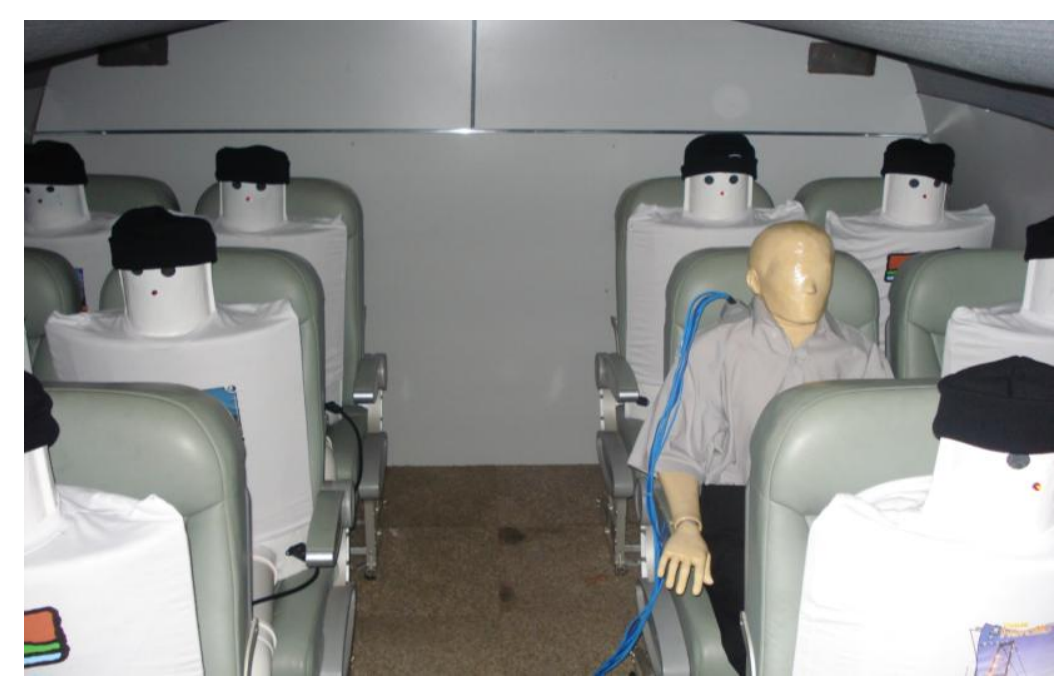

Figura 6.15- Posicionamento do manequim térmico instrumentado na cabine

Uma vez obtidas às temperaturas superficiais, $T_{s}$, apresentadas nas Tabelas $6.2 \mathrm{e}$ 6.3, foram determinadas as temperaturas equivalentes, $T_{\mathrm{eq}}$, para análise de condições de conforto térmico. Isto foi feito utilizando-se a Eq. 3.7

$$
T_{e q}=T_{s}-\frac{\dot{Q}}{h_{\text {cal }}}
$$

com os coeficientes de transferência de calor calibrados, $h_{\text {cal }}$, apresentados na Tabela 5.5 
Tabela 6.2 - Temperaturas equivalentes, temperaturas superficiais, coeficiente de troca de calor combinado e fluxo de calor do manequim para temperatura de cabine de $24^{\circ} \mathrm{C}$

\begin{tabular}{|c|l|c|c|c|}
\hline Seção & \multicolumn{1}{|c|}{ Segmento } & $\mathbf{h}_{\text {cal }}\left(\mathbf{W} / \mathbf{m}^{\mathbf{2}}{ }^{\mathbf{C}} \mathbf{C}\right)$ & $\mathbf{T}_{\mathbf{s}}\left({ }^{\circ} \mathbf{C}\right)$ & $\mathbf{T}_{\mathbf{e q}}\left({ }^{\circ} \mathbf{C}\right)$ \\
\hline 1 & corpo como todo & 4,3 & 41,0 & 24,7 \\
\hline 2 & face & 7,6 & 36,5 & 27,2 \\
\hline 3 & tórax & 3,2 & 49,3 & 27,5 \\
\hline 4 & costas & 2,7 & 55,0 & 29,2 \\
\hline 5 & braço esquerdo & 3,1 & 49,9 & 27,2 \\
\hline 6 & braço direito & 4,9 & 40,7 & 26,3 \\
\hline 7 & antebraço esquerdo & 5,1 & 40,0 & 26,3 \\
\hline 8 & antebraço direito & 6,0 & 36,2 & 24,6 \\
\hline 9 & mão esquerda & 9,4 & 33,7 & 26,3 \\
\hline 10 & mão direita & 9,1 & 32,5 & 24,8 \\
\hline 11 & coxa esquerda & 6,0 & 37,4 & 25,7 \\
\hline 12 & coxa direita & 5,2 & 38,9 & 25,4 \\
\hline 13 & canela esquerda & 6,3 & 37,6 & 26,5 \\
\hline 14 & canela direita & 5,9 & 37,9 & 26,0 \\
\hline 15 & pé esquerdo & 4,1 & 42,7 & 25,8 \\
\hline 16 & pé direito & 3,4 & 46,0 & 25,7 \\
\hline 17 & nádegas & 3,5 & 46,9 & 26,7 \\
\hline
\end{tabular}

Tabela 6.3 - Temperaturas equivalentes, temperaturas superficiais, coeficiente de troca de calor combinado e dissipação térmica do manequim para temperatura de cabine de $19^{\circ} \mathrm{C}$

\begin{tabular}{|c|l|c|c|c|}
\hline Seção & \multicolumn{1}{|c|}{ Segmento } & $\mathbf{h}_{\text {cal }}\left(\mathbf{W} / \mathbf{m}^{\mathbf{2}}{ }^{\mathbf{0}} \mathbf{C}\right)$ & $\mathbf{T}_{\mathbf{s}}\left({ }^{\circ} \mathbf{C}\right)$ & $\mathbf{T}_{\text {eq }}\left({ }^{\circ} \mathbf{C}\right)$ \\
\hline 1 & corpo como todo & 4,3 & 39,2 & 22,9 \\
\hline 2 & face & 7,6 & 31,5 & 22,3 \\
\hline 3 & tórax & 3,2 & 44,0 & 22,2 \\
\hline 4 & costas & 2,7 & 53,0 & 27,2 \\
\hline 5 & braço esquerdo & 3,1 & 45,7 & 23,0 \\
\hline 6 & braço direito & 4,9 & 36,7 & 22,3 \\
\hline 7 & antebraço esquerdo & 5,1 & 38,0 & 24,4 \\
\hline 8 & antebraço direito & 6,0 & 36,7 & 25,0 \\
\hline 9 & mão esquerda & 9,4 & 28,3 & 20,9 \\
\hline 10 & mão direita & 9,1 & 27,2 & 19,5 \\
\hline 11 & coxa esquerda & 6,0 & 33,1 & 21,4 \\
\hline 12 & coxa direita & 5,2 & 34,7 & 21,3 \\
\hline 13 & canela esquerda & 6,3 & 33,0 & 21,9 \\
\hline 14 & canela direita & 5,9 & 33,4 & 21,5 \\
\hline 15 & pé esquerdo & 4,1 & 39,6 & 22,7 \\
\hline 16 & pé direito & 3,4 & 42,4 & 22,0 \\
\hline 17 & nádegas & 3,5 & 43,0 & 22,7 \\
\hline
\end{tabular}


As temperaturas equivalentes obtidas para cada segmento do manequim nas duas condições de temperatura de cabine são apresentadas no diagrama de sensação térmica (Figura 6.16), da norma ISO 14505-2 (2004),

\section{Diagrama de sensação térmica}

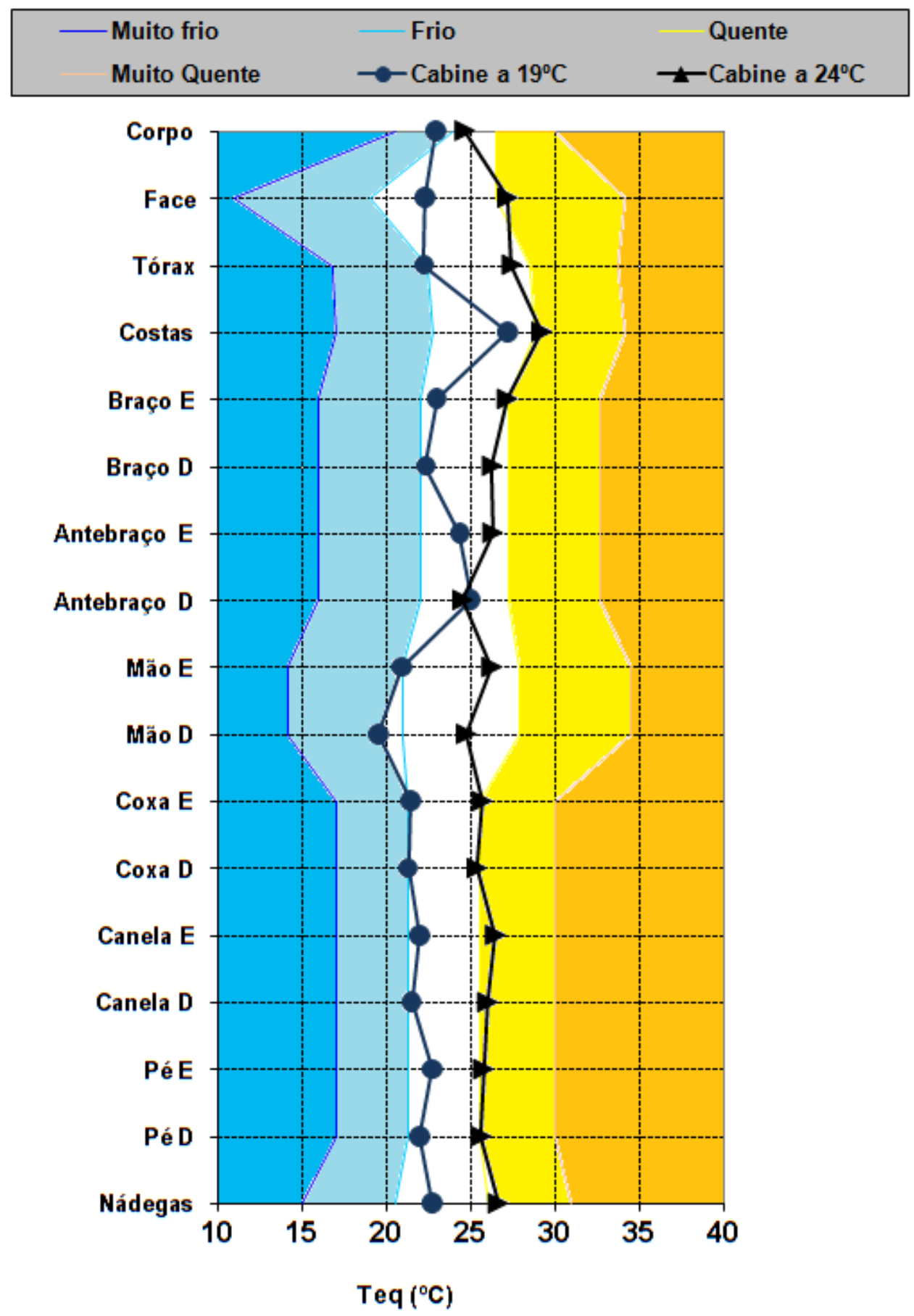

Figura 6.16 - Temperaturas equivalentes em diagrama de sensação térmica segundo norma ISO 14505-2 (2004) 
Da análise da Figura 6.16 é possível verificar que para temperatura de cabine de $24^{\circ} \mathrm{C}$ ocorre tendência à leve sensação de calor, enquanto para a temperatura de $19^{\circ} \mathrm{C}$ há tendência à leve sensação de frio.

\subsection{Resultados da avaliação subjetiva}

Avaliações subjetivas para levantamento da sensação térmica e desconforto local foram realizadas com participação de 11 voluntários respondendo questionário apresentado no Apêndice A. Em cada temperatura de cabine, de $24^{\circ} \mathrm{C}$ e $19^{\circ} \mathrm{C}$, os participantes estavam vestidos com roupas de verão com aprox. 0,6 clo, conforme mencionado no capitulo 5.

Com a aplicação dos questionários foi possível realizar o levantamento do voto térmico médio (VTM) e do voto de conforto médio (VCM) para cada parte do corpo considerada.

As Tabelas 6.4 e 6.5 apresentam, respectivamente, os votos dados pelas pessoas para condição de temperatura de cabine de $24^{\circ} \mathrm{C}$ e de $19^{\circ} \mathrm{C}$.

Tabela 6.4 - Votos dados pelas pessoas e VTM calculado para cada parte do corpo.

Temperatura de cabine de $24^{\circ} \mathrm{C}$

\begin{tabular}{|l|c|c|c|c|c|c|c|c|}
\hline \multicolumn{1}{|c|}{ Segmento } & -3 & -2 & -1 & 0 & 1 & 2 & 3 & VTM \\
\hline corpo como todo & 0 & 0 & 0 & 4 & 4 & 3 & 0 & 0,91 \\
\hline face & 0 & 0 & 0 & 0 & 6 & 5 & 0 & 1,45 \\
\hline tórax & 0 & 0 & 0 & 4 & 4 & 3 & 0 & 0,91 \\
\hline costas & 0 & 0 & 0 & 4 & 3 & 3 & 0 & 0,82 \\
\hline braço esquerdo & 0 & 0 & 0 & 4 & 4 & 3 & 0 & 0,91 \\
\hline braço direito & 0 & 0 & 0 & 3 & 5 & 2 & 0 & 0,82 \\
\hline antebraço esquerdo & 0 & 0 & 0 & 4 & 5 & 2 & 0 & 0,82 \\
\hline antebraço direito & 0 & 0 & 0 & 3 & 7 & 1 & 0 & 0,82 \\
\hline mão esquerda & 0 & 0 & 0 & 5 & 4 & 2 & 0 & 0,73 \\
\hline mão direita & 0 & 0 & 0 & 4 & 6 & 1 & 0 & 0,73 \\
\hline coxa esquerda & 0 & 0 & 0 & 1 & 7 & 3 & 0 & 1,18 \\
\hline coxa direita & 0 & 0 & 0 & 1 & 7 & 3 & 0 & 1,18 \\
\hline pé esquerdo & 0 & 0 & 0 & 3 & 4 & 4 & 0 & 1,09 \\
\hline pé direito & 0 & 0 & 0 & 2 & 5 & 4 & 0 & 1,18 \\
\hline nádegas & 0 & 0 & 0 & 1 & 7 & 3 & 0 & 1,18 \\
\hline
\end{tabular}


Tabela 6.5 - Votos dados pelas pessoas e VTM calculado para cada parte do corpo.

Temperatura de cabine de $19^{\circ} \mathrm{C}$

\begin{tabular}{|l|c|c|c|c|c|c|c|c|}
\hline \multicolumn{1}{|c|}{ Segmento } & -3 & -2 & -1 & 0 & 1 & 2 & 3 & VTM \\
\hline corpo como todo & 0 & 0 & 7 & 4 & 0 & 0 & 0 & $-0,64$ \\
\hline face & 0 & 1 & 2 & 8 & 0 & 0 & 0 & $-0,36$ \\
\hline tórax & 0 & 0 & 2 & 9 & 0 & 0 & 0 & $-0,18$ \\
\hline costas & 0 & 0 & 5 & 6 & 0 & 0 & 0 & $-0,45$ \\
\hline braço esquerdo & 0 & 2 & 3 & 6 & 0 & 0 & 0 & $-0,64$ \\
\hline braço direito & 0 & 0 & 6 & 4 & 1 & 0 & 0 & $-0,45$ \\
\hline antebraço esquerdo & 0 & 5 & 4 & 1 & 1 & 0 & 0 & $-1,18$ \\
\hline antebraço direito & 0 & 1 & 8 & 2 & 0 & 0 & 0 & $-0,91$ \\
\hline mão esquerda & 1 & 4 & 3 & 3 & 0 & 0 & 0 & $-1,27$ \\
\hline mão direita & 0 & 1 & 5 & 5 & 0 & 0 & 0 & $-0,64$ \\
\hline coxa esquerda & 0 & 3 & 3 & 4 & 1 & 0 & 0 & $-0,73$ \\
\hline coxa direita & 0 & 0 & 6 & 4 & 1 & 0 & 0 & $-0,45$ \\
\hline pé esquerdo & 0 & 1 & 6 & 4 & 0 & 0 & 0 & $-0,73$ \\
\hline pé direito & 0 & 0 & 5 & 6 & 0 & 0 & 0 & $-0,45$ \\
\hline nádegas & 0 & 0 & 00 & 6 & 4 & 1 & 0 & 0,55 \\
\hline
\end{tabular}

A escala considerada para a determinação do voto térmico médio (VTM) é apresentada na Figura 6.17 e os valores de VTM são apresentados na Figura 6.18.

\begin{tabular}{|c|c|c|c|c|c|c|}
\hline-3 & -2 & -1 & $\mathbf{0}$ & 1 & 2 & 3 \\
\hline MF & F & LF & C & LQ & Q & MQ \\
\hline
\end{tabular}

Figura 6.17 Escala utilizada na obtenção do voto térmico médio (VTM)

$\mathrm{Na}$ análise do VTM (Fig. 6.18) observa-se que a temperatura de cabine de $19^{\circ} \mathrm{C}$ ocasiona um desconforto menor do que a temperatura de $24^{\circ} \mathrm{C}$, sendo que os valores de VTM na temperatura de cabine de $24^{\circ} \mathrm{C}$ mostram leve sensação de calor na maior parte do corpo dos voluntários.

Pela análise das Figuras 6.18 e 6.16, observa-se que o comportamento apresentado no diagrama de VTM (Fig. 6.18) é semelhante ao apresentado no diagrama de sensação térmica construído com temperaturas equivalentes (Fig. 6.16). Nota-se, contudo, um leve deslocamento dos resultados de VTM para o lado direito do diagrama quando comparadas com aquelas do diagrama de sensação térmica construído com temperaturas equivalentes. 


\section{VTM - VOTO TÉRMICO MÉDIO}

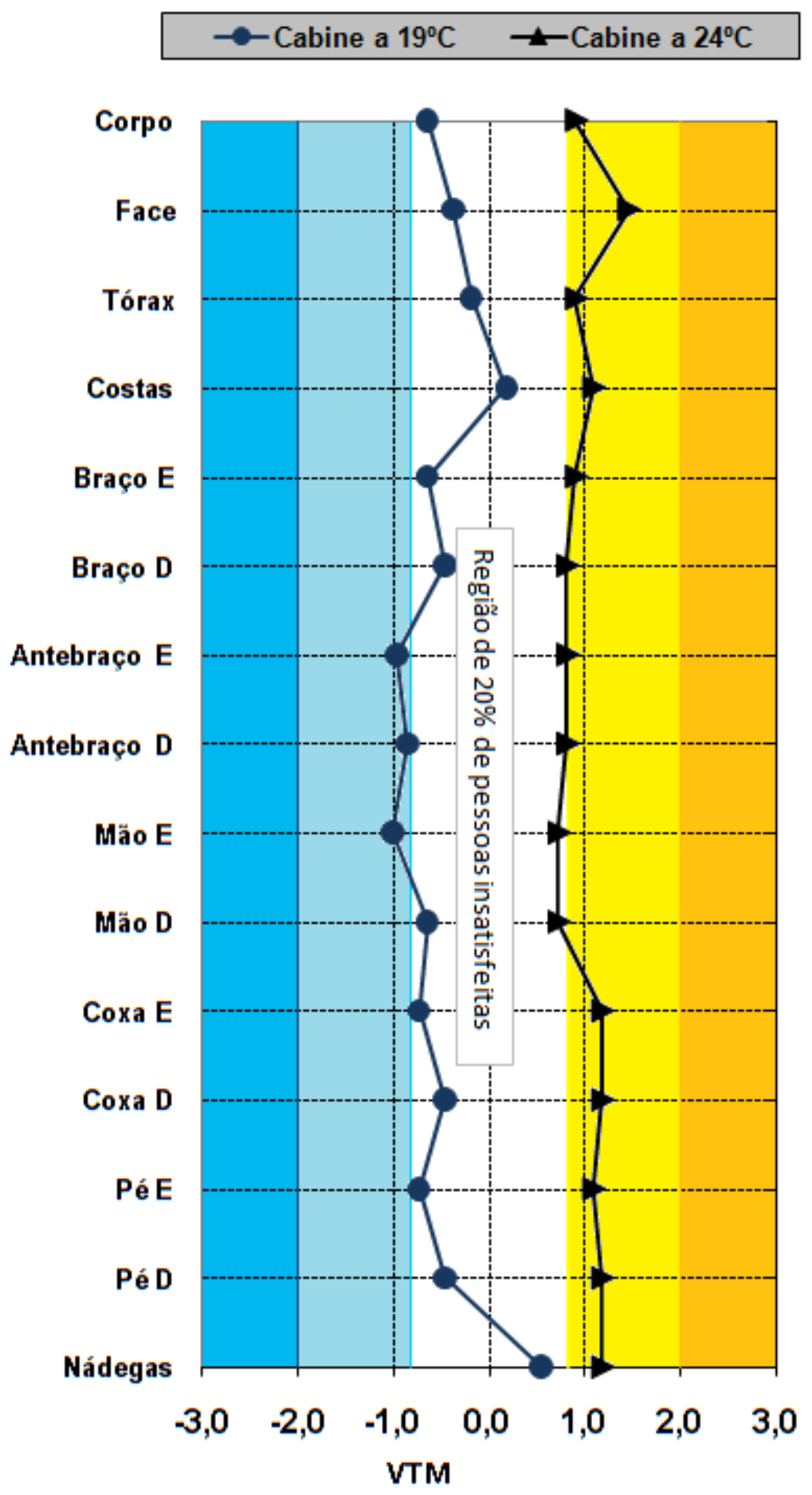

Figura 6.18 - Voto térmico médio (VTM)

Nas Tabelas 6.5 e 6.6 são apresentados, respectivamente, os votos dados pelas pessoas para o desconforto local em condições de temperatura de cabine de $24^{\circ} \mathrm{C}$ e $19^{\circ} \mathrm{C}$, assim como os valores dos votos de conforto médio (VCM) calculados. 
Tabela 6.5 - Votos dados pelas pessoas e VCM calculado para cada parte do corpo. Temperatura de cabine de $24^{\circ} \mathrm{C}$

\begin{tabular}{|l|c|c|c|c|c|c|c|c|}
\hline \multicolumn{1}{|c|}{ Segmento } & -3 & -2 & -1 & 0 & 1 & 2 & 3 & VCM \\
\hline corpo como todo & 0 & 1 & 4 & 2 & 4 & 0 & 0 & $-0,18$ \\
\hline face & 0 & 2 & 5 & 2 & 2 & 0 & 0 & $-0,64$ \\
\hline tórax & 0 & 1 & 4 & 4 & 1 & 1 & 0 & $-0,27$ \\
\hline costas & 0 & 1 & 4 & 4 & 1 & 1 & 0 & $-0,27$ \\
\hline braço esquerdo & 0 & 1 & 4 & 4 & 1 & 1 & 0 & $-0,27$ \\
\hline braço direito & 0 & 1 & 4 & 4 & 1 & 1 & 0 & $-0,27$ \\
\hline antebraço esquerdo & 0 & 1 & 3 & 5 & 1 & 1 & 0 & $-0,18$ \\
\hline antebraço direito & 0 & 1 & 3 & 5 & 1 & 1 & 0 & $-0,18$ \\
\hline mão esquerda & 0 & 0 & 4 & 5 & 2 & 0 & 0 & $-0,18$ \\
\hline mão direita & 0 & 1 & 5 & 2 & 2 & 1 & 0 & $-0,27$ \\
\hline coxa esquerda & 0 & 1 & 5 & 2 & 2 & 1 & 0 & $-0,27$ \\
\hline coxa direita & 0 & 1 & 5 & 2 & 2 & 1 & 0 & $-0,27$ \\
\hline pé esquerdo & 0 & 0 & 6 & 3 & 1 & 1 & 0 & $-0,27$ \\
\hline pé direito & 0 & 0 & 6 & 3 & 1 & 1 & 0 & $-0,27$ \\
\hline nádegas & 0 & 1 & 6 & 2 & 2 & 0 & 0 & $-0,55$ \\
\hline
\end{tabular}

Tabela 6.6 - Votos dados pelas pessoas e VCM calculado para cada parte do corpo.

Temperatura de cabine de $19^{\circ} \mathrm{C}$

\begin{tabular}{|l|c|c|c|c|c|c|c|c|}
\hline \multicolumn{1}{|c|}{ Segmento } & -3 & -2 & -1 & 0 & 1 & 2 & 3 & VCM \\
\hline corpo como todo & 0 & 0 & 4 & 4 & 0 & 3 & 0 & 0,18 \\
\hline face & 0 & 0 & 0 & 0 & 6 & 5 & 0 & 1,45 \\
\hline tórax & 0 & 0 & 0 & 6 & 1 & 4 & 0 & 0,82 \\
\hline costas & 0 & 0 & 1 & 5 & 2 & 3 & 0 & 0,64 \\
\hline braço esquerdo & 0 & 2 & 4 & 0 & 4 & 1 & 0 & $-0,18$ \\
\hline braço direito & 0 & 0 & 3 & 3 & 2 & 2 & 1 & 0,55 \\
\hline antebraço esquerdo & 1 & 1 & 2 & 4 & 2 & 1 & 0 & $-0,27$ \\
\hline antebraço direito & 0 & 0 & 3 & 3 & 2 & 2 & 1 & 0,55 \\
\hline mão esquerda & 1 & 1 & 4 & 2 & 1 & 2 & 0 & $-0,36$ \\
\hline mão direita & 0 & 0 & 3 & 3 & 2 & 2 & 1 & 0,55 \\
\hline coxa esquerda & 1 & 1 & 1 & 3 & 1 & 4 & 0 & 0,27 \\
\hline coxa direita & 0 & 1 & 0 & 3 & 2 & 4 & 1 & 1,00 \\
\hline pé esquerdo & 1 & 1 & 1 & 4 & 1 & 3 & 0 & 0,09 \\
\hline pé direito & 0 & 0 & 1 & 5 & 1 & 3 & 1 & 0,82 \\
\hline nádegas & 0 & 0 & 0 & 4 & 3 & 4 & 0 & 1,00 \\
\hline
\end{tabular}

A escala considerada para avaliação de desconforto local e obtenção do voto de conforto médio (VCM) para cada segmento do corpo é apresentada na Figura 6.19 e os valores de VCM são apresentados na Tabela 6.20 


\begin{tabular}{|c|c|c|c|c|c|c|}
\hline-3 & -2 & -1 & 0 & 1 & 2 & 3 \\
\hline MD & D & LD & I & LC & C & MC \\
\hline
\end{tabular}

MD - Muito Desconfortável D - Desconfortável LD - Ligeiramente Desconfortável

I - Indiferente LC - Ligeiramente Confortável C - Confortável MC - Muito Confortável

Figura 6.19. Escala utilizada na obtenção do voto de conforto médio (VCM)

\section{VCM - VOTO DE CONFORTO MÉDIO}

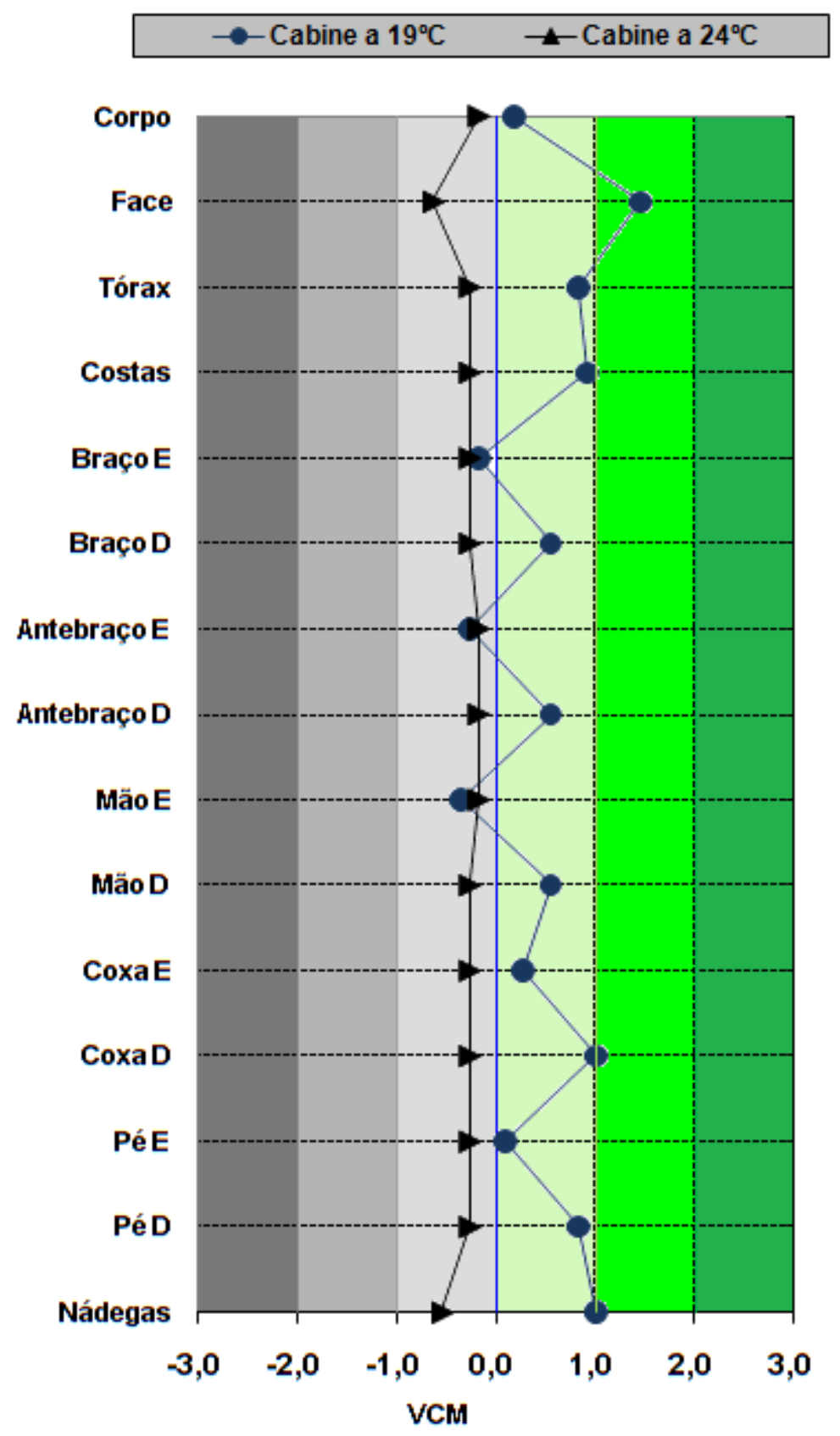

Figura 6.20 Voto de conforto médio (VCM) 
Analisando a Figura 6.20, verifica-se que as pessoas preferiram as condições de cabine na temperatura de $19{ }^{\circ} \mathrm{C}$, com votos de conforto médio (VCM) de indiferentes a ligeiramente confortáveis, enquanto na temperatura de cabine de $24{ }^{\circ} \mathrm{C}$ as condições foram consideradas ligeiramente desconfortáveis.

De uma forma geral, pode se dizer que os resultados obtidos na avaliação subjetiva apresentaram boa concordância com os resultados obtidos com a avaliação por meio da temperatura equivalente e utilização do diagrama de sensação térmica da norma ISO 14505-2 (2004). Estes resultados mostram que, para as condições de cabine avaliadas, o diagrama de sensação térmica da norma representa razoavelmente bem as condições de conforto na cabine.

Por outro lado, convém ressaltar que houve um leve deslocamento dos resultados obtidos por meio da avaliação subjetiva para a direita no diagrama com os votos térmicos médios (VTM).

Embora os resultados se refiram à avaliação com um grupo reduzido de voluntários e em duas condições de cabine somente, são um indicativo de que o preconizado na norma tem aplicabilidade em cabines de aeronaves - ao menos em certas condições, ao mesmo tempo que apontam para a necessidade do aprofundamento de estudos e de realização de ensaios com um número maior de participantes, de preferência treinados (júri), e de análise de conforto térmico em diferentes condições do escoamento, de temperaturas de insuflamento, de umidade relativa do ar etc. 


\section{Capítulo 7}

\section{CONCLUSÕES}

A utilização de mock-ups tem sido uma importante ferramenta no estudo de conforto térmico em cabines de aeronaves, proporcionando flexibilidade e autonomia para o pesquisador. No presente trabalho um mock-up de aeronave com 12 lugares foi projetado e construído para o estudo de condições do escoamento do ar e avaliação de conforto térmico em cabine de aeronave.

O mock-up apresentou desempenho satisfatório para o fim para o qual foi desenvolvido e construído, com obtenção de condições razoáveis de simetria no escoamento do ar na cabine.

Os perfis de temperatura e de velocidade do ar mostraram que o escoamento no interior da cabine é bastante influenciado pelo mobiliário (poltronas) e pela ocupação (pessoas) no interior da cabine. Também, pode-se verificar que apesar das condições complexas do escoamento, não ocorreram diferenças significativas de velocidade na região de ocupação e nem de temperatura na direção vertical, fatores que poderiam ocasionar grande desconforto.

Verificou-se a ocorrência de uma boa aproximação entre as avaliações de conforto térmico feitas por meio das temperaturas equivalentes e os resultados das análises subjetivas realizadas por meio de questionários. Nas avaliações subjetivas ocorreu um pequeno deslocamento dos resultados para o lado direito no diagrama de VTM. Finalmente, verificou-se que as pessoas preferiram as condições de cabine na temperatura de $19^{\circ} \mathrm{C}$, com votos de conforto médio (VCM) de indiferentes a ligeiramente confortáveis, enquanto na temperatura de cabine de $24{ }^{\circ} \mathrm{C}$ as condições foram consideradas ligeiramente desconfortáveis.

O procedimento aplicado para a investigação de conforto, passando pelo levantamento de características do escoamento, obtenção de temperaturas equivalentes com manequim térmico instrumentado e avaliação com pessoas, mostrou ser bastante adequado para a análise de conforto de cabine. Nas temperaturas de cabine avaliadas, de $19^{\circ} \mathrm{C}$ e $24^{\circ} \mathrm{C}$, verificou-se que nas duas condições os resultados de conforto térmico ficaram na faixa de conforto aceitável para cabines de veículos. 
É importante destacar que o desenvolvimento do presente trabalho foi um passo significativo de aprendizado no estudo do conforto térmico em aeronaves, bem como da aplicação de ferramentas e técnicas na análise de conforto neste tipo de veículo automotivo.

Ao mesmo tempo, é importante frisar que os resultados obtidos no presente trabalho são resultados iniciais. Isto porque há a necessidade de estudos bastante mais aprofundados, tanto no que se refere ao levantamento de temperaturas equivalentes, como na avaliação subjetiva com júri.

No presente trabalho foram avaliadas somente duas condições de cabine, próximas à condição de conforto térmico, e a participação de um número reduzido de voluntários. Além disto, os resultados de temperatura equivalente foram apresentados em diagrama genérico de conforto em cabines (ISO 14505-2, 2004), e os resultados de avaliação subjetiva de conforto foram apresentados somente em função do voto térmico médio (VTM) e do voto de conforto médio (VCM).

Para uma melhor análise de condições de conforto térmico há a necessidade de relacionar os votos das pessoas com as temperaturas equivalentes (Strøm-Tejsen et al., 2007) e construir diagramas de sensação térmica (Nilsson, 2004) para as condições de cabine de aeronave, considerando as peculiaridades deste veículo automotivo. Mas, para tal é necessário a realização de um número muito maior de testes, com e sem pessoas, e de realização de estudos específicos na avaliação subjetiva de conforto térmico; que demandam a realização de outros trabalhos.

\subsection{Continuidade do trabalho}

Para a continuidade e desenvolvimento da pesquisa realizada neste trabalho pode-se destacar:

a) Desenvolvimento de metodologia de análise subjetiva de conforto térmico em cabines de aeronaves considerando questões psicométricas, semânticas etc.

b) Realização de testes subjetivos com quantidade maior de condições termoambientais de cabine considerando a questão da umidade relativa baixa, para posterior correlação com as temperaturas equivalentes. 
c) Correlacionar os resultados de temperaturas equivalentes com os resultados da avaliação subjetiva e por meio de regressão obter os diagramas de sensação térmica para a cabine estudada.

Com o desenvolvimento destas atividades é possível realizar uma análise mais específica da cabine estudada e desenvolver uma metodologia que possa ser aplicada em outras cabines de aeronaves. 
Capítulo 8

\section{REFER ÊNCIAS BIBLIOGRÁFICAS}

Aboosaidi F, Warfield M, Choudhury M. (1991). Computational fluid dynamics applications in airplane cabin ventilation system design. Proceedings of the Society of Automotive Engineers, 246:249-58.

ASHRAE (2005). Handbook of Fundamentals, American Society of Heating, Refrigerating and Air Conditioning Engineers Inc., Atlanta.

ASHRAE 55 (2004). Thermal Environmental Conditions for Human Occupancy, American Society of Heating, Refrigerating and Air Conditioning Engineers Inc., Atlanta.

ASHRAE 62.1 (2004). Ventilation for Acceptable Indoor Air Quality, American Society of Heating, Refrigerating and Air Conditioning Engineers Inc., Atlanta.

ASHRAE 111 (2004). Measurement, testing, adjusting and balancing of building HVAC Systems, American Society of Heating, Refrigerating and Air Conditioning Engineers Inc, Atlanta.

Cisternino, M. (1999) Thermal climate in cabs and measurements problems. Proceedings of the Assessment of the thermal climate in operator's cabs, Florence, Italy.

Duffon, A. F. (1932). The Equivalent Temperature of a room and its Measurement. Building Research Technical Paper 13. London.

Evin, F.; Siekierski, E. Sensory evaluation of heating and air conditioning systems. Energy and Buildings. 34 (2002) 647-651.

Fanger, P.O. (1972). Analysis and Applications in Environmental Engineering. McGrawHill, New York.

Fanger, P.O.; Melikov, A. K.; Hanzawa, H; Ring, J. (1988). Air turbulence and sensation of draught. Energy and Buildings, n 12, pp 21-39.

Gameiro da Silva, M. C. (2002). Measurements of Comfort in Vehicles. Meas. Sci. Technol. 13 (2002) R41 - R60 PII: S095-0233(02)27461-5.

Gao N. P, Niu J. L. (2007). Personalized ventilation for commercial aircraft cabins. 45th AIAA Aerospace Sciences Meeting and Exhibit. 
Guan, Y.; Hosni, M. H.; Jones, W. J.; Gielda, T. P. (2003a). Investigation of Human Thermal Comfort under Highly Transient Conditions for Automotive Applications - Part 1: Experimental Design and Human Subject Testing Implementation ASHRAE Trans., 109(2): 885-897.

Guan, Y.; Hosni, M. H.; Jones, W. J.; Gielda, T. P. (2003b). Investigation of Human Thermal Comfort under Highly Transient Conditions for Automotive Applications - Part 2: Thermal Sensation Modeling. ASHRAE Trans., 109(2): 898-907.

Guan, Y.; Hosni, M. H.; Jones, W. J.; Gielda, T. P. (2003c). Literature Review of the Advances in Thermal Comfort Modeling. ASHRAE Trans., 109(2): 908-916.

Hinninghofen H.; Enck P. (2006). Passenger well-being in airplanes. Autonomic Neuroscience: Basic and Clinical (in press).

Irgens, S.; Melikov. A. (2004) Assessment of the thermal environment in an aircraft cabin. Proceedings of Roomvent 2004. Coimbra. Portugal. 5-8 September 2004.

ISO 7730 (2005). Ergonomics of the thermal environment - Analytical determination and interpretation of thermal comfort using calculation of the PMV and PPD indices and local thermal comfort criteria. International Organization for Standardization, Geneva.

ISO 7726. (1998). Thermal environments - Instruments and methods for measuring physical quantities, International Organization for Standardization, Geneva.

ISO 14505-2. (2004). Ergonomics of the thermal environment - Evaluation of thermal environment in vehicle - Part2: Determination of Equivalent Temperature. International Organization for Standardization, Geneva.

ISO 14505-3 (2006). Ergonomics of the Thermal Environment - Evaluation of Thermal Environment in Vehicles Part 3: Evaluation of Thermal Comfort Using Human Subjects. International Organization for Standardization, Geneva.

Jacobs P, Gids W.F.(2005) .The aircraft seat as indoor air quality and temperature control system. Proceedings of Indoor Air 2005. Beijing.

Leite, B. C. C.; Tribess, A. (2001). Por uma economia mais competitiva- De baixo para cima. Revista Abrava, v.183, 28-29. 
Leite, B. C. C. (2003). Sistema de Ar Condicionado com Insuflamento pelo Piso em Ambientes de Escritórios: Avaliação do Conforto Térmico e Condições de Operação. Tese de Doutorado - Escola Politécnica da Universidade de São Paulo, 162 p.

Lin C, Horstman R, Ahlers M, Sedwick L, Dunn K, Topmiller J, Bennet J, Wirogo S. (2005). Numerical simulation of airflow and airborne pathogen transport in aircraft cabins - Part I: Numerical simulation of the flow field. ASHRAE Transactions, 111(1): 764-8.

Loomans, M.; Jacobs, P.; Tissot, A.; Miles, S.(2004) In-flight measurement and simulation of aircraft environment. Proceedings of Roomvent 2004. Coimbra. Portugal. 5-8 September 2004.

Madsen, T. L. (1976). Thermal Comfort Measurements . ASHRAE Transactions 821.

Madsen, T. L.; Olesen, B. W.; Kristensen, N. K. (1984). Comparison Bettween Operative and Equivalent Temperature Under Typical Indoor Conditions. ASHRAE Transactions 90 1077-90.

Madsen, T. L.; Olesen, B.; Reid, K. (1986). New methods for evaluation of the thermal environment in automotive vehicles, ASHRAE Transactions 92 part 1B, 38-54.

Mizuno T, Warfield M. (1992). Development of three-dimensional thermal airflow analysis computer program and verification test. ASHRAE Transactions, 98(2):329-38.

Nilsson, H.O. (2004). Comfort Climate Evaluation with Thermal Manikin Methods and Computer Simulation Modes. Stockholm. Tese (Doutorado) - Department of Technology and Built Environment - University of Gaule, Sweden. 202p.

Pennecot, J.; Bosbach, J.; Wagner, C.; Rafael, M.; Lerche, T.; Repp, S. (2004) Mixed convection in Idealized Airplane-Cabins: A Comparison Between Numerical Simulations and Particle Image Velocimetry Measurements. Proceedings of Roomvent 2004. Coimbra. Portugal. 5-8 September.

Singh A, Hosni M, Horstman R. (2002). Numerical simulation of airflow in an aircraft cabin section. ASHRAE Transactions, 108(1):1005-13.

Stancato, F., Ferreira, T. A., Cruz, D. A., Araújo, G. S., Pustelnik, M., Santos, L. C. C.; Tribess (2006). A. Aircraft Cabin Thermal Comfort Evaluation Using Numerical Manikins. Anais do Congresso SAE Brasil 2006, Paper 2006-01-2562, São Paulo. 
Strøm-Tejsen P, Wyon D P, Zukowska D, Jama A, Fang L. (2005). Occupant Evaluation of 7-hour Exposures in a Simulated Aircraft Cabin - Part 2: Thermal effects. Proceedings of Indoor Air 2005, p. 1-10, Beijing.

Strøm-Tejsen P, Zukowska D, Jama A, Wyon D P. (2007). Assessment of the Thermal Environment in a Simulated Aircraft Cabin Using Thermal Manikin Exposure. Proceedings of the 10th International Conference on Air Distribution in Rooms, Helsinki, p. 1-10.

Zhang T, Chen Q. (2007). Novel Air Distribution Systems for Commercial Aircraft Cabins. Building and Environment (42):1675-1684.

Zhang Z, Chen X, Mazundar S, Zhang, T. Chen, Q. (2007). Experimental and Numerical Investigation of Airflow and Contaminant Transport in an Airliner Cabin Mock-up. Proceedings of the 10th International Conference on Air Distribution in Rooms, Helsinki, p. 1-10. 
ANEXO A

\section{Questionário para avaliação subjetiva}

1) Observe a legenda abaixo e marque com um " $X$ " o campo que representa a sensação térmica que VOCÊ está sentindo AGORA:

$$
\begin{gathered}
\mathbf{M F}=\text { muito frio } \mathbf{F}=\text { frio } \mathbf{L F}=\text { ligeiramente frio } \\
\mathbf{N}=\text { neutro } \\
\mathbf{L Q}=\text { ligeiramente quente } \mathbf{Q}=\text { quente } \mathbf{M Q}=\text { muito quente }
\end{gathered}
$$

\begin{tabular}{|c|c|c|c|c|c|c|c|}
\hline MF & $\mathbf{F}$ & $\mathbf{L F}$ & $\mathbf{N}$ & LQ & $\mathbf{Q}$ & MQ & Escalpo (nuca) \\
\hline MF & $\mathbf{F}$ & $\mathbf{L F}$ & $\mathbf{N}$ & LQ & $\mathbf{Q}$ & MQ & Face (rosto) \\
\hline MF & $\mathbf{F}$ & $\mathbf{L F}$ & $\mathbf{N}$ & LQ & $\mathbf{Q}$ & MQ & Peito \\
\hline MF & $\mathbf{F}$ & LF & $\mathbf{N}$ & LQ & $\mathbf{Q}$ & MQ & Costas superior \\
\hline MF & $\mathbf{F}$ & $\mathbf{L F}$ & $\mathbf{N}$ & LQ & $\mathbf{Q}$ & MQ & Costas inferior \\
\hline MF & $\mathbf{F}$ & $\mathbf{L F}$ & $\mathbf{N}$ & LQ & $\mathbf{Q}$ & MQ & Assento \\
\hline MF & $\mathbf{F}$ & LF & $\mathbf{N}$ & LQ & $\mathbf{Q}$ & MQ & Braço esquerdo \\
\hline MF & $\mathbf{F}$ & $\mathbf{L F}$ & $\mathbf{N}$ & LQ & $\mathbf{Q}$ & MQ & Braço direito \\
\hline MF & $\mathbf{F}$ & $\mathbf{L F}$ & $\mathbf{N}$ & LQ & $\mathbf{Q}$ & MQ & Antebraço esquerdo \\
\hline MF & $\mathbf{F}$ & $\mathbf{L F}$ & $\mathbf{N}$ & LQ & $\mathbf{Q}$ & MQ & Antebraço direito \\
\hline MF & $\mathbf{F}$ & $\mathbf{L F}$ & $\mathbf{N}$ & LQ & $\mathbf{Q}$ & MQ & Mão esquerda \\
\hline MF & $\mathbf{F}$ & LF & $\mathbf{N}$ & LQ & $\mathbf{Q}$ & MQ & Mão direita \\
\hline MF & $\mathbf{F}$ & $\mathbf{L F}$ & $\mathbf{N}$ & LQ & $\mathbf{Q}$ & MQ & Coxa esquerda \\
\hline MF & $\mathbf{F}$ & LF & $\mathbf{N}$ & LQ & Q & MQ & Coxa direita \\
\hline MF & $\mathbf{F}$ & $\mathbf{L F}$ & $\mathbf{N}$ & LQ & $\mathbf{Q}$ & MQ & Pé esquerdo \\
\hline MF & $\mathbf{F}$ & $\mathbf{L F}$ & $\mathbf{N}$ & LQ & $\mathbf{Q}$ & MQ & Pé direito \\
\hline
\end{tabular}

\begin{tabular}{|l|l|l|l|l|l|l|l}
\hline MF & F & LF & N & LQ & Q & MQ & De forma geral (o corpo como todo)
\end{tabular}


2) Observe a legenda abaixo e marque com um " $X$ " o campo que representa o conforto térmica que VOCÊ está sentindo AGORA:

$$
\begin{gathered}
\mathbf{M D}=\text { muito desconfortável } \quad \begin{array}{c}
\mathbf{D}=\text { desconfortável } \\
\mathbf{I}=\text { indiferente }
\end{array} \\
\mathbf{L F}=\text { ligeiramente desconfortavel }
\end{gathered}
$$

LC = ligeiramente confortável $\quad \mathbf{C}=$ confortável $\quad \mathbf{M C}=$ muito confortável

\begin{tabular}{|c|c|c|c|c|c|c|c|}
\hline $\mathrm{MD}$ & D & LD & I & LC & $\mathrm{C}$ & MC & Escalpo ( nuca) \\
\hline MD & D & LD & I & LC & $\mathrm{C}$ & MC & Face (rosto) \\
\hline MD & D & LD & I & LC & C & MC & Peito \\
\hline MD & D & LD & I & LC & $\mathrm{C}$ & MC & Costas superior \\
\hline
\end{tabular}

\begin{tabular}{l|l|l|l|l|l|l|l} 
MD & D & LD & I & LC & C & MC & De forma geral (o corpo como todo)
\end{tabular}

\begin{tabular}{l|l|l|l|l|l|l|l} 
MD & D & LD & I & LC & C & MC & Costas inferior
\end{tabular}

\begin{tabular}{l|l|l|l|l|l|l|l|} 
MD & D & LD & I & LC & C & MC & Assento
\end{tabular}

\begin{tabular}{l|l|l|l|l|l|l|l} 
MD & D & LD & I & LC & C & MC & Braço esquerdo
\end{tabular}

\begin{tabular}{l|l|l|l|l|l|l|l} 
MD & D & LD & I & LC & C & MC & Braço direito
\end{tabular}

\begin{tabular}{l|l|l|l|l|l|l|l} 
MD & D & LD & I & LC & C & MC & Antebraço esquerdo
\end{tabular}

\begin{tabular}{l|l|l|l|l|l|l|} 
MD & D & LD & I & LC & C & MC \\
Antebraço direito
\end{tabular}

\begin{tabular}{l|l|l|l|l|l|l|l} 
MD & D & LD & I & LC & C & MC & Mão esquerda \\
\hline
\end{tabular}

\begin{tabular}{l|l|l|l|l|l|l|} 
MD & D & LD & I & LC & C & MC \\
Mão direita
\end{tabular}

\begin{tabular}{l|l|l|l|l|l|l|l} 
MD & D & LD & I & LC & C & MC & Coxa esquerda \\
\hline
\end{tabular}

\begin{tabular}{l|l|l|l|l|l|l|l} 
MD & D & LD & I & LC & C & MC & Coxa direita \\
\hline
\end{tabular}

\begin{tabular}{l|l|l|l|l|l|l|} 
MD & D & LD & I & LC & C & MC \\
\hline
\end{tabular}

\begin{tabular}{l|l|l|l|l|l|l|l} 
MD & D & LD & I & LC & C & MC & Pé direito
\end{tabular}

